$s$

$$
\text { do moroflm }
$$

NUREG/CR-4399

PNL-5557

RECEIVED BY OSTI DEC 10989

\title{
Possible Options for \\ Reducing Occupational Dose From the TMI-2 Basement
}

Prepared by L. F. Munson, R. Harty

Pacific Northwest Laboratory

Operated by

Battelle Memorial Institute

Prepared for

U.S. Nuclear Regulatory

Commission 


\section{LO NOT MACROFLLM \\ $(-1) \times 3$ \\ NOTICE}

This report was prepared as an account of work sponsored by an agency of the United States Government. Neither the United States Government nor any agency thereof, or any of their employees, makes ony warranty. expressed or implied, or assumes any legal liability of re. sponsibility for any third party's use, or the results of such use, of any information, apparatus, product or process disclosed in this report, or represents that its use by such third party would not infringe privately owned rights.

NOTICE

Availability of Reference Materials Cited in NRC Publications

Most documents cited in NRC publications will be available from one of the following sources:

1. The NRC Public Document Room, 1717 H Street, N.W. Washington, DC 20555

2. The Superıntendent of Documents, U.S. Government Printing Office, Post Office Box 37082, Washington, DC 20013.7082

3. The National Technical information Service, Springfield, VA 22161

Although the listing that follows represents the majority of documents cited in NRC publications. it is not intended to be exhaustive.

Referenced documents available for inspection and copying for a fee from the NRC Public Docu ment Room include NRC correspondence and internal NRC memoranda; NRC Office of Inspection and Enforcement bulletins, circulars, information notices, inspection and investigation notices; Licensee Event Reports; vendor reports and correspondence; Commission papers; and applicant and licensee documents and correspondence.

The following documents in the NUREG series are available for purchase from the GPO Sales Program: formal NRC staff and contractor reports, NRC-sponsored conference proceedings, and NRC booklets and brochures. Also available are Regulatory Guides, NRC regulations in the Code of Federal Regulations, and Nuclear Regulatory Commission Issuances.

Documents available from the National Technical Information Service include NUREG series reports and technical reports prepared by other federal agencies and reports prepared by the Atomic Energy Commission, forerunner agency to the Nuclear Regulatory Commission.

Documents available from public and special technical libraries include all open literature items, such as books, journal and periodical articles, and transactions. Federal Register notices, federal and state legislation, and congressional reports can usually be obtained from these libraries.

Documents such as theses, dissertations, foreign reports and translations, and non-NRC conference proceedings are available for purchase from the organization sponsoring the publication cited.

Single copies of NRC draft reports are available free, to the extent of supply, upon written request to the Division of Technical Information and Document Control, U.S. Nuclear Regulatory Com mission, Washington, DC 20555.

Copies of industry codes and standards used in a substantive manner in the NRC regulatory process are maintained at the NRC Library, 7920 Norfolk Avenue, Bethesda, Maryland, and are available there for reference use by the public. Codes and standards are usually copyrighted and may be purchased from the originating organization or, if they are American National Standards, from the American National Standards Institute, 1430 Broadway, New York, NY 10018. 


\section{DISCLAIMER}

This report was prepared as an account of work sponsored by an agency of the United States Government. Neither the United States Government nor any agency Thereof, nor any of their employees, makes any warranty, express or implied, or assumes any legal liability or responsibility for the accuracy, completeness, or usefulness of any information, apparatus, product, or process disclosed, or represents that its use would not infringe privately owned rights. Reference herein to any specific commercial product, process, or service by trade name, trademark, manufacturer, or otherwise does not necessarily constitute or imply its endorsement, recommendation, or favoring by the United States Government or any agency thereof. The views and opinions of authors expressed herein do not necessarily state or reflect those of the United States Government or any agency thereof. 


\section{DISCLAIMER}

Portions of this document may be illegible in electronic image products. Images are produced from the best available original document. 


\section{Possible Options for Reducing Occupational Dose From the TMI-2 Basement

Manuscript Completed: September 1985

Date Published: November 1985

Prepared by

L. F. Munson, R. Harty

Pacific Northwest Laboratory

Richland, WA 99352

\section{Prepared for \\ TMI Program Office \\ Office of Nuclear Reactor Regulation \\ U.S. Nuclear Regulatory Commission \\ Washington, D.C. 20555 \\ NRC FIN B2525}

\section{DISCLAIMER}

This report was prepared as an account of work sponsored by an agency of the United States employees, makes any warranty, express or implied nor any agency thereof, nor any of their bility for the accuracy, completeness, or usefulness of assumes any legal liability or responsiprocess disclosed, or represents that its use woulness of any information, apparatus, product, or ence herein to any specific commercial product, proces, infringe privately owned rights. Refermanufacturer, or otherwise does not necessarily process, or service by trade name, trademark, mendation, or favoring by the United Statesily constitute or imply its endorsement, recomand opinions of authors expressed herein Government or any agency thereof. The views United States Government or any agency thereof. 
NOTICE

This report was prepared as an account of work sponsored by an agency of the United States Government. Neither the United States Government nor any agency thereof, or any of their employees, makes any warranty. expressed or implied, or assumes any legal liability of re sponsibility for any third party's use, or the results of such use, of any information, apparatus. product or process disclosed in this report, or represents that its use by such third party would not infringe privately owned rights.

\section{NOTICE}

Avallability of Reference Materials Cited in NRC Publications

Most documents cited in NRC publications will be available from one of the following sources:

1. The NRC Public Document Room, $1717 \mathrm{H}$ Street, N.W. Washington, DC 20555

2 The Superintendent of Documents, U.S. Government Printing Office. Post Office Box 37082. Washington, DC 20013.7082

3. The National Technical Information Service, Springfield, VA 22161

Although the listıng that follows represents the majority of documents cited in NRC publications. it is not intended to be exhaustive.

Referenced documents available for inspection and copying for a fee from the NRC Public Docu ment Room include NRC correspondence and internal NRC memoranda; NAC Office of Inspection and Enforcement bulletins, circulars, information notices, inspection and investigation notices; Licensee Event Reports; vendor reports and correspondence; Commission papers; and applicant and licensee documents and correspondence.

The following documents in the NUREG series are available for purchase from the GPO Sales Program: formal NRC staff and contractor reports, NRC-sponsored conference proceedings, and NRC booklets and brochures. Also available are Regulatory Guides, NRC regulations in the Code of Federal Regulatıons, and Nuclear Regulatory Commission Issuances.

Documents available from the National Technical Information Service include NUREG series reports and technical repons prepared by other federal agencies and reports prepared by the Atomic Energy Commission, forerunner agency to the Nuclear Regulatory Commission.

Documents avaltable from public and special technical libraries include all open literature iterns. such as books, journal and periodical articies, and transactions. Federal Register notices, federal and state legislation. and congressional reports can usually be obtained from these libraries.

Documents such as theses, dissertations, foreign reports and translations, and non NRC conference proceedings are avallable for purchase from the organization sponsoring the publication cited.

Single copies of NRC draft reports are avallable free, to the extent of supply, upon written request to the Division of Technical information and Document Control, U.S. Nucledr Regulatory Com mission, Washington, DC 20555.

Copies of industry codes and standards used in a substantive manner in the NRC regulatory process are maintained at the NRC Library. 7920 Norfolk Avenue. Bethesda, Maryland, and are available there for reference use by the public. Codes and standards are usually copyrighted and may be purchased from the originating organization or, if they are American National Standards, from the American National Standards Institute, 1430 Broadway. New York. NY 10018. 


\section{ABSTRACT}

The Pacific Northwest Laboratory (PNL) is providing assistance to the Nuclear Regulatory Commission (NRC) Three Mile Island (TMI) Program Office to assess the sources of exposure in the TMI-2 reactor building basement and to evaluate possible approaches to basement cleanup.

The major sources of exposure in the basement include the enclosed stairwell/elevator shaft structure, water and sludge in the elevator shaft, cast concrete walls, concrete floor slab, water and sludge on the floor, and activity in the paint and loose surface contamination. The sources were identified using data obtained by the utility from water processing, water and solid samples, remote video inspections and radiation monitoring with a robot, and strings of thermoluminescent dosimeters lowered from upper elevations. The area dose rates in the basement range from approximately $4 \mathrm{R} / \mathrm{hr}$ (in the NE quadrant) to over $1100 \mathrm{R} / \mathrm{hr}$ (near the enclosed stairwell/elevator shaft structure). It is estimated that the basement contains between 11,000 and 21,000 curies of ${ }^{137} \mathrm{Cs}$.

Specific decontamination and cleanup techniques are discussed. These techniques include flushing with water, high-pressure water blasting, leaching, scabbling and chemical cleaning. The applicability of these techniques to the major sources of radiation are discussed, and possible approaches and work sequences for basement cleanup are given. 


\section{EXECUTIVE SUMMARY}

Cleaning the TMI-2 reactor building is one of the most challenging decontamination projects ever undertaken, and cleaning the basement, at the 282foot above sea level elevation, is one of the most challenging tasks of that project.

Activities in the TMI-2 basement have included: sampling water and solids collected remotely and in one instance by a worker who descended the stairs into the basement; extensive water processing; high- and low-pressure water flushing from upper elevations; radiation monitoring by robot and with thermoluminescent (TLD) strings lowered from above; viewing video inspections while they were being taken by a robot and by cameras lowered on cables; and flushing and pumping the elevator shaft.

These activities provided considerable data on which to base future cleanup plans. Sections 2 and 3 of this study contain a detailed analysis of the available data on the basement. Basement data comes from knowledge of the accident sequence, data from TLD strings lowered into the basement, observations and measurements made by a robot, and analyses of water and solids removed from the basement.

The concrete and painted metal basement has three distinct areas. The first area, which includes the NE and NW quadrants, has area dose rates in the range of 4 to $10 \mathrm{R} / \mathrm{hr}$ gamma, with a few locations as low as $2 \mathrm{R} / \mathrm{hr}$ and others approaching $20 \mathrm{R} / \mathrm{hr}$ gamma, from waterborne and airborne contamination. Many surfaces in this area also have beta activity up to several hundred $\mathrm{rad} / \mathrm{hr}$. The concrete floor in most of this large area is covered with sludge and water. In a few locations, the floor is only moist and dirty.

The second area, which is around the reactor coolant drain tank vent in the SW quadrant, is similar to the above area except that it is more contaminated. Beside the contamination that is common to the previous two quadrants, there is fine reactor core debris on the floor and fine particulate contamination above the previous water line. These contaminants were deposited by water and steam during the accident. Gamma doses in this area are as high as $50 \mathrm{R} / \mathrm{hr}$.

The third area, the SE quadrant, contains the elevator shaft and the stairwell enclosure. These are constructed of hollow concrete block, and the elevator shaft has no drainage. Dose rates in contact with this concrete block structure exceed $1000 \mathrm{R} / \mathrm{hr}$ in some locations. Like other areas of the basement, the concrete block structure is painted, but not inside the stairwell and elevator shaft and not up to the 305-foot elevation. This structure is estimated to contain about 11,000 to over 19,000 curies of ${ }^{137} \mathrm{Cs}$. This concrete block structure will have to be remotely disassembled (or possibly shielded) before any hands-on decontamination work can be done in the basement. 
The NRC asked the Pacific Northwest Laboratory (a) to evaluate decontamination options and to investigate characterization and other activities that will be necessary to clean the basement. The principal conclusions from this evaluation are described here, and the bases for them are in the referenced chapters of this report.

Sources on the basement floor, walls and equipment below the high-water mark contribute very slightly to the dose rate at the 305-foot elevation. Most of this contribution has already been mitigated by shielding. Other, much smaller sources above the high-water mark in the basement contribute as much to the doses at the 305-foot elevation as the much larger sources at lower elevations. The dose contribution from these sources has also been mitigated in most areas. The mitigation method used most frequently has been shielding; however, remote decontamination processes, such as hydroblasting penetrations in the sources, scrubbing, and using strippable coatings should be considered for future operations.

Processes that could reduce the dose from the elevator shaft and enclosed stairwe 11 by even $90 \%$ would save very little occupational radiation dose because remote dismantling would still be required. Leaching by filling the basement with water might remove a large number of curies of activity from this source but is not expected to save much of the basement cleanup dose.

Analyses of the enclosed stairwell and elevator shaft structural materials have not proceeded far enough to allow any firm recommendations. If future tests demonstrate the leachability of exposed concrete block, it may help to remotely demolish the staimell and leave the rubble on the 282-foot elevation under a leach solution. If, however, the concrete block exhibits an extremely high selectivity for cesium, as certain naturally occurring minerals (zeolites) do, then any attempt to leach the material will fail, and radiological conditions would not be improved by leaching.

Sludge on the floor is not a significant radiological concern at the present time except in the areas where there was direct drainage from the reactor coolant drain tank during the accident. Particulates in the sludge around the reactor coolant drain tank vent are a radiological concern, but not to the extent that they greatly overshadow other basement sources. Sludge whether wet or dry. would hamper hands-on basement cleanup efforts when they become practical from a dose rate standpoint. Therefore, most of the sludge should be removed fairly early in the basement cleanup effort. Further, there is no identified benefit in postponing desludging, other than using resources for higher priority work. Prompt collection and analysis of the sludge might also help verify that it is unnecessary to use highly borated water in the basement. Preliminary planning and sufficient technology are available to remove, solidify and dispose of the sludge with relatively little occupational dose. Sludge removal will, however, require substantial equipment modifications and procurements.

(a) The Pacific Northwest Laboratory is operated for the Department of Energy by Batte1le Memorial Institute. 
Leaching and removing cesium from basement sources could be done more efficiently if the licensee had not require that 10,000 gallons of water be kept in the basement at all times. The water is for controlling airborne contamination. Controlling airborne contamination is valid of course, but it can be done other ways, including: 1) studying the contamination to determine if it will become airborne if allowed to dry out, 2) keeping the contaminated areas wet with sprays, and 3 ) adding water immediately after pumpout. The containment floor was not completely submerged during the last robot inspection.

Robot measurements and video and TLD investigations of the basement showed radioactive contamination and dirt on walls and equipment in the basement. This phenomenon, called the bathtub ring, appears to be a relatively broad, discontinuous band, such as might result from black oil floating on water as the water level slowly receded. There were a few attempts to flush or hydroblast areas of the basement, but the only data taken did not demonstrate that this was effective at reducing dose rates on the upper elevation. A program of smear surveys, either performed by the robot or by long poles lowered through the seismic gap and other penetrations, would be a costeffective way to collect a statistically significant quantity of data that could be used to design an approach to clean the bathtub ring and other contaminated locations. A survey program would show whether or not the contamination is closely associated with the $0 i 1$ and/or dirt and if the oil and dirt is readily removable by mechanical methods. More effective removal methods are likely to include steam cleaning, specially designed scrubbing devices, hydroblasting with heated water, and applying and removing strippable coatings. (The Navy uses magnetically attached scrubbing devices that operate unattended to remove marine growth from drydocked ships. A similar device might work well on the outside containment walls.) Detergents may be effective in removing oil. A smear survey program would also indicate the advisability of attempting to lower dose rates at the 305-foot elevation by decontaminating surfaces above the previous water level.

After the most significant basement source, the elevator shaft and enclosed stairwe11, has been dealt with, it may be desirable to identify the other basement sources by performing additional TLD surveys and using a computer program to model the locations of the remaining contamination.

Reflooding the basement so that divers can perform decontamination work warrants further investigation. The risk to workers is considerably less if the cleanup work is done by robots, but robot work may not be economically feasible in the near future. Protecting workers by water shielding is a possible alternative, although it would still entail significant radiation doses and would require some instrument and equipment development. 


\section{ACKNOWLEDGMENTS}

The authors would like to acknowledge Dr. Bernard Snyder, Director of the Nuclear Regulatory Commission's Three Mile Island Program Office and Dr. Ronnie Lo, the NRC Project Manager for their support and assistance. Appreciation is also extended to GPU Nuclear, Inc., and their contractors, especially to Greg R. Eidam, Carl Distenfeld, Lawrence E. Katonak, and Cindy $G$. Hitz for providing information and data. We acknowledge the assistance of W. Daniel Reece of our organization, who wrote our shielding codes.

Finally, we wish to thank our editors, Ann Marshall and Kathleen R. Hanson, for their help in preparing the manuscript, Diana $L$. Swanger for assistance with the graphics, and Marianna Cross for word processing support. 



\section{CONTENTS}

ABSTRACT

EXECUTIVE SUMMARY

ACKNOWLEDGMENTS .

1.0 INTRODUCTION

1.1 THE TMI UNIT-2 ACCIDENT SEQUENCE.$\quad \cdot \quad \cdot \quad \cdot \quad \cdot \quad \cdot 1.1$

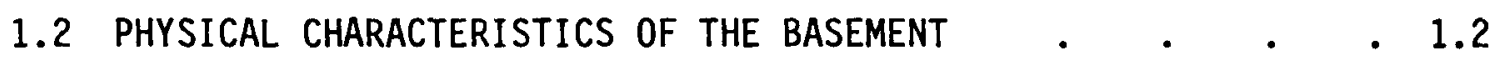

2.0 ANALYSIS OF DATA ON CESIUM IN BASEMENT WATER.$\quad \cdot \quad \cdot \quad \cdot \quad \cdot 2.1$

2.1 ANALYSIS OF PUMPOUTS 1 TO 16 .

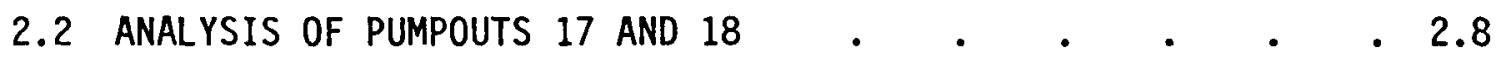

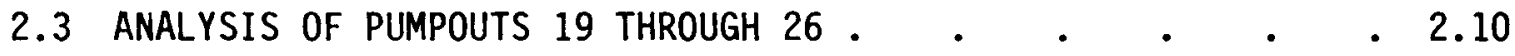

2.4 ANALYSIS OF PUMPOUTS 27 THROUGH $29 . \quad$. $. \quad . \quad . \quad$. 2.10

3.0 RADIOLOGICAL CONDITIONS IN THE TMI -2 BASEMENT

3.1 SE QUADRANT 3.2

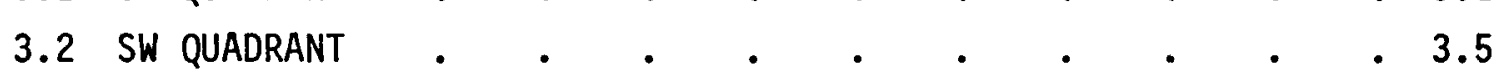

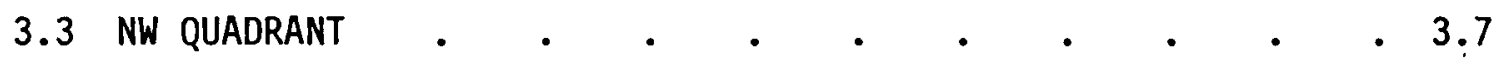

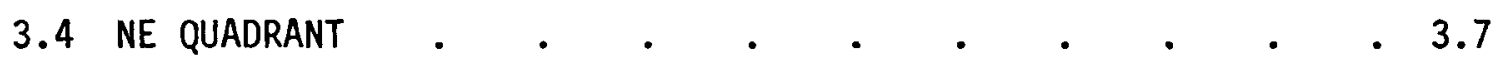

4.0 LOCATION OF RADIOACTIVITY IN THE BASEMENT $. \quad . \quad . \quad . \quad$. 4.1

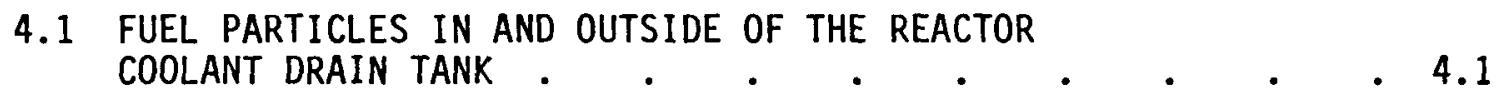

4.2 WATER AND SLUDGE ON THE FLOOR AND IN THE SUMP $\cdot e^{*} \cdot 4.1$

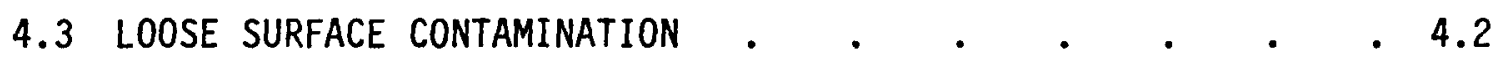

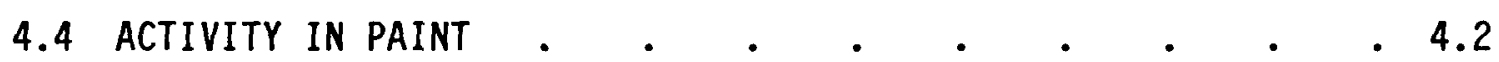

4.5 CONCRETE FLOOR SLAB . . . . . . . . . . . . 4.2

4.6 CAST CONCRETE WALLS . . . . . . . . . . . . . . 4.3

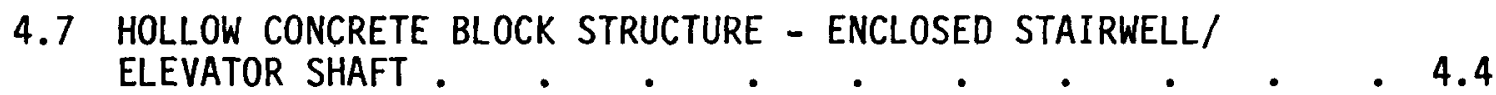

4.8 WATER AND SLUDGE IN THE ELEVATOR SHAFT . . . . . . 4.5

4.9 SUMMARY OF THE LOCATION OF THE ACTIVITY IN
THE BASEMENT $. \quad . \quad . \quad . \quad . \quad . \quad . \quad . \quad . \quad .4 .5$

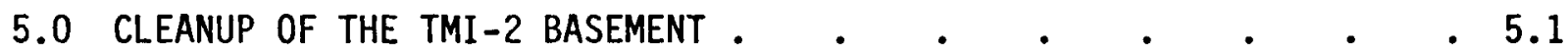

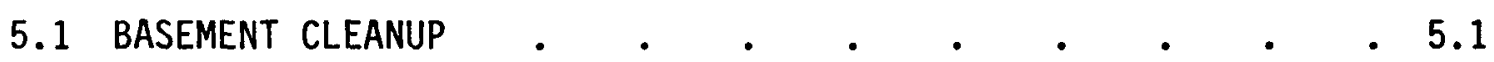

5.1.1 Removal of Sludge and Fuel Particulates . . . 5.1 
5.1.2 Hollow Concrete Block . $\quad$. $\quad$. $\quad$. $\quad$. 5.2

5.1 .3 Vertical Surfaces . . . . . . . . 5.3

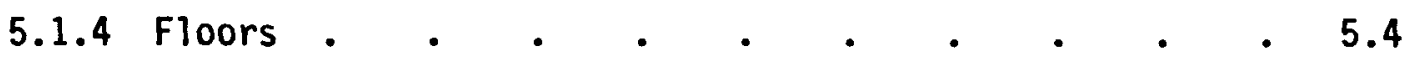

5.2 OCCUPATIONAL DOSE CONSIDERATIONS FOR BASEMENT CLEANUP . $\quad 5.4$

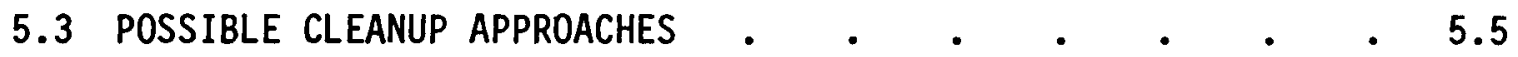

5.3.1 Robotics and Work From Above . . . . . 5.6

5.3.2 Shielded Locations Within the Basement $\quad$ • $\quad$ • 5.6

5.3.3 Reflood the Basement . . . . . . . 5.7

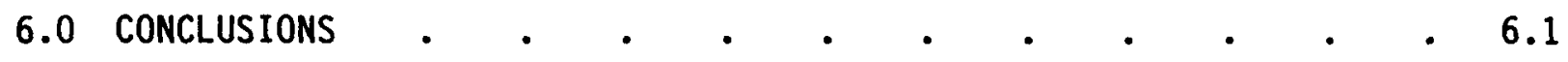

APPENDIX A - REACTOR BUILDING WATER LEVEL DATA . . . . . . A.1

APPENDIX B - MODEL OF THE CONCRETE FLOOR SLAB • • • • • • • • B. 1

APPENDIX C - MODEL OF THE ENCLOSED STAIRWELL/ELEVATOR SHAFT

STRUCTURE $\cdot \quad \cdot \quad \cdot \quad \cdot \quad \cdot \quad \cdot \quad \cdot \quad \cdot \quad \cdot \quad \cdot$ C.1

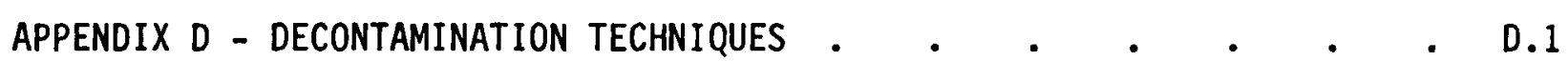

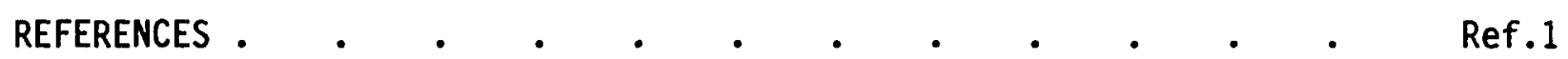

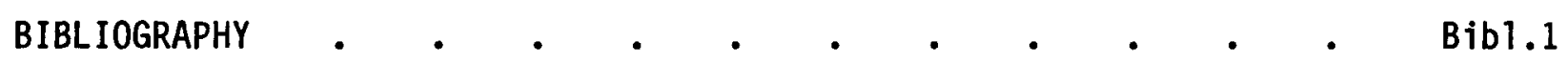




\section{FIGURES}

1.1 The TMI-2 Reactor Building Basement (282-foot elevation) . 1.3

1.2 The Elevator Shaft/Enclosed Stairwell Structure • • • 1.4

2.1 Water Elevation . . . . . . . . . . . 2.3

2.2 Calculated Curies ${ }^{137}$ Cs Remaining . . . . . . . 2.3

$2.3{ }^{137} \mathrm{Cs}$ Concentration in Basement Pumpouts . . . . . 2.7

2.4 Calculated Curies Remaining Versus Gallons Remaining During the First 16 Pumpouts . . . . . . . . 2.8

3.1 Dose Rates on the 305-foot Elevation . . . . . . 3.10

3.2 Exposure Rates in the Basement (286to289-foot elevation) . . 3.11

3.3 Exposure Rates at about the 300-foot Elevation . • . 3.12

3.4 Location of TLD Strings Suspended in the Basement . . . 3.13

3.5 Dose Rate Profile at Location B-3 . . . . . . . 3.14

3.6 Dose Rate Profile at Location B-15 . . . . . . . 3.15

3.7 Dose Rate Profile at Location B-23 . . . . . . . 3.16

3.8 Dose Rate Profile at Location B-13 . . . . . . . 3.17

3.9 Dose Rate Profile at Location B-12 . . . . . . . 3.18

3.10 Locations of Dose Rate Readings by the ROVER Robot . . . 3.19

3.11 Dose Rate Profile at Robot Location AA . . . . . 3.20

3.12 Dose Rate Profile at Robot Location U . . . . . . 3.21

3.13 Dose Rate Profile at Robot Location S . • • • • • 3.22

3.14 Dose Rate Profile at Location B-7 • • • • . • . 3.23

3.15 Dose Rate Profile at Location B-11 . . . . . . . 3.24

3.16 Dose Rate Profile at Location B-1 . . . . . . . 3.25

3.17 Dose Rate Profile at Location B-2 . . . . . . . . 3.26

3.18 Dose Rate Profile at Location B-29 . . . . . . . 3.27

3.19 Dose Rate Profile at Location B-10 . . . . . . . 3.28

3.20 Dose Rate Profile at Robot Location A . . . . . . 3.29

3.21 Dose Rate Profile at Robot Location B . . . . . . 3.30

3.22 Dose Rate Profile at Robot Location H . . . . . . . 3.31

3.23 Dose Rate Profile at Robot Location E . . . . . . 3.32

3.24 Dose Rate Profile at Location B-5 . . . . . . . 3.33

3.25 Dose Rate Profile at Location B-6 . . . . . . . 3.34 
3.26 Dose Rate Profile at Location B-9 . . . . . . . 3.35

3.27 Dose Rate Profile at Location B-16 . . . . . . . 3.36

3.28 Dose Rate Profile at Location B-30 . . . . . . . 3.37

3.29 Dose Rate Profile at Location B-17 . . . . . . . 3.38

3.30 Dose Rate Profile at Location B-18 . . . . . . . 3.39

3.31 Dose Rate Profile at Location B-19 . . . . . . . 3.40

3.32 Dose Rate Profile at Location B-20 . . . . . . . . 3.41

3.33 Dose Rate Profile at Location B-21 . . . . . . . 3.42

3.34 Dose Rate Profile at Location B-22 . . . . . . . 3.43

3.35 Dose Rate Profile at Location B-4 . . . . . . . 3.44

3.36 Dose Rate Profile at Location B-27 . . . . . . . 3.45

3.37 Dose Rate Profile at Location B-14 . . . . . . . 3.46

3.38 Dose Rate Profile at Location B-24 . . . . . . . 3.47

3.39 Dose Rate Profile at Location B-8 . . . . . . . 3.48

3.40 Dose Rate Profile at Location B-25 . . . . . . . . 3.49

3.41 Dose Rate Profile at Location B-26 . . . . . . . 3.50

3.42 Dose Rate Profile at Location B-28 . . . . . . . . 3.51

3.43 Dose Rate Profile at Location B-31 . . . . . . . 3.52

3.44 Dose Rate Profile at Robot Location HH . . . . . . $\quad .3 .53$

3.45 Dose Rate Profile at Robot Location JJ . . . . . . 3.54

3.46 Dose Rate Profile at Robot Location KK . . . . . . 3.55

4.1 Types of Concrete in the TMI-2 Basement . . . . . 4.4 


\section{$\underline{\text { TABLES }}$}

2.1 Special Water Samples from the Reactor Building . . . $\quad$. 2.4

2.2 TMI-2 Basement Water Samples • . . . • . . 2.5

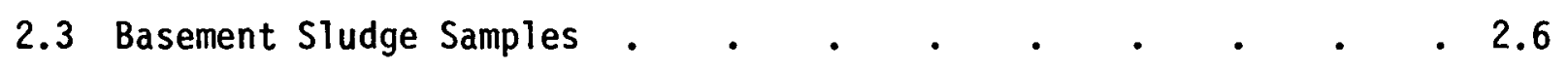

2.4 Volume and Activity of Solids . • • • • • • • $\quad$ • 2.12

3.1 ROVER Robot Data from the SE Quadrant . . . . . 3.4

3.2 ROVER Robot Data from the SW Quadrant . . . . . . 3.6

3.3 ROVER Robot Data from the NE Quadrant . . . . . . 3.9

4.1 Cesium Activity in the Basement . . . . . . . . 4.6 


\subsection{INTRODUCTION}

The Pacific Northwest Laboratory (PNL) ${ }^{(a)}$ was asked by the NRC-TMI Program Office to identify the sources of exposure in the TMI-2 basement and evaluate decontamination techniques that might faciliate cleanup progress. This document deals with current data about the TMI-2 basement and the source terms (radionuclide inventory) and with possible approaches to basement cleanup. While the licensee, not the NRC, is charged with planning and conducting cleanup, it is the responsibility of the NRC to see that cleanup is accomplished safely and that occupational radiation doses during cleanup are as low as is reasonably achievable (ALARA). Because of potentially high radiation doses to workers, the basement of the TMI reactor building is expected to be one of the most difficult cleanup tasks ever undertaken in the U.S. commercial nuclear industry. For this reason, evaluation by the NRC is appropriate before a specific proposal is received from the licensee.

\subsection{THE TMI UNIT-2 ACCIDENT SEQUUENCE}

The 28 March 1979 accident at TMI Unit 2 happened because decay heat was not removed by circulating primary coolant after the reactor was shut down. This resulted in serious damage to the fuel. When circulation was restored debris and fission products were fuel throughout the primary system of the reactor. The primary flow path out of the reactor core was through the primary piping to the pressurizer, out the pressurizer vent line into the reactor coolant drain tank (RCDT), and out the RCDT vent line (through a ruptured blow-out disk) into the reactor building basement. Most of the water from the accident remained in the basement, though some was pumped to the auxillary building (Rogovin and Frampton 1979).

The accident left the lower level of the reactor building, the 282-foot 6-inch elevation (relative to sea level), also called the basement, covered with about 1,000,000 liters of water (Cox, Horan and Worku 1983). The depth of the water was estimated at slightly over 3-1/2 feet. Most of this water came from the primary coolant system, through the pressurizer relief valve, into the RCDT, out the ruptured blow-out disk, through the vent line and onto the basement floor. This coolant carried both dissolved and particulate contaminants.

A small amount of borated water from the reactor building sprays that followed the hydrogen burn was also added to the contaminated water on the floor. The volume of this borated water was estimated at 6440 liters (Cox, Horan and Worku 1983), which corresponds to less than 0.1 foot in the basement. This water contained essentially no radioactivity, although it may have contributed some contamination from the air or from surfaces at upper elevations.

(a) The Pacific Northwest Laboratory is operated for the Department of Energy by Battelle Memorial Institute. 
For more than two years following the accident, primary coolant continued to enter the basement via the same flow path as before, but at a rate of $0.49 \mathrm{~L} / \mathrm{min}$ (Cox, Horan and Worku 1983). Primary coolant samples during this time showed decreasing levels of activity as soluble fission products were leached from the damaged fuel into the basement. This source contributed approximately 674,000 liters. During this time, the water level in the basement rose at a higher rate than could be accounted for by primary coolant leakage. This addition was ultimately attributed to river water inleakage from the building air coolers, probably through a relief valve on the cooling coils. This source was estimated to account for 681,000 liters (Cox, Horan and Worku 1983) or about 2.4 feet of the 1981 water level.

The first sample of basement water, taken 28 August 1979 through a reactor building penetration, contained $174 \mu \mathrm{Ci} / \mathrm{mL}$ of ${ }^{137} \mathrm{Cs}$ in solution and an additional $0.008 \mu \mathrm{Ci} / \mathrm{mL}$ in the solids. Successive samples and pumpouts contained correspondingly less cesium activity, which was consistent with the dilution that was occurring. Pumping of the basement began in September 1981 and continued, with only brief interruptions for water processing and treatment system maintenance, until April 1982 when the water level had been reduced to about three or four inches.

\subsection{PHYSICAL CHARACTERISTICS OF THE BASEMENT}

When the basement water was processed, the dose rates in the basement and the remainder of the building did not decrease as expected. The basement remained highly contaminated with dose rates considerably higher than those in other areas. After the accident water was drained, additional decontamination solutions were added and some samples and measurements were taken. On one occasion a worker agreeded to descend to the bottom of the open stairwell to obtain a sample and observe basement conditions. Except for this one occasion, the basement has remained unentered by workers since the accident.

The basement is structurally similar to many other reactors in that it is divided into two distinct areas: inside the D-rings and outside the D-rings (see Figure 1.1). Within the D-rings are the two steam generators and the reactor coolant pumps. Outside the D-rings are support facilities, tanks, pumps and equipment; and the stairways. The D-rings are constructed of 5000-psi reinforced concrete. (Concrete is designated by the breaking strength.) Other materials in the basement include 3000-psi concrete, hollow concrete block and a steel containment liner. The inside of the D-rings is one continuous area with no intervening floors and continues up to the top of the D-ring walls at the 367-foot elevation. This document deals primarily with the area outside of the D-rings.

In this document, the basement is divided into quadrants, SE, SW, NW, and $\mathrm{NE}$, and the available data is discussed in that order. In the SE quadrant, the only major structure is the elevator shaft/enclosed stairwell, which is constructed of concrete block (with metal reinforcement for seismic restraint). This structure is the largest known source of radiation in the basement. The bottom of the elevator shaft is about 1 foot below the floor 


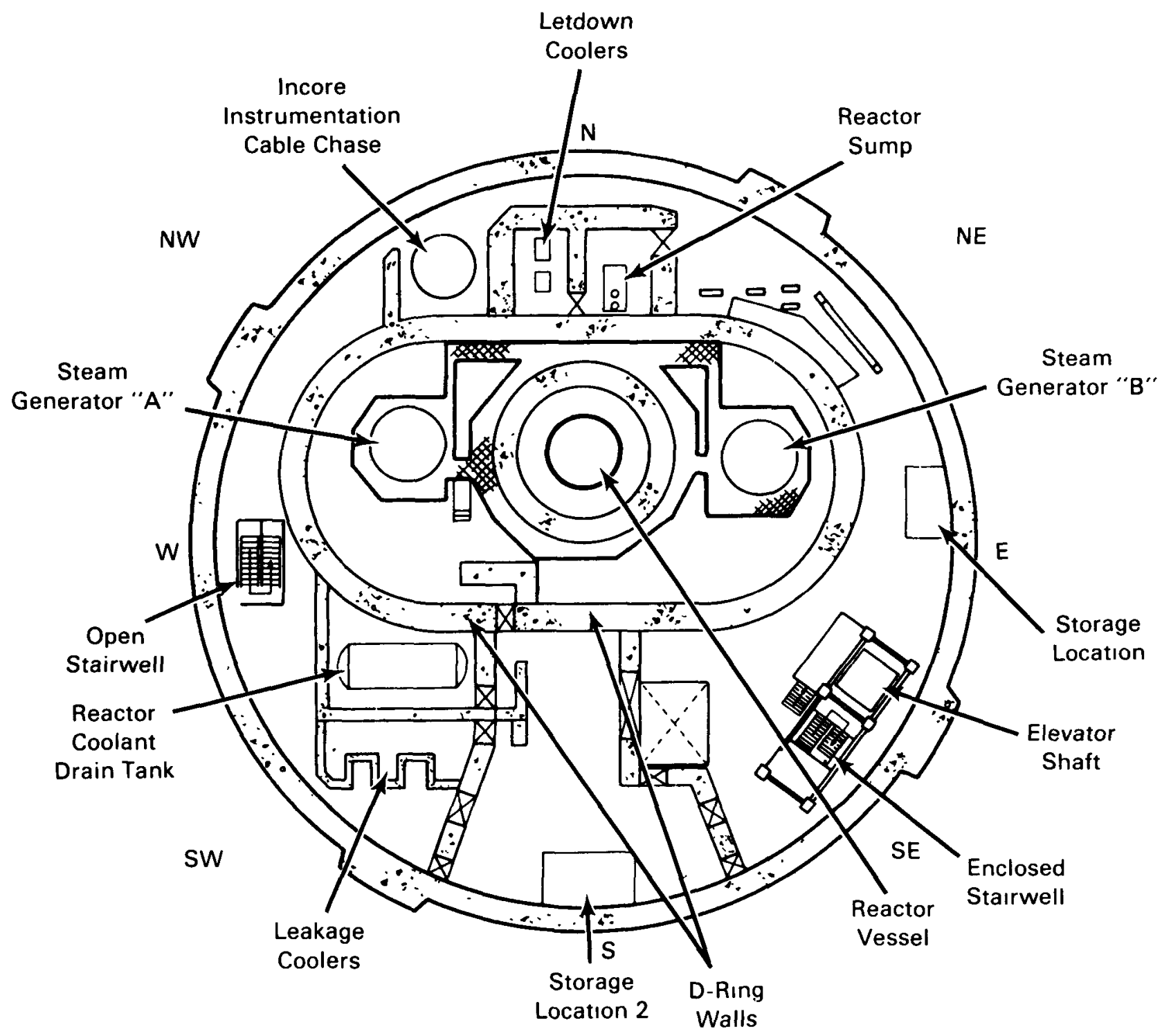

FIGURE 1.1. The TMI-2 Reactor Building Basement (282-foot elevation)

level. There is no drain, but it has been pumped and flushed (see Figure 1.2). Inspections by the robot have shown two large tool chests near the stairwell structure. There are also electrical, instrument, and ventilation systems in this quadrant.

In the SW quadrant, there are numerous structures, most constructed of 3000-psi concrete. A wire mesh door on a wooden frame leads to the inside of the D-rings. The RCDT is enclosed in a cubicle that also has a door of wire mesh on a wooden frame. The leakage coolers and leakage transfer pumps are located in this quadrant. Moving clockwise past this area, there are several instrument racks and an open staircase to the 305-foot elevation. The top of 


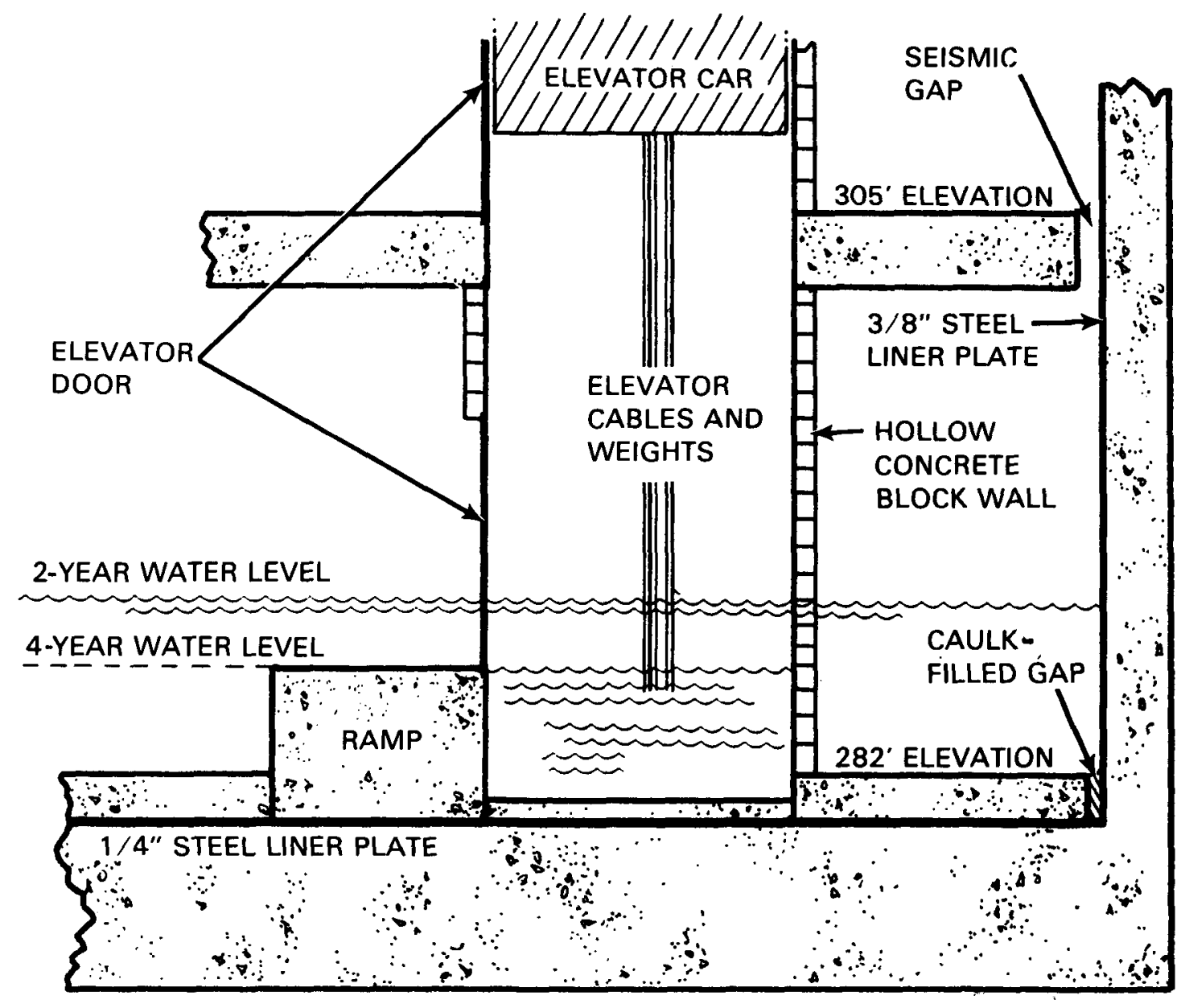

NOT TO SCALE

FIGURE 1.2. The Elevator Shaft/Enclosed Stairwell Structure

the staircase has been shielded to reduce the dose rate at the 305 -foot elevation where workers prepare to defuel the reactor.

In the NW quadrant, there are additional instrument racks and another shielding wall, which shields the remainder of the basement from the incore instrument cable chase. Additional shielding walls surround the letdown coolers and, in the NE quadrant, the sump.

The sump, in the NE quadrant, is below floor level and consists of two compartments: one side is for settling solids, and the pump and outlet are on the other side. The sump is protected from plugging by a trash rack and screens that are designed to collect debris before it enters the sump. There are also radiation monitor cabinets, instrument racks, a chemical addition tank, and various pumps in this quadrant. 
Also located within the D-rings, in addition to the steam generators and primary system piping and pumps mentioned previously, there are oil shield drain tanks, a concrete baffle wall and the reactor vessel.

Radiation dose rates in the basement range from approximately $4 \mathrm{R} / \mathrm{hr}$ to greater than $1000 \mathrm{R} / \mathrm{hr}$. To date, all of the information obtained in the reactor building suggests that the most important radionuclide from a dose rate standpoint is ${ }^{137} \mathrm{Cs}$, and, consequently, it is the primary radionuclide of concern in this analysis. The other radionuclides are important when dealing with waste disposal, beta exposure or the indication of fuel particulates; however, ${ }^{137} \mathrm{Cs}$ is the principal source of occupational radiation dose. Moreover, most processes that remove cesium are expected to remove the other radionuclides as well (with the exception of ion exchange on zeolite).

This analysis presents a summary of what is known about the physical and radiological characteristics of the basement and evaluates courses of action for data collection and for decontamination based on conservation of doses to workers who will complete the cleanup procedure. Conservation of occupational dose was the principal consideration in this analysis. 
. 


\subsection{ANALYSIS OF DATA ON CESIUM IN BASEMENT WATER}

Conditions in the basement have been severely effected by the contaminated water that remained there for two years. We therefore analyzed pumpout data to determine if processes such as leaching, precipitation or ion exchange could be identified. Knowledge of such processes is considered pivotal to evaluating basement cleanup options.

This analysis is based on data from:

- volumes and concentrations of cesium in water pumped out of the reactor building basement

- tracings from instruments monitoring the water levels of the reactor building basement (Appendix A)

- samples of other basement waste and sludge

- additional information (from stated references).

This data was originally gathered for determining the radionuclide inventory transported offsite, not for the detailed analysis for which we have used it here.

In spite of the limitations of the available data, this analysis substantiates two important conclusions. First, the majority of the activity removed from the reactor building basement (approximately 305,000 (95\%) of the estimated total 322,000 curies of ${ }^{137} \mathrm{Cs}$ from the total of $1,080,000$ gallons $\left(4.1 \times 10^{6} \mathrm{~L}\right)$ of water processed) was present in the basement water immediately after the accident. Only about 17,000 curies, or 5\%, came from other sources, which may include: sludge containing undissolved solids and interstitial water; water with a higher concentration of cesium, which is more representative of undiluted accident water; water trapped in the elevator shaft; decontamination; leaching; line backflushing; suspended solids; and other sources. To date, significant concrete leaching is not well substantiated by the data. Second, there is considerable evidence that the interstitial water associated with the sludge is not evenly mixed with the remainder of the basement water (bulk solution) and that the interstitial water is more highly contaminated than the bulk solution.

Throughout this analysis, we have assumed that water reaching to the 283.87-foot elevation represents 100,000 gallons and a height of 0.1 foot of water equals 7400 gallons, as indicated in GPU operating procedures. This latter assumption uses as a model a vertical cylinder with an inside diameter of 112.2 feet. The reactor building is about 138 feet in diameter but has numerous pieces of equipment and other structures that account for the difference between the inside diameter of the model used, 112.2 feet, and the actual inside diameter of the reactor building. These two assumptions also appear reasonable because the mean floor elevation is then calculated to be 282.51 feet. 
Normal conventions concerning the use of significant digits are not used in this discussion. The reader should, however, understand the limitations of the data used in the analysis. Level measurements are read from a graph and are accurate to about \pm 0.05 foot, which corresponds to $\pm 3,700$ gallons. Results of sample analysis are given to the nearest 1 or $0.1 \mathrm{Ci} / \mathrm{mL}$, but actual precision is somewhat less among duplicate samples. One $\mu \mathrm{Ci} / \mathrm{mL}$ (standard deviations are given where applicable) for the largest single batch of water processed, represents 314 curies.

Twenty-nine batches (pumpouts) were pumped out of the sump, and seven additional samples were collected between September 1981 and the end of November 1984. These are described in the following sections. The water levels are shown in Figure 2.1, and the activity levels (curies of $137 \mathrm{Cs}$ ) are illustrated in Figure 2.2.

Additional data was provided by the first three water samples collected between July 1979 and May 1981 from the lower level of the reactor building. The results of these and other special samples are presented in Table 2.1. In chronological order, these three samples showed a concentration of 176-, 162-, and $143-\mu C i$ of ${ }^{137} \mathrm{Cs}$ per $\mathrm{mL}(\bar{x}=159.7, \mathrm{~s}=15.6)$. The decreasing concentration over time is probably due to dilution by water sources with lower concentrations of cesium.

\subsection{ANALYSIS OF PUMPOUTS 1 TO 16}

Data obtained from transferring basement water from the reactor building to the initial stages of the water treatment system are shown in Table 2.2. In all but a few cases, the data, given in the table for batches 1 through 17 , were obtained from a single sample from each batch of pumpout water sent offsite to Oak Ridge National Laboratory for analysis.

The water elevation when pumping began in September 1981 was about 290.9 feet. Water was removed in batches until May 1982 (between pumpouts 24 and 25) when use of the tank farm was discontinued and water was pumped directly to the submerged demineralizer system (SDS).

The ${ }^{137} \mathrm{Cs}$ concentration in the initial pumpout was $128 \mu \mathrm{Ci} / \mathrm{mL}$, and the average concentration during the first 16 pumpouts was $127.8 \mu \mathrm{Ci} / \mathrm{mL}$, (standard deviation 4.5 , the mean for the first 15 pumpouts was 127 and standard deviation 3.75) (see Figure 2.1). These data, except where noted in Table 2.1, were based on one sample from each batch of pumpout water sent offsite to Oak Ridge National Laboratory for analysis.

The special samples that were sent to the national laboratories were also analyzed for cesium in solids. The results are shown in Table 2.3. It appears that even before the start of decontamination activities, both the concentration of solids in the basement water and the activity of the solids varied considerably. 


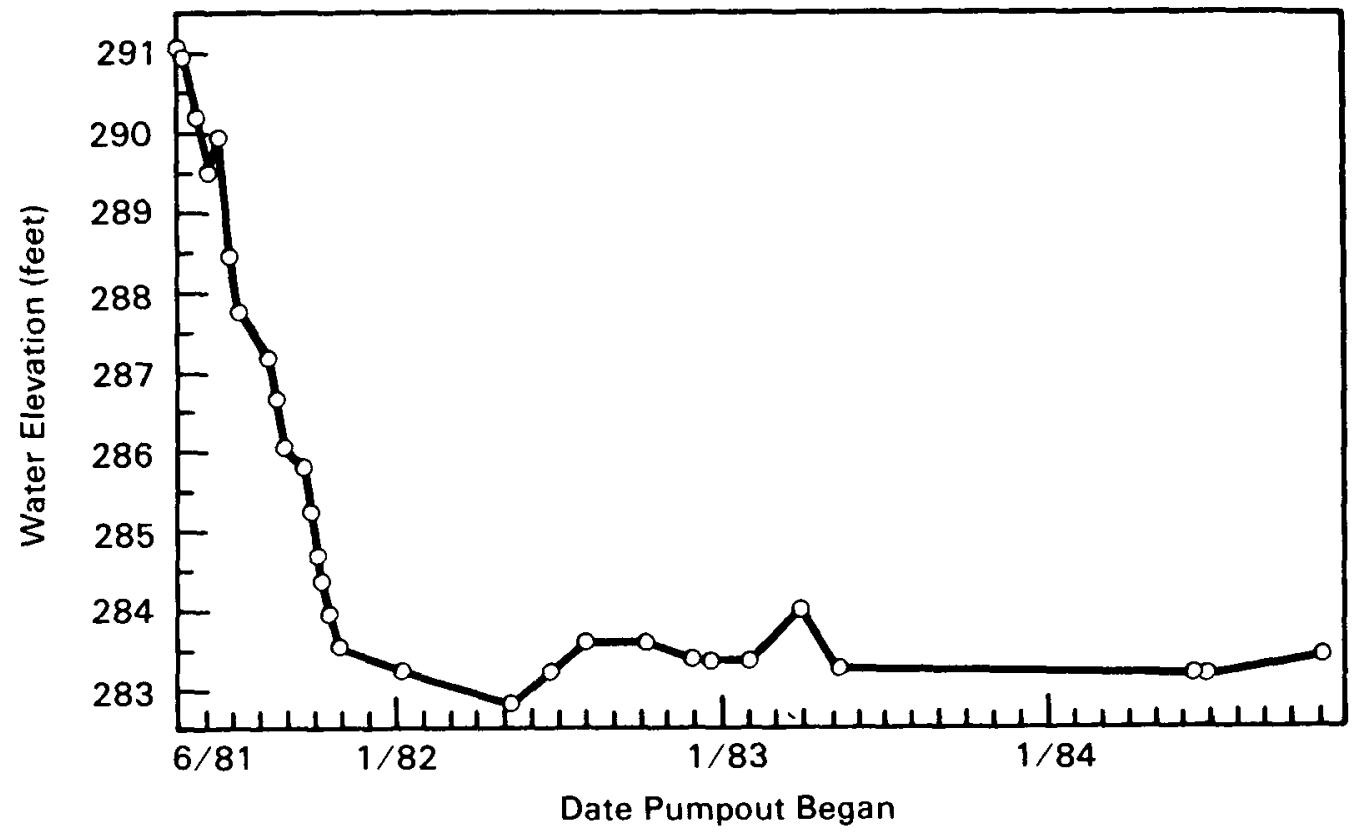

FIGURE 2.1. Water Elevation

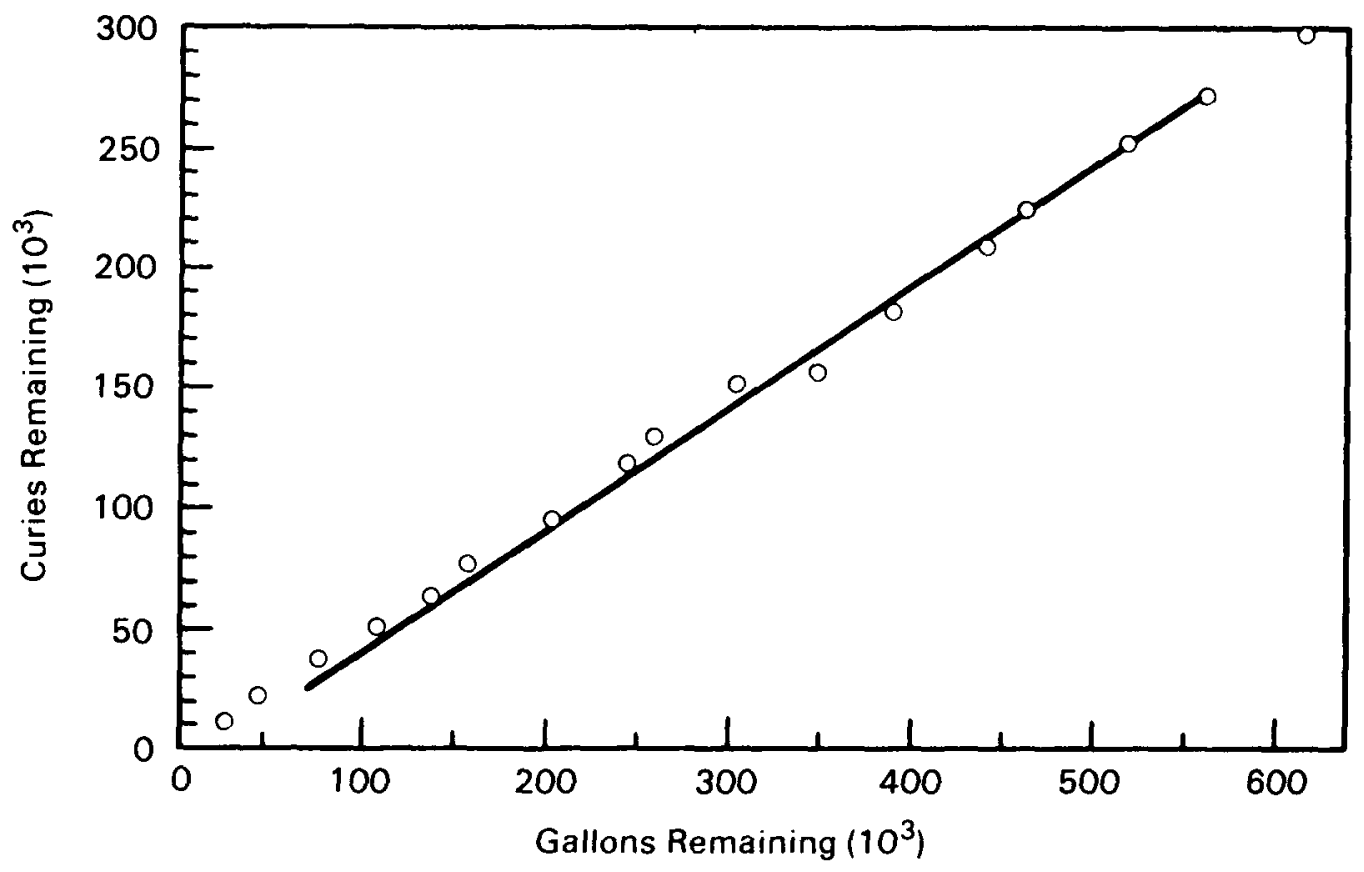

FIGURE 2.2. Calculated Curies ${ }^{137}$ Cs Remaining 
TABLE 2.1. Special Water Samples from the Reactor Building

\begin{tabular}{|c|c|c|c|c|c|c|}
\hline Sample Location & Date & Sample Type & Laboratory & $\begin{array}{l}137 \mathrm{Cs} \\
\text { in Water } \\
\mu \mathrm{Ci} / \mathrm{ml} \\
\end{array}$ & $\begin{array}{c}\text { Total Solids } \\
\mathrm{mg} / \mathrm{ml} \\
\end{array}$ & $\begin{array}{r}{ }^{137} \mathrm{Cs} \\
\text { in Solids } \\
\mu \mathrm{Ci} / \mathrm{g} \\
\end{array}$ \\
\hline Penetration 401 & $8 / 28 / 79$ & Water & ORNL & 176 & $\sim 0.5$ & 25 \\
\hline Penetration 401 & $11 / 15 / 79$ & Water & ORNL & 162 & 0.3 & 76 \\
\hline $\begin{array}{l}\text { From } 305-f t \text { elevation } \\
\text { via covered hatch }\end{array}$ & $5 / 14 / 81$ & 8 water samples & INEL & 143 & 0.98 & 808 \\
\hline $\begin{array}{l}\text { From 305-ft elevation } \\
\text { via open stairwell }\end{array}$ & $9 / 24 / 81$ & & INEL & 137 & 0.21 & 324 \\
\hline $\begin{array}{l}\text { Bottom of open } \\
\text { stairwell }\end{array}$ & $6 / 23 / 82$ & Sludge and water & ORNL/WHEDL & $151 / 159$ & $21.6 / 26.1$ & $802 / 2040$ \\
\hline Covered hatch & $1 / 11 / 83$ & Sludge and water & PNL-TMI & 12.0 & 0.04 & 3600 \\
\hline $\begin{array}{l}\text { Floor penetration } \\
\text { NE quadrant }\end{array}$ & $1 / 11 / 83$ & Sludge and water & PNL-TMI & 8.2 & 0.02 & $>540$ \\
\hline $\begin{array}{l}\text { Floor penetration } \\
\text { SW quadrant }\end{array}$ & $1 / 11 / 83$ & Sludge and water & PNL-TMI & 8.3 & 9 & 29.9 \\
\hline $\begin{array}{l}\text { Sump pump discharge } \\
\text { line }\end{array}$ & $8 / 22 / 83$ & 2 water samples & INEL/WHEDL & 85.5 & 0.4 & 53.7 \\
\hline $\begin{array}{l}\text { ORNL = Oak Ridge Natio } \\
\text { INEL = I daho National } \\
\text { WHEDL = Westinghouse } \\
\text { PNL-TMI = Pacific Nort }\end{array}$ & $\begin{array}{l}\text { Laborat } \\
\text { ineering } \\
\text { ord Engi } \\
\text { st Labor }\end{array}$ & $\begin{array}{l}\text { aboratory } \\
\text { ering Developmen } \\
\text { ory - Three Mile }\end{array}$ & aboratory & & TMI) & \\
\hline
\end{tabular}


TABLE 2.2. TMI-2 Basement Water Samples (a)

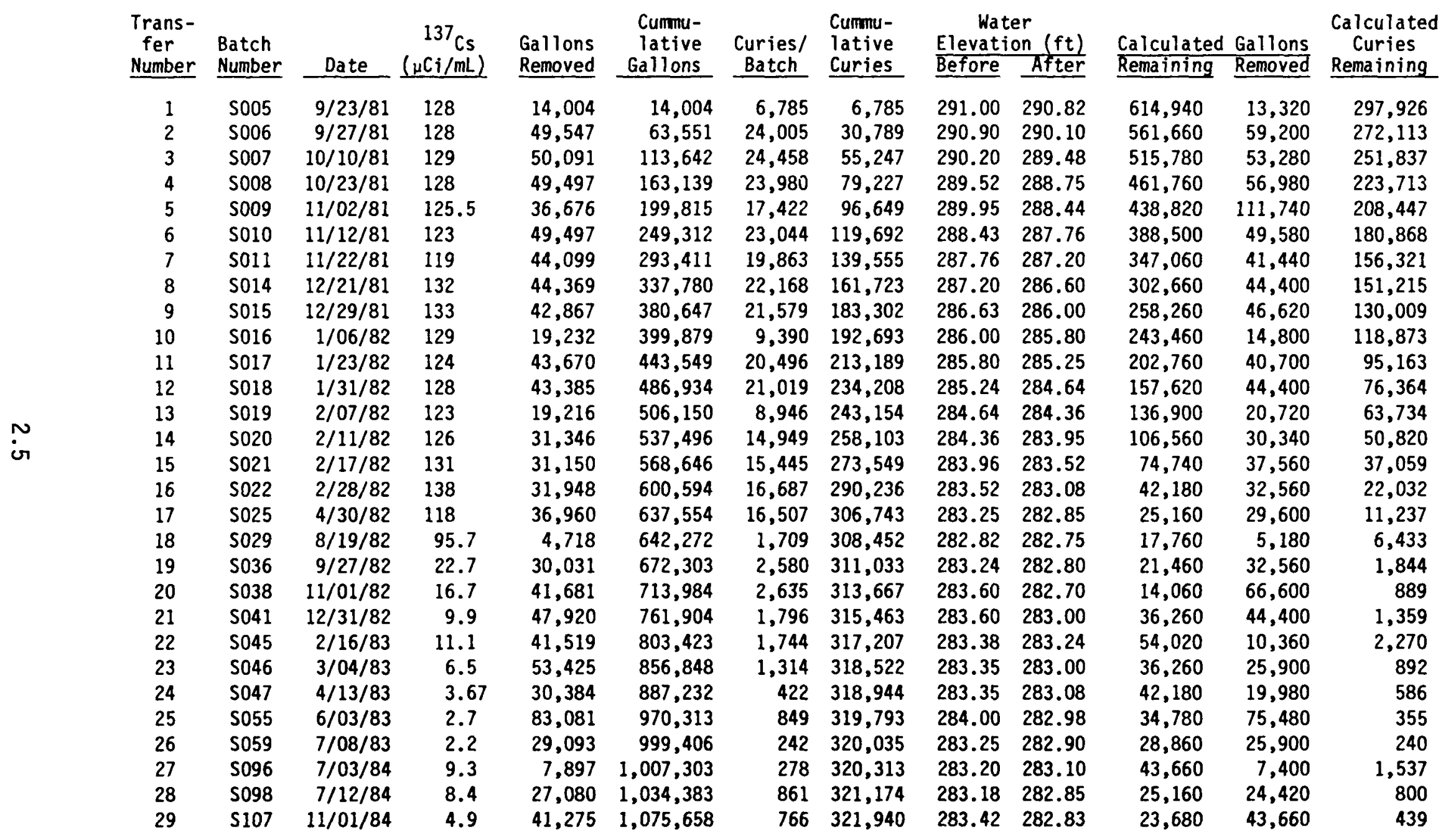

(a) This data is documented in a letter from Linda Munson, Pacific Northwest Laboratory, to Ronnie Lo, NRC, dated 9 May 1985. 
TABLE 2.3. Basement Sludge Samples

\begin{tabular}{|c|c|c|c|c|c|c|}
\hline $\begin{array}{c}\text { Sample } \\
\text { Date }\end{array}$ & $\begin{array}{l}\text { Sample } \\
\text { Location }\end{array}$ & $\begin{array}{c}\text { Analyzed } \\
\text { by } \\
\end{array}$ & $\begin{array}{l}\text { Dissolved } \\
137 \mathrm{Cs} \\
\mu \mathrm{Ci} / \mathrm{mL} \\
\end{array}$ & $\begin{array}{l}\text { Total } \\
\text { Solids } \\
\mathrm{mg} / \mathrm{mL} \\
\end{array}$ & $\begin{array}{c}137 \mathrm{Cs} \\
\text { Activity } \\
\text { in Solids } \\
\mu \mathrm{Ci} / \mathrm{g} \\
\end{array}$ & $\begin{array}{c}\text { Suspended } \\
137 \mathrm{CS}(\mathrm{a}) \\
\mu \mathrm{Ci} / \mathrm{L} \\
\end{array}$ \\
\hline $8 / 28 / 79$ & Penetration 401 & ORNL & 176 & $w 0.5$ & 25 & 12.5 \\
\hline $11 / 15 / 79$ & Penetration 401 & ORNL & 162 & 0.3 & 76 & 22.8 \\
\hline $5 / 14 / 81$ & Covered hatch & $\operatorname{INEL}^{(b)}$ & 143 & 0.8 & 808 & 78.4 \\
\hline $9 / 24 / 81$ & Open stairwell & INEL & 137 & 0.21 & 324 & 68 \\
\hline $6 / 23 / 82$ & Open stairwell & ORNL & 151 & 0.26 & 803 & 17,300 \\
\hline $6 / 23 / 82$ & Open stairwell & WHEDL & 159 & 26.1 & 2040 & 53,000 \\
\hline $1 / 11 / 83$ & Covered hatch & PNL-TMI & 12.0 & 0.04 & 3600 & 144 \\
\hline $1 / 11 / 83$ & $\begin{array}{l}\text { NE quadrant, } \\
\text { Penetration } 238\end{array}$ & PNL-TMI & 8.2 & 0.02 & $>540$ & $>10.8$ \\
\hline $1 / 11 / 83$ & $\begin{array}{l}\text { SW quadrant } \\
\text { Penetration } 225\end{array}$ & PNL-TMI & 8.3 & 9.0 & 29.9 & 269.1 \\
\hline $8 / 22 / 83$ & Sump pump & INEL & 95.5 & 0.4 & 53.7 & 21.48 \\
\hline
\end{tabular}

(a) Calculated quantity. Other data from Isaac and Keefer 1984.

(b) Eight samples were taken; four samples from $0.95 \mathrm{~cm}$ above the floor were used here.

The quantity of cesium remaining in the water can be estimated using the water level and the ${ }^{137} \mathrm{Cs}$ concentration from the last pumpout. This data is presented in Table 2.2 and shown graphically in Figure 2.4. Any trend such as dilution or addition of activity would have resulted in a curved line.

After completing pumpout number 16 , which began on 28 February 1982, a total of 600,594 gallons $(2.3 \times 106 \mathrm{~L})$ containing 290,236 curies had been removed. The water elevation following pumpout number 16 was 283.08 feet, which represents 42,180 gallons. Pumpout 16 contained the highest concentration of ${ }^{137 \mathrm{Cs}}$ of any batch removed from the building, $138 \mu \mathrm{Ci} / \mathrm{mL}$. Previous pumpouts ranged from 119 to $132 \mu \mathrm{Ci} / \mathrm{mL}$.

The measured cesium concentration from pumpout 16 is $138 \mu \mathrm{Ci} / \mathrm{mL}$. This is above the average of the previous 15 samples by approximately 3 standard deviations, which indicates that there is less than 1 in 100 chance that it is a random analytical error. The measured concentration from pumpout 16 may 
result because the water associated with sludge has a significantly higher cesium concentration than the bulk solution above it.

If the average concentration of the water from all pumpouts preceding 16 $(128 \mu \mathrm{Ci} / \mathrm{mL})$ is representative of the concentration in the basement solution, then the remaining water can be calculated to have contained 20,435 curies. If, instead, the representative concentration is $138 \mu \mathrm{Ci} / \mathrm{mL}$, as determined by data from only pumpout 16 , the remaining basement water can be estimated to have contained 22,031 curies. If, however, the water associated with the sludge in the basement contains considerabiy more activity than the bulk solution above it, which would account for the observed value, then the actual cesium burden in the basement water cannot be predicted more accurately than to say it exceeds 22,000 curies. (The best evidence that water associated with the sludge contains more activity than the bulk solution above it is given by January 1983 samples where the activity in the two samples containing sludge exceeded the cesium concentration in the bulk solution.)

A sample of the basement water and sludge was taken in June 1982, between pumpouts 17 and 18, by a worker who descended the open stairwell to the basement. The sample, which was split and sent for analysis to two national laboratories, showed 151 and $159 \mu \mathrm{Ci} / \mathrm{mL}{ }^{137} \mathrm{Cs}$ in the associated water. This is especially significant because the bulk solution remaining in the basement after sampling contained only $118 \mu \mathrm{Ci} / \mathrm{mL}$, which indicated that the water associated with the sludge may have contained more concentrated cesium activity than the remaining water.

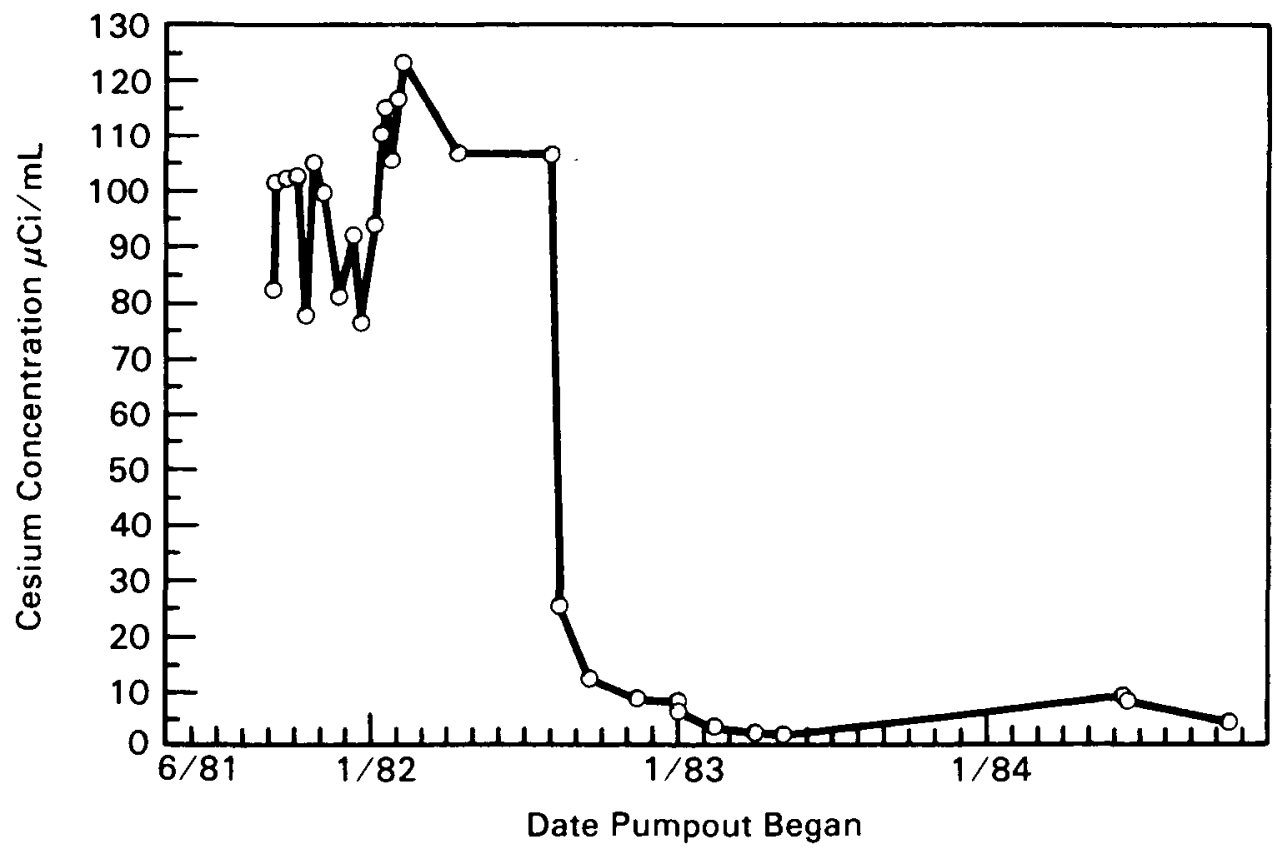

FIGURE 2.3. ${ }^{137} \mathrm{Cs}$ Concentration in Basement Pumpouts 


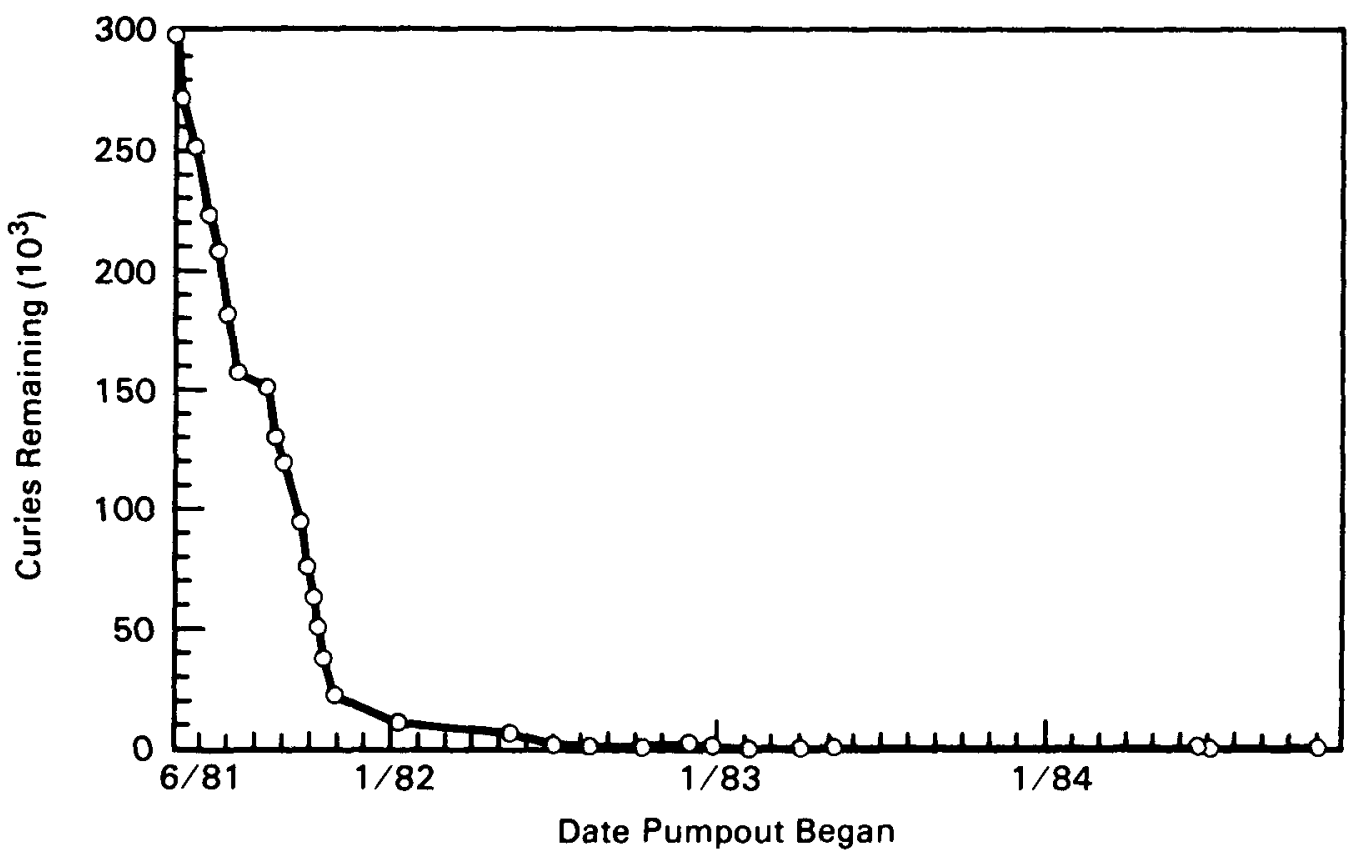

FIGURE 2.4. Calculated Curies Remaining Versus Gallons Remaining During the First 16 Pumpouts

If, at the completion of pumpout 16 , the water associated with the sludge contained approximately $200 \mu \mathrm{Ci} / \mathrm{mL}$ (probably the approximate concentration of the bulk solution immediately after the accident), then the cesium burden in the basement water would have been approximately 32,000 curies ${ }^{137} \mathrm{Cs}$.

\subsection{ANALYSIS OF PUMPOUTS 17 and 18}

A large quantity of relatively clean water drained to the basement before pumpout 17. Pumpout 17 removed 16,507 curies of activity. Pumpouts 18 and beyond continued to remove activity, totalling 15,125 curies. While a portion of this activity probabiy entered the basement with the decontamination solutions, it is extremely unlikely that all of this activity came from decontamination efforts. It is, however, possible that much of it came from water entrained in the basement sludge. Pouring clean water down the elevator shaft, which already contained accident water, probably also introduced some activity. (Assuming the elevator shaft contained water at $175 \mu \mathrm{Ci} / \mathrm{mL}$ and estimating the dimensions as $10 \mathrm{ft} \times 10 \mathrm{ft} \times 5 \mathrm{ft}$, the elevator shaft water was estimated to contain almost 2,500 curies.)

Between pumpout 16, which began on 28 February 1982, and pumpout 17, which began on 30 April 1982, the water elevation rose from 283.08 feet to 283.25 feet. This 0.17 -foot increase in elevation corresponds to approximately 12,580 gallons of solution. Sources of this water were decontamination activities and primary coolant leakage. The cesium concentration in the decontamination water is, of course, unknown, but the concentration in the 
coolant at that time was approximately $2.7 \mu \mathrm{Ci} / \mathrm{mL}$. Water removed in pumpout 17 consisted of 36,960 gallons $\left(1.4 \times 10^{5} \mathrm{~L}\right)$ at a concentration of $118 \mu \mathrm{Ci} / \mathrm{mL}$ $(16,507$ curies). If the concentration of the previous water was $138 \mu \mathrm{Ci} / \mathrm{mL}$ and the basement water was homogeneous, then the average concentration of cesium in the water that was added to the basement can be calculated at $51 \mu \mathrm{Cl} / \mathrm{mL}$, for a total of 2,425 curies. This seems highly unlikely. It seems much more probable that the water associated with the sludge contained more activity than the bulk solution above it. Some leaching of activity from sludge and other sources may also have contributed to the total concentration.

Pumpout 17 reduced the water elevation to about 282.85 feet. However, it appears from the tracing (see Appendix A) that the level recorder may have been reading abnormaliy at this time. The 282.85-foot water elevation corresponds to 25,160 gallons. Calculations from the water elevations show that the pumpout removed only 29,600 gallons, rather than the 36,960 gallons reported. This may be due to inaccurate gage readings, the addition of water during the pumpout, or a combination of these two factors. At the completion of pumpout 17 , there were approximately 25,160 gallons $\left(9.5 \times 10^{4} \mathrm{~L}\right)$, a concentration of about $118 \mu \mathrm{Ci} / \mathrm{mL}$, of water remaining--or about 11,237 curies still remaining in the basement water.

During the approximately 3-1/2-month period between pumpout 17 and the next significant addition of water, very little change in water elevation was noted. The split sample, which was discussed previously, from the open stairwell was taken during this time. Although the two samples showed little difference in dissolved cesium, they showed a discrepancy in the quantity of solids present and the specific cesium activity of those solids (see Table 2.3).

Pumpout 18 consisted of only 4,718 gallons $\left(1.8 \times 10^{4} \mathrm{~L}\right)$ of approximately $95.7 \mu \mathrm{Ci} / \mathrm{mL}$ water; $(1,709$ curies). Water-level tracings (Appendix A) in the basement showed pumpout 18 occurred at a time when little, if any, water was being added. The $95.7 \mu \mathrm{Ci} / \mathrm{mL}$ value for pumpout 18 was derived by averaging the licensee's measurements and applying a factor of 1.1 to account for the bias (calibration error) inherent in the counting system at this time. The $22.7 \mu \mathrm{Ci} / \mathrm{mL}$ value for pumpout 19 was similarly derived from the licensee's value of $20.6 \mu \mathrm{Ci} / \mathrm{mL}$.

Before pumpout 19 , the elevation of the water rose from 282.75 to 283.24 feet, corresponding to a total of 54,020 gallons in the building. If the remaining activity (6433 curies) was dispersed uniformly in this volume of solution with no additional activity added, then the concentration would have been $31.5 \mu \mathrm{Ci} / \mathrm{mL}$. A slightly higher concentration was expected because of the activity in the decontamination solution, but the water that was pumped out reportedly contained only $22.7 \mu \mathrm{Ci} / \mathrm{mL}$. This indicated either incorrect measurements or phenomena such as layering or precipitation that prevented complete dispersion of the activity already present in the basement. 


\subsection{ANALYSIS OF PUMPOUTS 19 THROUGH 26}

Pumpout 19 and the next several pumpouts removed progressively more dilute water until, at pumpout 26 , the concentration was only $2.2 \mu \mathrm{Ci} / \mathrm{mL}$. During these pumpouts, 1,352 curies were removed. Assuming pumpout 26 was representative of the bulk solution, there should have been only about 240 curies in solution in the basement water plus whatever was incorporated in sludge, concrete, and other matrices.

There were no additional pumpouts for almost a year following pumpout 26 . There was, however, sampling of the basement sludge and associated water at three different locations. The samples were analyzed at TMI-2 in a mobile analytical laboratory operated on site by the Pacific Northwest Laboratory. One sample taken through the covered hatch in the SE quadrant from the 305-foot elevation showed $12.0-\mu \mathrm{Ci} / \mathrm{mL}$ dissolved cesium and $0.04-\mu \mathrm{Ci} / \mathrm{mL}$ suspended cesium. The total mass of solid was reportedly only about $1 \mathrm{mg}$, assuring a non-representative sample. A second sample, taken from the NE quadrant (the quadrant between the elevator and the sump) showed $8.20-\mu \mathrm{Ci} / \mathrm{mL}$ dissolved $137 \mathrm{Cs}$ and less than $10.8-\mu \mathrm{Ci} / \mathrm{L}$ suspended ${ }^{137} \mathrm{Cs}$. The sample from the SW quadrant, outside the reactor coolant drain tank (RCDT) cubicle, showed $8.3-\mu \mathrm{Ci} / \mathrm{mL}$ dissolved ${ }^{137} \mathrm{Cs}$ and $269-\mu \mathrm{Ci} / \mathrm{L}$ suspended ${ }^{137} \mathrm{Cs}$. Because these samples contained sludge, the suspended cesium concentration indicates successful sampling.

If our previous assessment was correct, that the water associated with the sludge had a significantly higher activity than the bulk solution, then samples indicate: 1) the same phenomenon is still occurring, that is, the basement water associated with the sludge is not fully mixed with the bulk solution above it, and 2) the repeated introduction and removal of decontamination solutions has greatly reduced the cesium burden in the water associated with the sludge. The latter assumption is consistent with the data regarding the quantity of cesium removed in the interim.

The samples also showed that cesium activity of the solids in the sludge varied more than two orders of magnitude, with a $137 \mathrm{Cs}$ concentration of 29.9- $\mu \mathrm{C} i 137 \mathrm{Cs}$ per gram in the SW quadrant and more than one hundred times that activity in the NE quadrant.

\subsection{ANALYSIS OF PUMPOUTS 27 THROUGH 29}

Difficulties were experienced with the instruments measuring water elevations in the reactor basement during most of the 1-year period between pumpouts 26 and 27 . It is, therefore, difficult to accurately track water additions during this time; however, it appears that additions were not large or numerous.

Before pumpout 27, there was not only a year of diffusion, leaching and other passive processes taking place, but the reactor building sump was sampled by pumping with the installed sump pump, and the decay heat lines from the auxiliary building to the sump were backflushed. The sump sample showed $95.5 \mu \mathrm{Ci} / \mathrm{mL}$, again indicating that the water in the lowest areas and 
associated with the sludge was not fully mixed with the bulk solution but had given up a considerable amount of cesium from its original concentration after the accident. The sump sample also showed relatively little suspended solids, $0.4 \mathrm{mg} / \mathrm{mL}$, and about average activity in these solids, $53.7 \mu \mathrm{Ci} / \mathrm{g}$. The lack of solids in the sample was not too surprising because of the design of the two-part sump.

Backflushing the lines both agitated and added activity to the basement water. The cesium concentration in pumpout 27 was $9.3 \mu \mathrm{Ci} / \mathrm{mL}$. The pumpout consisted of only 7,897 gallons $\left(3.0 \times 10^{4} \mathrm{~L}\right)$, so only 278 curies were removed. During pumpouts 28 and 29 , the cesium concentration in the basement water continued to decline, probably as a result of dilution, to 8.4 and $4.9 \mu \mathrm{Ci} / \mathrm{mL}$, respectively. The volumes of pumpouts 28 and 29 were 27,080 and 41,275 gallons, and they contained 861 and 766 curies, respectively. Based on the results of samples from pumpout 29 and the basement-water inventory, we expect there are about 440 curies of cesium activity remaining in the basement solution. Based on the history of pumpouts and water additions, there may be considerably more.

Overal1, the basement pumpouts have removed approximately 321,940 curies of cesium activity. This is about 17,000 curies more than the initial pumpouts indicated were available and is within the analytical error of the original measurements. However, the apparent increase in basement-water cesium quantity in the later pumpouts cannot be explained by analytical error. The additional activity is most likely from a combination of the following sources: 1) higher activity in the water associated with the sludge, 2) activity trapped in the elevator shaft, 3) cesium leached from the basement solids and sludge, 4) activity from backflushing decay heat lines, 5) activity from decontamination solutions, 6) material from reactor building drains, 7) activity from the addition of primary coolant, and 8) activity leached from concrete, paint and other solid matrices.

Because sludge is nonuniform both in quantity and concentration of activity, it is difficult to estimate its activity. The sludge samples taken before water additions began have an average cesium activity in the solids of $680 \mu \mathrm{Ci} / \mathrm{g}$ and a standard deviation of $749 \mu \mathrm{Ci} / \mathrm{g}$. If the additional 17,000 curies mentioned above were all from this sludge, they would represent the activity in $2.3 \times 10^{7} \mathrm{~g}$ of solids. Because the area of the basement floor is $12,868 \mathrm{ft}^{2}$ (based on the 128-foot effective diameter of the building), this amount of sludge corresponds to $1,809 \mathrm{~g} / \mathrm{ft}^{2}$. Video inspection by the robot suggests there are areas with this quantity of sludge, but there are also areas with much less. Observations made by the worker who descended the stairs indicated that the sludge is highly nonuniform and that areas with $1.8 \mathrm{~kg}$ (4 pounds) of sludge per square foot are the exception rather than the rule.

Before the robot made video inspections, Cox, Horan and Worku (1983) attempted to calculate the quantity of solids using sample data and information regarding the depth and method of sampling. Table 2.4 gives their calculated values based on the individual samples. The values range from 7700 grams ( 17 pounds) to $1.34 \times 10^{6}$ grams ( 3000 pounds). The 7700 -gram value 
is clearly inconsistent with the video data from the robot. A GPU (1983) technical plan for sludge removal estimates that between 200 to $850 \mathrm{ft}^{3}$ of dewatered sludge will require disposal. Assuming that this material contains 1 gram of solids per cubic centimeter, the GPU estimate would correspond to between $5.7 \times 10^{6}$ and $24 \times 10^{6}$ grams of sludge.

TABLE 2.4. Volume and Activity of Solids

\begin{tabular}{|c|c|c|c|c|}
\hline $\begin{array}{c}\text { Sample } \\
\text { Date }\end{array}$ & $\begin{array}{l}\text { Assumed } \\
\text { Solids } \\
\text { Depth } \\
(\mathrm{cm})\end{array}$ & $\begin{array}{l}\text { Total Soljdds } \\
\text { Estimated } \\
(\mathrm{g}) \\
\end{array}$ & $\begin{array}{c}137 \mathrm{Cs} \\
\text { Activity } \\
\text { in Solids } \\
(\mu \mathrm{C} / \mathrm{g}) \\
\end{array}$ & $\begin{array}{l}\text { Estimate( }) \\
\text { Total } \mathrm{Ci}\end{array}$ \\
\hline $5 / 14 / 81$ & $0-13.65$ & 136,696 & 808 & 100 \\
\hline $9 / 24 / 81$ & 0.95 & 7,730 & 324 & 2.5 \\
\hline $6 / 23 / 82$ & 2.54 & $1.12 \times 10^{6}$ & 727 & 872.4 \\
\hline $6 / 23 / 82$ & $2.54^{(c)}$ & $1.34 \times 10^{6}$ & 2,032 & 2,723 \\
\hline $1 / 11 / 83$ & $10.16^{(d)}$ & $\begin{array}{l}2.14 \times 10^{5} \\
9.86 \times 10^{4} \\
1.28 \times 10^{6}\end{array}$ & $\begin{array}{l}12.3(\mathrm{e}) \\
122.0(\mathrm{e}) \\
192\end{array}$ & $\begin{array}{c}2.6 \\
12 \\
245\end{array}$ \\
\hline
\end{tabular}

\footnotetext{
(a) From Cox, Horan and Worku 1983.

(b) Based on assumed area sampled.

(c) Manual scoop. Sample split.

(d) Three locations.

(e) These samples were taken after addition of the decontamination water began.
} 


\subsection{RADIOLOGICAL CONDITIONS IN THE TMI-2 BASEMENT AND DOSE RATES AT UPPER ELEVATIONS}

The licensee's program to reduce doses has led to decontamination and shielding of radiation sources at upper elevations of the TMI-2 reactor building. It has also led to the placement of shielding at the open stairwell, around the enclosed stairwell and elevator shaft, over the covered hatch and at various other penetrations. Figure 3.1 illustrates dose rates and locations on the 305-foot elevation. (Because of the large number of illustrations in this chapter, they are grouped together at the end of the chapter.)

The licensee has concluded that the basement is no longer making a significant contribution to the doses received by workers in other portions of the facility. This is based on their assessment of the dose at the 305-foot elevation, the effectiveness of the shielding, and the 305-foot-elevation work force, which is relatively small now and is expected to remain low throughout the defueling period.

Presented below is an independent assessment of the licensee's conclusions. In general, we concur that sources below the previous water elevation are making a minor contribution, if any, to dose rates on the upper elevations of the reactor building, and that dose reduction efforts have largely ameliorated those effects. One exception to the general conclusions about basement conditions is the enclosed stairwell. There may also be exceptions within and around the air coolers and at penetrations near the personnel hatch, but these are relatively unimportant because little work is presently planned in these areas through the defueling phase of cleanup.

The dose rate in the basement of the reactor building varies from approximately $4 \mathrm{R} / \mathrm{hr}$ to more than $1100 \mathrm{R} / \mathrm{hr}$ (in contact with the concrete block). These data are based on both TLD string data and data taken by the robot. Figure 3.2 shows the general area dose rates in the basement between the 286- and 289-foot elevation. Figure 3.3 is a map of the dose rates near the 300-foot elevation. Figure 3.4 shows the TLD string locations and Figures 3.5 through 3.46 show the gamma or beta/gamma dose profiles at the various locations in the basement. The TLD string data are helpful in assessing the dose rates near the 300-foot elevation.

As discussed in the preceding chapter, the maximum elevation of water levels following the September 1981 accident was 291 feet. Any activity between the high-water mark and the present water level was probably left by the receding water. Any activity above the high-water mark was deposited from contaminated atmosphere, from condensation, from flushing upper areas, or, in the case of the area around the RCDT vent line, from high-velocity water and steam during the accident.

This analysis is based on dose rates and how they change with elevation. It also relies on levels of beta radiation, where available, to indicate the 
physical proximity of contaminants. Because the range of beta radiation in air is fairly short, any appreciable beta dose recorded by the TLDs comes from a source that is within a foot or so from the dosimeter. Beta and gamma activity are thought to have been deposited at approximately the same locations; however, decontamination efforts at the upper elevations appeared to reduce beta activity more readily than they did gamma activity.

There is a great deal of information regarding radiological conditions in the basement. To facilitate the presentation, we have divided the basement into four quadrants and have presented the conditions in each quadrant beginning with due east and continuing clockwise. The SE quadrant is discussed first because it contains the most significant radiation source. The quadrants are illustrated in Figures 3.2 and 3.3 .

\subsection{SE QUADRANT}

The SE quadrant contains the concrete block structure that comprises the elevator shaft and the enclosed stairwell. There are data from three TLD strings within the stairwell and elevator shaft, from two TLD strings outside the structure, and from the robot. Figures $3.5,3.6$, and 3.7 illustrate the dose-rate profiles at locations $B-3, B-15$, and $B-23$, which are all within the concrete block structure. The peak dose rate measured in each of these locations is in the range of 400 to $900 \mathrm{R} / \mathrm{hr}$. Samples collected from the first two locations, measured at 700 and $400 \mathrm{R} / \mathrm{hr}$, respectively, indicate the most intense radiation source is at about the 287 -foot elevation. The $700 \mathrm{R} / \mathrm{hr}$ reading was probably measured closer to the contaminated surfaces in the stairwell. Location B-23, immediately in front of the elevator doors, shows the highest dose rate, $900 \mathrm{R} / \mathrm{hr}$, at the lowest TLD, 283 feet. There is little evidence of a bathtub ring on the elevator doors. (The term bathtub ring is used to refer to the collection of radiation sources that has concentrated at the previous air-water interface. In most locations, an oil deposit is also visible in this area.)

The two TLD strings, B-13 (Figure 3.8) and B-12 (Figure 3.9), located outside of the concrete block structure (stairwell and elevator shaft) also show very high dose rates. The TLDs at location B-13 show dose rates of nearly $400 \mathrm{R} / \mathrm{hr}$ and a slight bathtub ring at about the 286-foot elevation. TLD string B-12 is located directly below the covered hatch. This string had TLDs placed at 5-foot intervals, with none in the vicinity of the 287-foot elevation. The TLD nearest the 287-foot elevation was on the bottom of the string, and it exhibited the highest dose rate, about $85 \mathrm{R} / \mathrm{hr}$. The principal contribution is probably still from the concrete block.

TLD strings (locations $B-3, B-23$ and $B-13$ ) used both shielded and unshielded TLDs to determine the beta dose rate. The B-3 string was close to contaminated surfaces only above the 294-foot elevation and, therefore, had no significant beta contribution at the lower elevation. The TLD string at location $\mathrm{B}-23$ was close enough to contaminated surfaces to have significant 
beta readings at most locations, both above and below the previous water line. For location B-13, the beta contribution below the 290-foot elevation is not available, and there was apparently no significant beta contribution above that level, except at the penetration where the string was lowered.

Measurements made by the ROVER robot in this quadrant (see Table 3.1 and Figures $3.10,3.11$, and 3.12) corroborate the TLD string readings with a few exceptions. Dose rates measured at location $A A$, corresponding to the hollow concrete block outside the elevator shaft, exceeded $1100 \mathrm{R} / \mathrm{hr}$. This dose-rate profile is shown in Figure 3.11. The highest dose rate appeared at the 289-foot elevation, which contradicted data from the TLD string. Dose rate readings were also taken at several different elevations at location $U$ (Figure 3.12). While there are some anomalies between the two detectors in this location, both seem to show the location between 288.1 and 289 feet as the area of highest activity. The local differences in dose rates are much more pronounced in the TLD readings than they are in the ion chamber readings made by the robot. In a nonuniform field such as the basement, the much smaller size of the TLDs allows them to follow local field gradients while ion chambers respond to the dose rates averaged over the entire chamber: The reason for the different elevations for maximum readings ( 287 feet for TLD, 286 feet for the robot) is not known, but differences in methods for measuring elevation cannot be ruled out. The robot also measured dose rates on a vertical drain pipe at location $S$ (Figure 3.13). The maximum measured dose rate was $38 \mathrm{R} / \mathrm{hr}$. The majority of this dose is probably from the stairwell; however, the variation between the side-by-side detectors indicates the presence of local sources as well.

Measurements were made in seven locations with a shielded teletector probe placed on the ROVER robot. The probe was located 5 inches above the floor and shielded from above. The data is shown in Table 3.1. The dose-rate readings at points $T, U, V, W$ and $X$ were $2 \%$ to $3 \%$ of the general area dose rates. These points are located near the enclosed stairwell/elevator shaft structure. At points $Q$ and $S$, the robot was further from the enclosed stairwell/elevator shaft, and the teletector readings of the floor were $12 \%$ to $14 \%$ of the general area dose rate. The teletector measurements were used to calculate the amount of activity in the concrete floor slab. The complete analys is is described in Appendix B.

In this quadrant, it is possible that basement sources may be impacting dose rates at higher elevations. Without question, there is a significant contribution within the stairwell, and there was a significant contribution over the covered hatch before it was shielded. Some other small contributions may remain.

The air coolers penetrate through the 3-foot-thick-concrete floor in this area, and, while their metal components provide some shielding, the coolers may allow radiation from the basement to contribute to the amount of general radiation on the 305-foot level. This is very difficult to determine, however, because the air coolers are themselves contaminated. The current plan to shield the air coolers should reduce the dose contributed by both the basement and the air coolers. 
TABLE 3.1. ROVER Robot Data from the SE Quadrant

\begin{tabular}{|c|c|c|c|c|}
\hline $\begin{array}{c}\text { Quadrant } \\
\text { and } \\
\text { Locations } \\
\end{array}$ & $\begin{array}{l}\text { Height } \\
\text { Above } \\
\text { Floor } \\
\text { (inches) } \\
\end{array}$ & $\begin{array}{c}\text { Elevation } \\
\text { (feet) }\end{array}$ & $\begin{array}{c}\text { Dose Rate } \\
\frac{\text { Detector P-1 }}{\text { (R/hr) }} \\
\end{array}$ & $\begin{array}{l}\text { Measurements } \\
\frac{\text { Detector P-2 }}{(R / h r)}\end{array}$ \\
\hline SE DD & 48 & 286 & 6 & 9 \\
\hline SE EE & 48 & 286 & 8 & 9 \\
\hline SE CC & 48 & 286 & 51 & 52 \\
\hline SE BB & 48 & 286 & 264 & 248 \\
\hline SE Z & 48 & 286 & 27 & 31 \\
\hline SE $A A^{(a)}$ & $\begin{array}{l}48 \\
54 \\
60 \\
66 \\
72 \\
77 \\
85\end{array}$ & $\begin{array}{l}286 \\
287 \\
287.5 \\
288 \\
288.5 \\
289 \\
289.6\end{array}$ & $\begin{array}{r}707 \\
749 \\
830 \\
965 \\
1102 \\
1122 \\
1058\end{array}$ & $\begin{array}{r}717 \\
753 \\
815 \\
957 \\
1089 \\
1139 \\
1019\end{array}$ \\
\hline SE $Y$ & 48 & 286 & 105 & 97 \\
\hline SE $S$ & $\begin{array}{r}5(b) \\
48(c) \\
59(c) \\
71(c) \\
85(c)\end{array}$ & $\begin{array}{l}283 \\
286 \\
287.4 \\
288.4 \\
289.6\end{array}$ & $\begin{array}{l}4.2^{(b)} \\
31 \\
37 \\
35 \\
31\end{array}$ & $\begin{array}{l}37 \\
32 \\
38 \\
36\end{array}$ \\
\hline SE T & $5_{48}^{(b)}$ & $\begin{array}{l}283 \\
286\end{array}$ & $100^{3.1^{(b)}}$ & 95 \\
\hline SE $V$ & $5_{48}^{(b)}$ & $\begin{array}{l}283 \\
286\end{array}$ & $179^{3.1^{(b)}}$ & 172 \\
\hline SE W & $5_{48}^{(b)}$ & $\begin{array}{l}283 \\
286\end{array}$ & $214^{4.9^{(b)}}$ & 196 \\
\hline SE $X$ & $\begin{array}{l}5^{(b)} \\
48 \\
85\end{array}$ & $\begin{array}{l}283 \\
286 \\
298.6\end{array}$ & $\begin{array}{l}6.3^{(b)} \\
311^{(b)} \\
290\end{array}$ & $\begin{array}{l}325 \\
321\end{array}$ \\
\hline SE $u^{(a)}$ & $\begin{array}{l}5^{(b)} \\
48 \\
55 \\
61 \\
67 \\
73 \\
79 \\
85\end{array}$ & $\begin{array}{l}283 \\
286 \\
287.1 \\
287.6 \\
288 \\
288.6 \\
289 \\
289.6\end{array}$ & $\begin{array}{l}10.2^{(b)} \\
440 \\
679 \\
685 \\
791 \\
685 \\
679 \\
754\end{array}$ & $\begin{array}{l}433 \\
525 \\
581 \\
644 \\
879 \\
872 \\
600\end{array}$ \\
\hline SE Q & $5_{48}^{(b)}$ & $\begin{array}{l}283 \\
286\end{array}$ & $\begin{array}{r}5 \\
36\end{array}$ & 37 \\
\hline SE R & 48 & 286 & 38 & 37 \\
\hline
\end{tabular}

(a) 2 inches from wa 11.

(b) Directional probe.

(c) Contact on a drain line. 


\subsection{SW QUADRANT}

There have been only five TLD strings lowered into the SW quadrant (10cations $B-7, B-11, B-1, B-2$ and $B-29)$. The dose rate profiles from these five strings are shown in Figures 3.14 through 3.18. The TLD string at location B-7 (Figure 3.14) was within the RCDT cubicle. As in other elevations (285and 290-foot) where the TLDs were 5 feet apart, a bathtub ring was not apparent. The maximum dose rate measured within the RCDT cubicle was $17 \mathrm{R} / \mathrm{hr}$. The tank is currently full of water. If fuel particles are present in the tank, as the accident sequence indicates they are, the dose rate will increase substantially if the tank is drained.

The TLD strings at locations $B-11, B-1$ and $B-2$ were lowered through the seismic gap and were therefore close to the outside wall of containment. The dose rate profiles for these locations are shown in Figures $3.15,3.16$, and 3.17. The gamma dose rates at locations $B-11$ and $B-2$ show only minor indications of the bathtub ring and show a maximum dose rate of about 38 and $50 \mathrm{R} / \mathrm{hr}$, respectively. The beta profile from location $\mathrm{B}-2$, however, shows a significant localized source that may be the bathtub ring. In the gamma readings, this source occurs at about the 287-foot elevation, as it does at other locations, but in the beta readings it appears at the 291-foot elevation. According to licensee personnel, locations B-1 and B-11 were both selected to be close to the 3000-psi concrete wall and are slightly mislocated on the TLD location figure (Figure 3.4). Only location B-1 shows a bathtub ring, which occurs at 287 feet in the gamma profile and 288 feet in the beta profile. These data indicate that the major gamma bathtub ring phenomenon is probably confined to concrete surfaces.

The area around TLD string B-2 initially received the drainage from the RCDT. Small, highly radioactive particulate sources from the reactor core may still be on the floor and possibly on the walls and overheads (the ceilings and piping, equipment, ducts, etc., near the ceilings) in this area. These particulates may account for the observed dose rates.

The only remaining TLD string in this quadrant is at location B-29, adjacent to the open stairwel1. This string, the data from which is shown in Figure 3.18, contained four TLDs, all below the elevation of the stair landing at 290 feet. The maximum measured dose rate (approximately $40 \mathrm{R} / \mathrm{hr}$ ) was at about 283 feet, just above the floor. The other TLDs were all in fields of less than $20 \mathrm{R} / \mathrm{hr}$. The reason for the lower dose rate here is not apparent.

TLD string B-10, Figure 3.19, though slightly outside of the SW quadrant, should probably be considered as part of it because the open stairwell, in the SW quadrant, is the major contributor to dose. It shows a maximum dose rate of about $45 \mathrm{R} / \mathrm{hr}$ near the floor, possibly due to the highly radioactive particulate contamination of the floor area.

The ROVER robot took measurements in a portion of this quadrant near the hatch, but was not able to pass to the other side of the concrete shielding. The measurements that were made in this quadrant are shown in Table 3.2 and in Figures 3.20 through 3.23. These measurements are generally not directly comparable with the TLD string data because of the locations. 
TABLE 3.2. ROVER Robot Data from the SW Quadrant

\begin{tabular}{|c|c|c|c|c|}
\hline $\begin{array}{c}\text { Quadrant } \\
\text { and } \\
\text { Locations }\end{array}$ & $\begin{array}{l}\text { Height } \\
\text { Above } \\
\text { Floor } \\
\text { (inches) } \\
\end{array}$ & $\begin{array}{c}\begin{array}{c}\text { El evation } \\
\text { (feet) }\end{array} \\
\end{array}$ & $\begin{array}{r}\text { Dose Rate } \\
\frac{\text { Detector P-1 }}{\text { (R/hr) }} \\
\end{array}$ & $\begin{array}{l}\text { Measurements } \\
\frac{\text { Detector P-2 }}{(\text { R/hr) }}\end{array}$ \\
\hline SW P & 48 & 286 & 31 & 29 \\
\hline $\sin A^{(a)}$ & $\begin{array}{l}48 \\
54 \\
60 \\
66 \\
72 \\
85\end{array}$ & $\begin{array}{l}286 \\
287 \\
287.5 \\
288 \\
288.5 \\
289.6\end{array}$ & $\begin{array}{l}40 \\
44 \\
55 \\
55 \\
55 \\
45\end{array}$ & $\begin{array}{l}39 \\
43 \\
54 \\
60 \\
55 \\
46\end{array}$ \\
\hline SW 0 & 48 & 286 & 35 & 35 \\
\hline SW N & 48 & 286 & 23 & 25 \\
\hline SW 0 & 48 & 286 & 35 & 35 \\
\hline SW M & 48 & 286 & 21 & 21 \\
\hline SW L & 48 & 286 & 22 & 22 \\
\hline $\operatorname{SW} B^{(a)}$ & $\begin{array}{l}48 \\
53 \\
60 \\
66 \\
72 \\
78 \\
85\end{array}$ & $\begin{array}{l}286 \\
286.9 \\
287.5 \\
288 \\
288.5 \\
289 \\
289.6\end{array}$ & $\begin{array}{r}68 \\
75 \\
99 \\
142 \\
171 \\
163 \\
159\end{array}$ & $\begin{array}{r}69 \\
75 \\
99 \\
143 \\
165 \\
164 \\
158\end{array}$ \\
\hline SW K & 48 & 286 & 46 & 45 \\
\hline SW J & $\begin{array}{l}48 \\
85\end{array}$ & $\begin{array}{l}286 \\
289.6\end{array}$ & $\begin{array}{l}29 \\
29\end{array}$ & $\begin{array}{l}30 \\
30\end{array}$ \\
\hline SW 1 & 48 & 286 & 45 & 50 \\
\hline $\operatorname{SW} H^{(a)}$ & $\begin{array}{l}48 \\
55 \\
60 \\
66 \\
72 \\
78 \\
85\end{array}$ & $\begin{array}{l}286 \\
287.1 \\
287.5 \\
288 \\
288.5 \\
289 \\
289.6\end{array}$ & $\begin{array}{r}45 \\
69 \\
109 \\
233 \\
298 \\
350 \\
344\end{array}$ & $\begin{array}{r}44 \\
71 \\
109 \\
232 \\
315 \\
367 \\
333\end{array}$ \\
\hline SW D & 48 & 286 & 62 & 63 \\
\hline SW C & 48 & 286 & 54 & 60 \\
\hline SW G & 48 & 286 & 61 & 61 \\
\hline SW F & 48 & 286 & 74 & 74 \\
\hline$S W E^{(a)}$ & $\begin{array}{l}48 \\
54 \\
60 \\
66 \\
72 \\
78 \\
85\end{array}$ & $\begin{array}{l}286 \\
287 \\
287.5 \\
288 \\
288.5 \\
289 \\
289.6\end{array}$ & $\begin{array}{r}46 \\
63 \\
100 \\
240 \\
305 \\
262 \\
241\end{array}$ & $\begin{array}{r}47 \\
64 \\
100 \\
241 \\
303 \\
288 \\
278\end{array}$ \\
\hline
\end{tabular}

(a) 2 inches from wall. 
These robot measurements seem to confirm the theory that the 3000-psi concrete has a far greater affinity for contamination than metal or the 5000-psi concrete aithough not as great an affinity as the hollow concrete block. A rougher surface is apparent on this concrete, and, as seen from the video pictures taken by the robot, it may have been poured in lifts with visible joints approximately 1 foot apart.

With the exception of individual penetrations and the open stairwell itself, the basement in this quadrant is probably not significantly affecting the dose rates on the 305-foot elevation, even though there are areas in this quadrant where the floor (of the 305-foot elevation) is 6 inches thick rather than 3 feet thick as found at other locations. The open stairwell is shielded at the present time.

\subsection{NW QUADRANT}

The NW quadrant data is from nine TLD strings. (Robot data was not obtained.) They are (in clockwise order around the containment building) $\mathrm{B}-10, \mathrm{~B}-5, \mathrm{~B}-6, \mathrm{~B}-9, \mathrm{~B}-16, \mathrm{~B}-30, \mathrm{~B}-17, \mathrm{~B}-18$, and $\mathrm{B}-19$. The TLD data at location $B-10$ is shown in Figure 3.19; the data from the other locations are shown in Figures 3.24 through 3.31. The data at location B-10, adjacent to the open stairwell, was discussed previously (SW quadrant). A11 but the strings at locations $B-10$ and $B-30$ were inserted through the seismic gap. With the exception of location $\mathrm{B}-10$, the highest gamma dose rate recorded at any location was less than or equal to $20 \mathrm{R} / \mathrm{hr}$. The gamma dose rate data from these strings gives little support to the idea that there is any major contribution from a bathtub ring, but there may be comparable contamination on equipment in the area that was not detected by the TLDs because they were close to the outside painted metal wall of containment.

In locations where beta measurements were made, there is evidence of substantial beta activity close to the strings. There is also substantial beta contamination well above the high-water mark indicating that this contamination was not deposited in the accident water that covered the floor. The beta exposure rate at location B-18 exceeds $500 \mathrm{rad} / \mathrm{hr}$ and is among the highest measured in the basement.

Toward location B-19 and into the NE quadrant there appears to be a slight increase in dose rates, probably from the sump area and trash rack.

This quadrant has some of the lowest dose rates in the basement, and the dose rate immediately below the 305-foot elevation floor is less than $2 \mathrm{R} / \mathrm{hr}$ in all areas. It is therefore highly unlikely that this portion of the basement is making a significant contribution to dose rates observed at the upper elevations. It is possible, however, that relatively small sources within the penetrations and the seismic gap are making a significant contribution.

\subsection{NE QUADRANT}

In the NE quadrant, 12 TLD strings were hung and the robot took measurements. TLD strings were hung in a clockwise direction around the containment 
building, through the seismic gap at locations B-20, B-21, B-22 and B-4. TLD strings were also hung from penetrations around the core flood tank on the 305-foot elevation at locations B-27, B-14, B-24, B-8, B-25, B-26 and B-28. A TLD string was also hung through a penetration at location $B-31$. The data from these TLD strings are illustrated in Figures 3.32 through 3.43.

The TLD strings around the outside containment wall resemble those in similar locations in the NW quadrant because the maximum dose rate at each location is less than $20 \mathrm{R} / \mathrm{hr}$ and highest near the floor. Where beta contributions were measured, there is evidence of significant contamination.

The robot was able to traverse this quadrant completely. A summary of the radiation readings taken by the robot in this area is presented in Table 3.3 and shown graphically in Figures 3.44 to 3.46 . These values agree with the TLD string values.

Most of the TLD strings hung from penetrations near the core flood tank did not extend past the 294-foot elevation. The two exceptions are at locations B-14 and B-8. Both strings indicated a maximum dose rate of almost $20 \mathrm{R} / \mathrm{hr}$, which occurred at the 288.5-foot elevation for B-14 and between the 285-foot and the 290-foot elevation for B-8 (the TLDs on string B-8 were placed every 5 feet). Beta contribution was measured at location B-14.

The TLDs were placed every 5 feet on string B-31. The lowest TLD (281.5-foot elevation) gave the highest reading, approximately $12.5 \mathrm{R} / \mathrm{hr}$. 
Table 3.3. ROVER Robot Data from the NE Quadrant

\begin{tabular}{|c|c|c|c|c|}
\hline $\begin{array}{c}\text { Quadrant } \\
\text { and } \\
\text { Locations }\end{array}$ & $\begin{array}{l}\text { Height } \\
\text { Above } \\
\text { Floor } \\
\text { (inches) } \\
\end{array}$ & $\begin{array}{c}\text { Elevation } \\
\text { (feet) }\end{array}$ & $\begin{array}{l}\text { Dose Rate } \\
\frac{\text { Detector P-1 }}{(\text { R/hr) }} \\
\end{array}$ & $\begin{array}{l}\text { Moasurements } \\
\frac{\text { Dotector P-2 }}{(\mathrm{R} / \mathrm{hr})}\end{array}$ \\
\hline NE FF & 48 & 286 & 9 & 10 \\
\hline$N E H^{(a)}$ & $\begin{array}{l}48 \\
55 \\
61 \\
67 \\
73 \\
79 \\
85\end{array}$ & $\begin{array}{l}286 \\
287 \\
287.6 \\
288.1 \\
288.6 \\
289.1 \\
289.6\end{array}$ & $\begin{array}{l}8 \\
7 \\
7 \\
7 \\
5 \\
6 \\
7\end{array}$ & $\begin{array}{l}7 \\
8 \\
8 \\
7 \\
6 \\
7 \\
7\end{array}$ \\
\hline NE GG & 48 & 286 & 5 & 7 \\
\hline NE $\mid$ | & 48 & 286 & 7 & 5 \\
\hline NE Jj(a) & $\begin{array}{l}48 \\
54 \\
60 \\
66 \\
72 \\
78 \\
82\end{array}$ & $\begin{array}{l}286 \\
287 \\
287.5 \\
288 \\
288.5 \\
289 \\
289.3\end{array}$ & $\begin{array}{l}4 \\
4 \\
4 \\
5 \\
5 \\
7 \\
5\end{array}$ & $\begin{array}{l}5 \\
5 \\
5 \\
5 \\
7 \\
5 \\
8\end{array}$ \\
\hline$N E K^{(a)}$ & $\begin{array}{l}54 \\
62 \\
66 \\
73 \\
78 \\
85\end{array}$ & $\begin{array}{l}287 \\
287.7 \\
288 . \\
288.6 \\
289 \\
289.6\end{array}$ & $\begin{array}{l}3 \\
2 \\
4 \\
4 \\
4 \\
4\end{array}$ & $\begin{array}{l}2 \\
3 \\
4 \\
4 \\
4 \\
4\end{array}$ \\
\hline NE LL & 48 & 286 & 5 & 6 \\
\hline
\end{tabular}




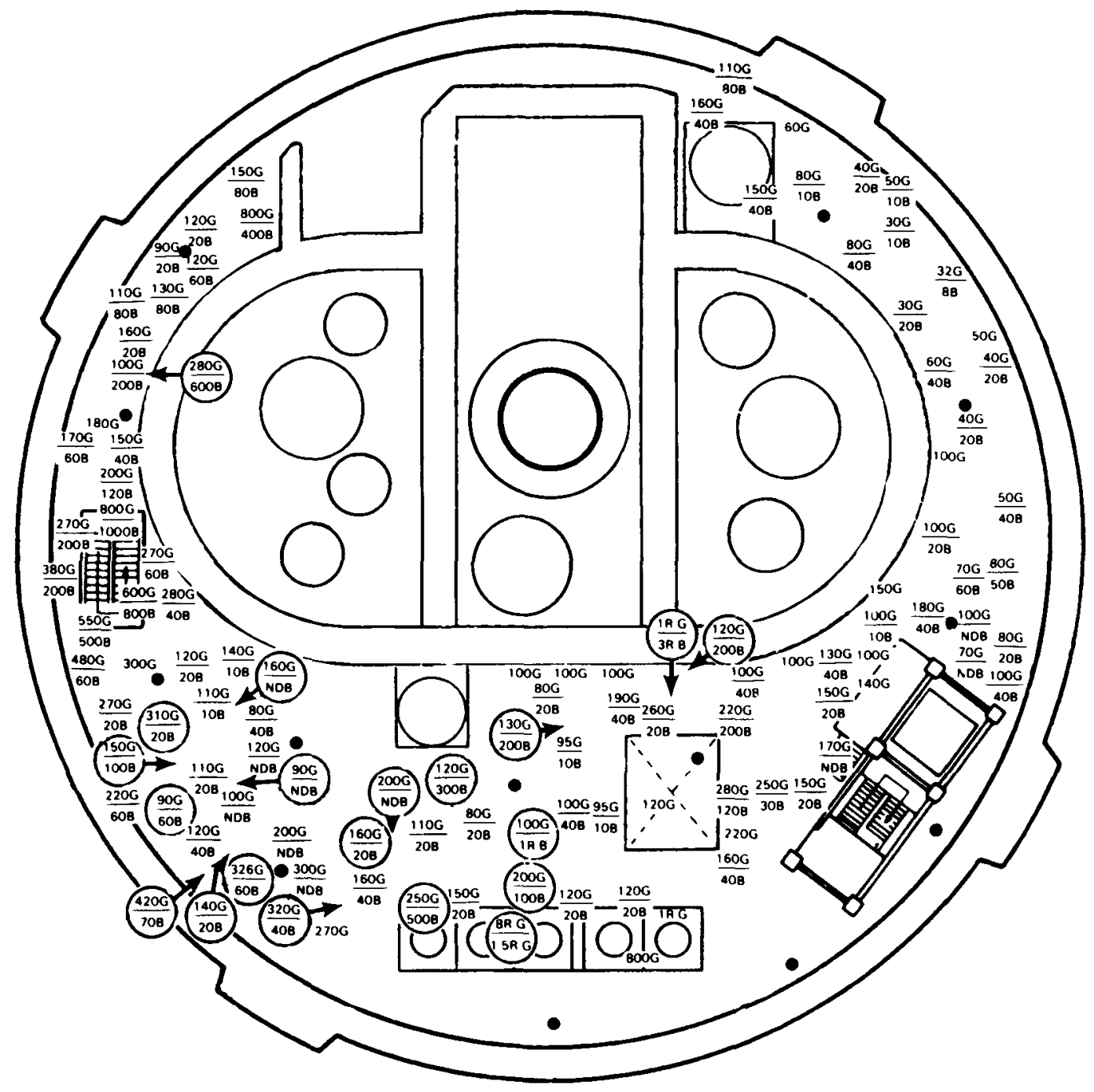

All Readings in $\mathrm{mR} / \mathrm{hr}$ or $\mathrm{mrad} / \mathrm{hr}$ Unless Otherwise Noted

All Data Taken Before 12/17/84

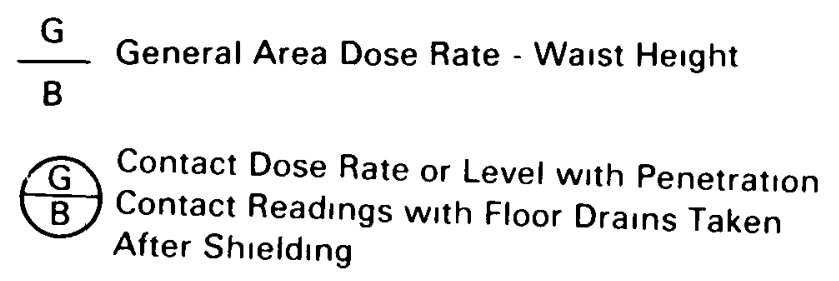

- Floor Draın

NDB No Detectable Beta

FIGURE 3.1. Dose Rates on the 305-foot Elevation 


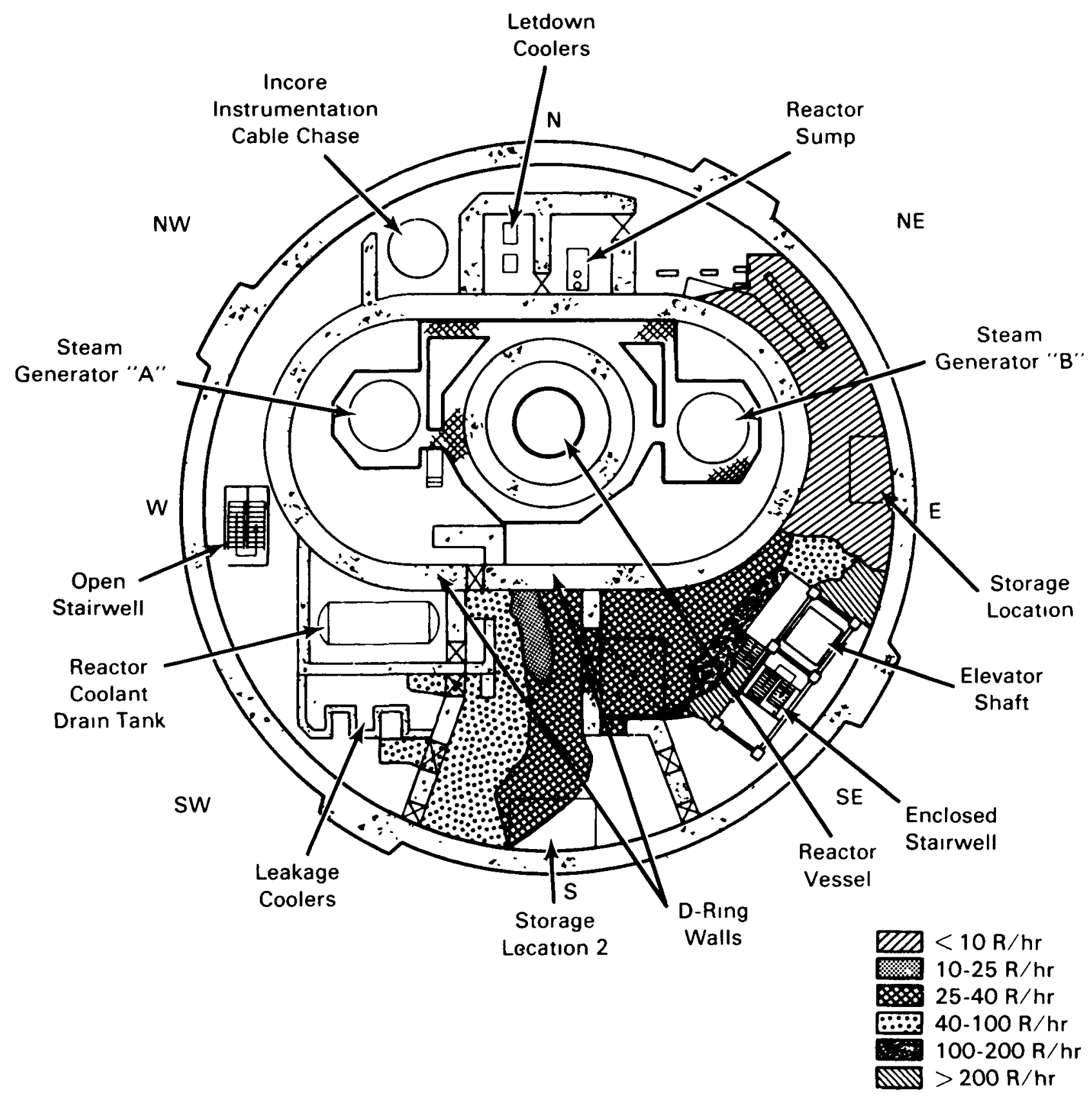

FIGURE 3.2. Exposure Rates in the Basement (286to289-foot elevation) 


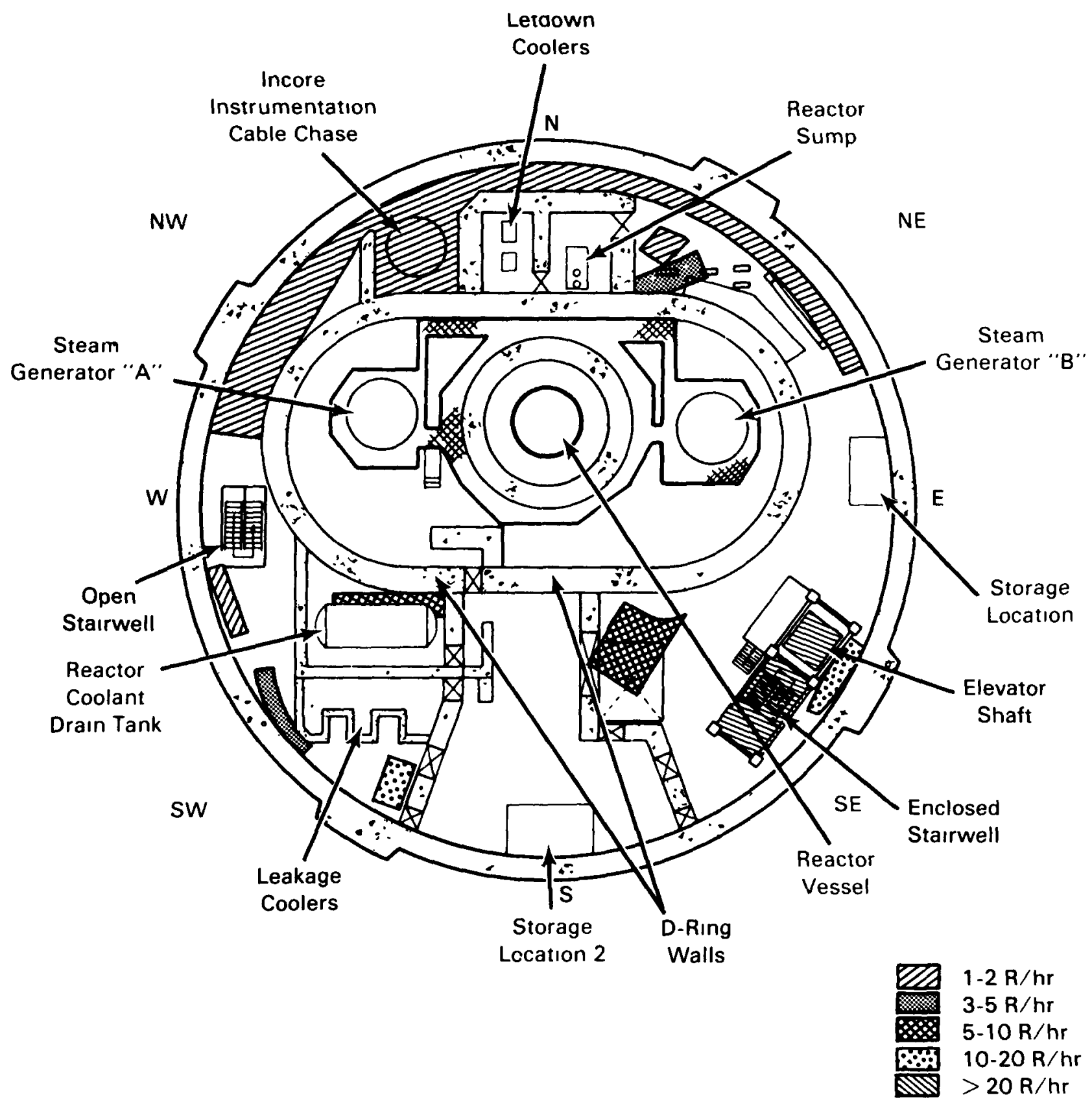

FIGURE 3.3. Exposure Rates at About the 300-foot Elevation 


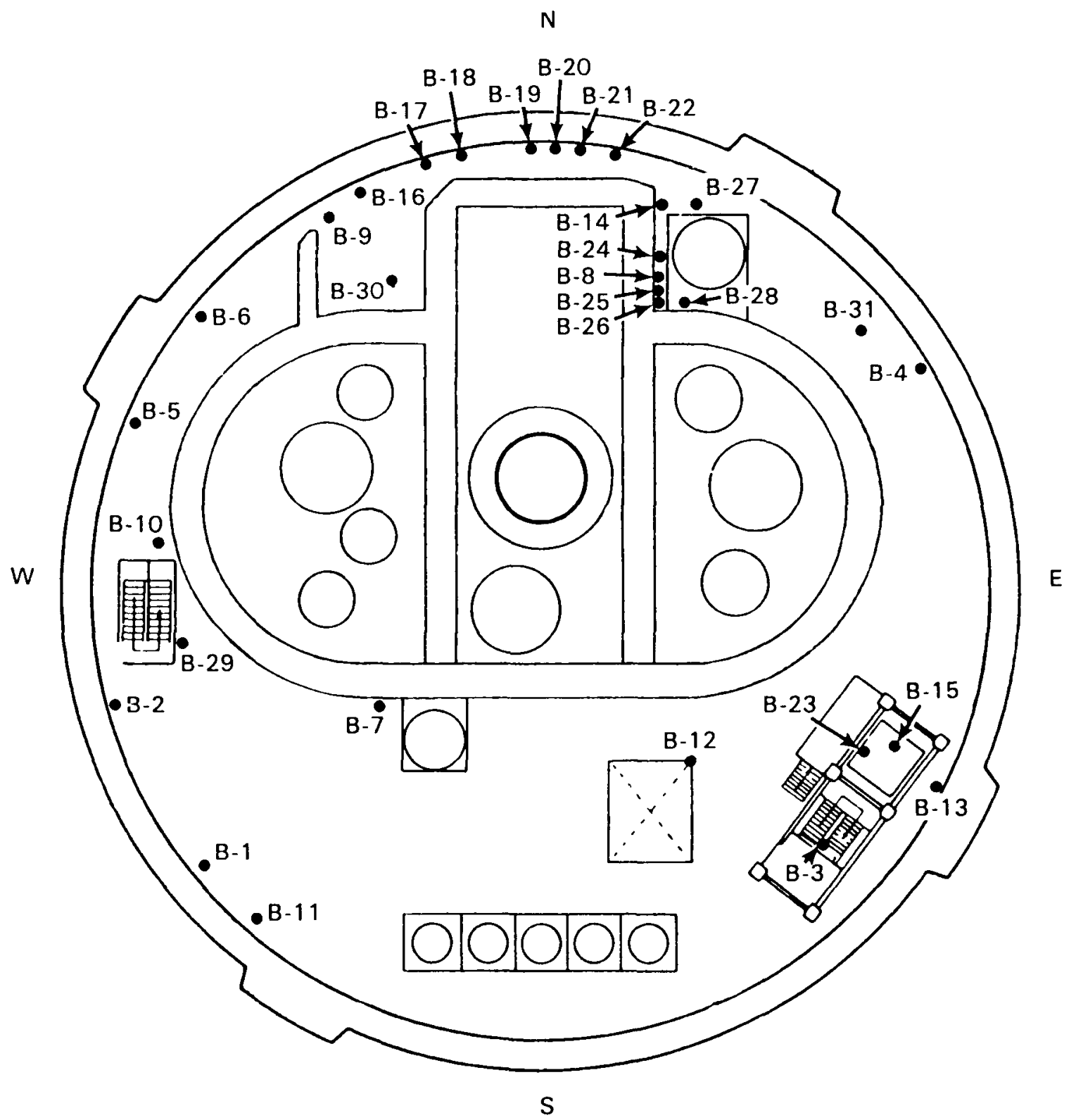

FIGURE 3.4. Location of TLD Strings Suspended in the Basement 


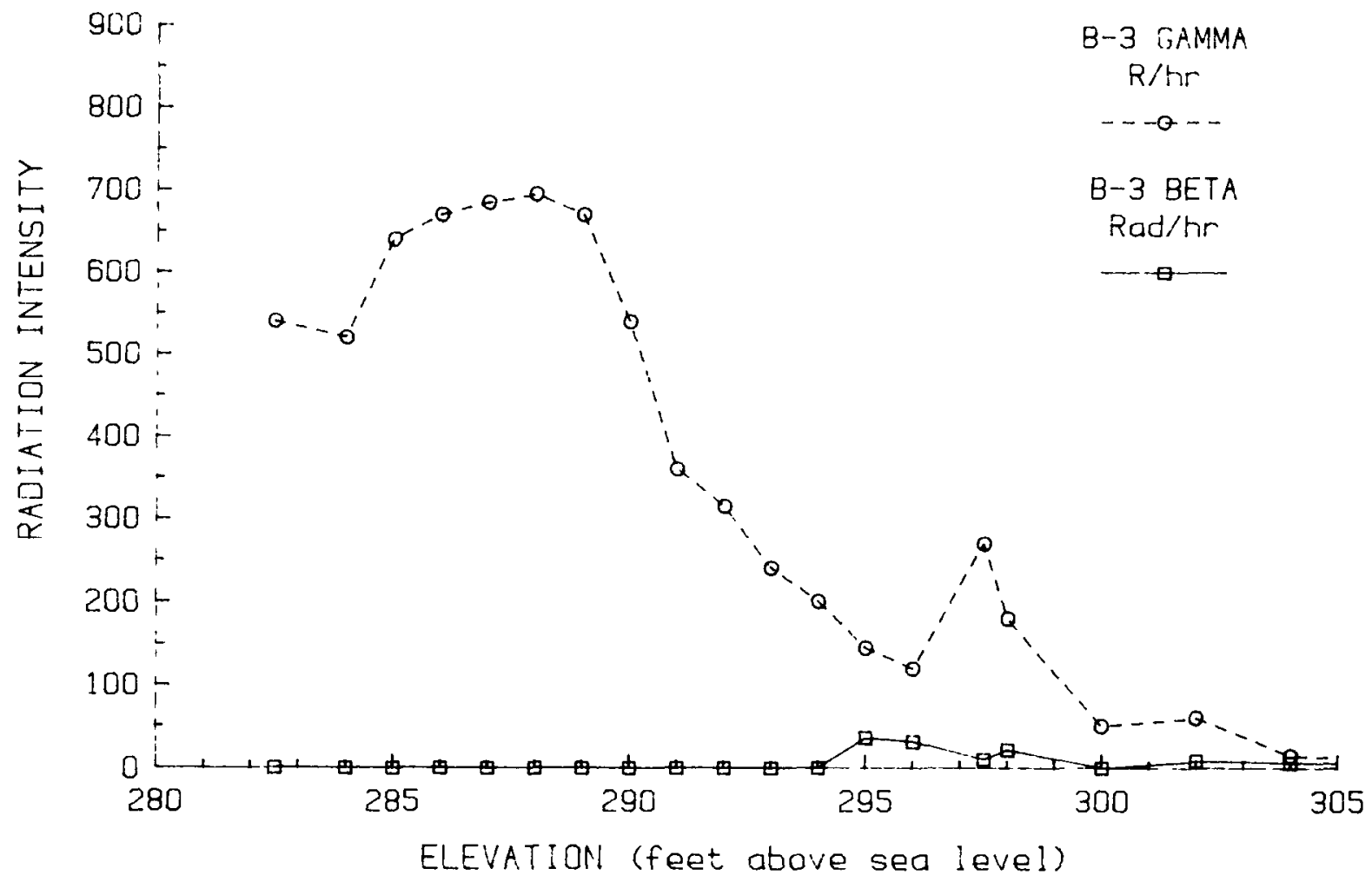

FIGURE 3.5. Dose Rate Profile at Location B-3 


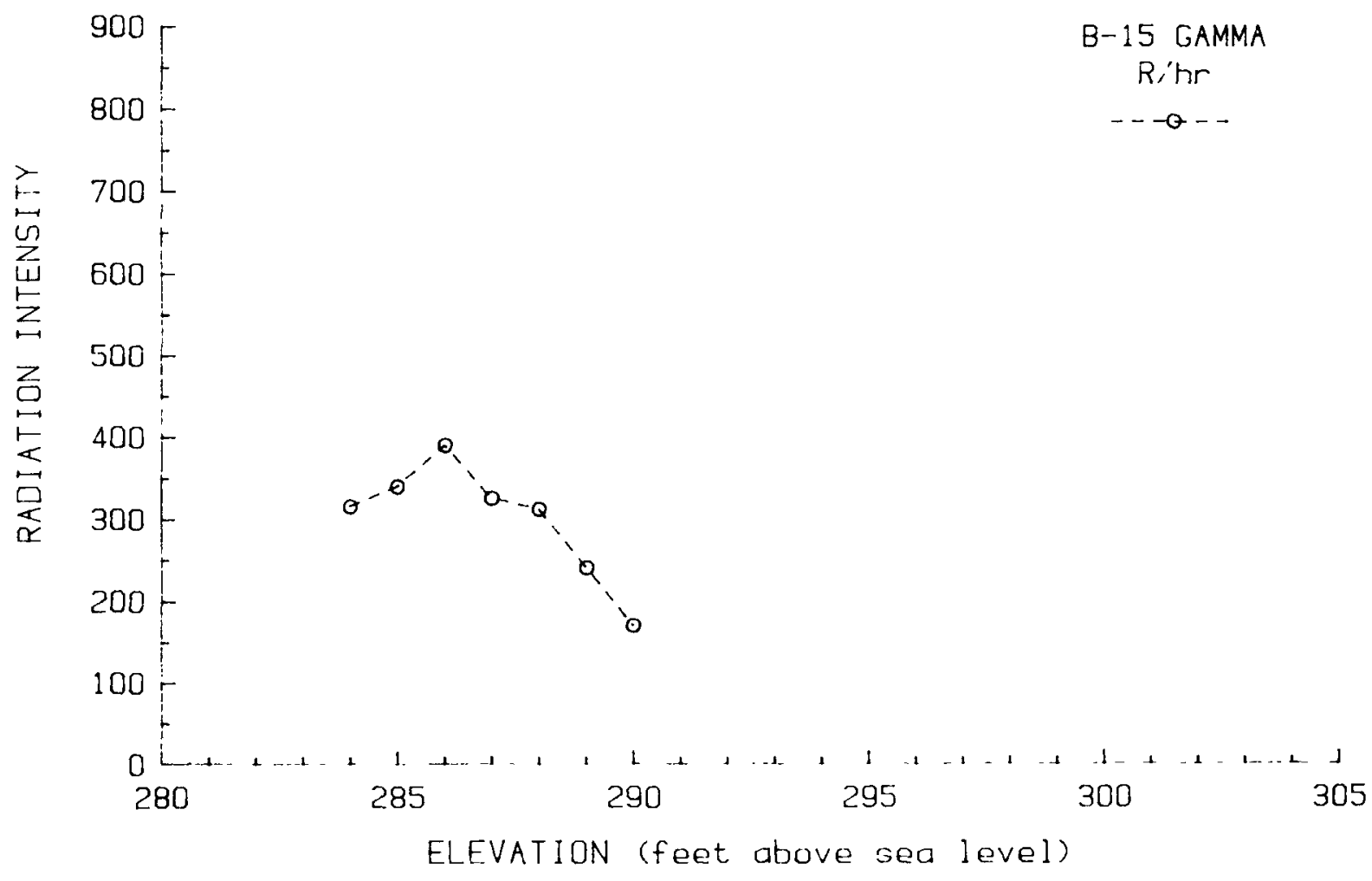

FIGURE 3.6. Dose Rates Profile at Location B-15 


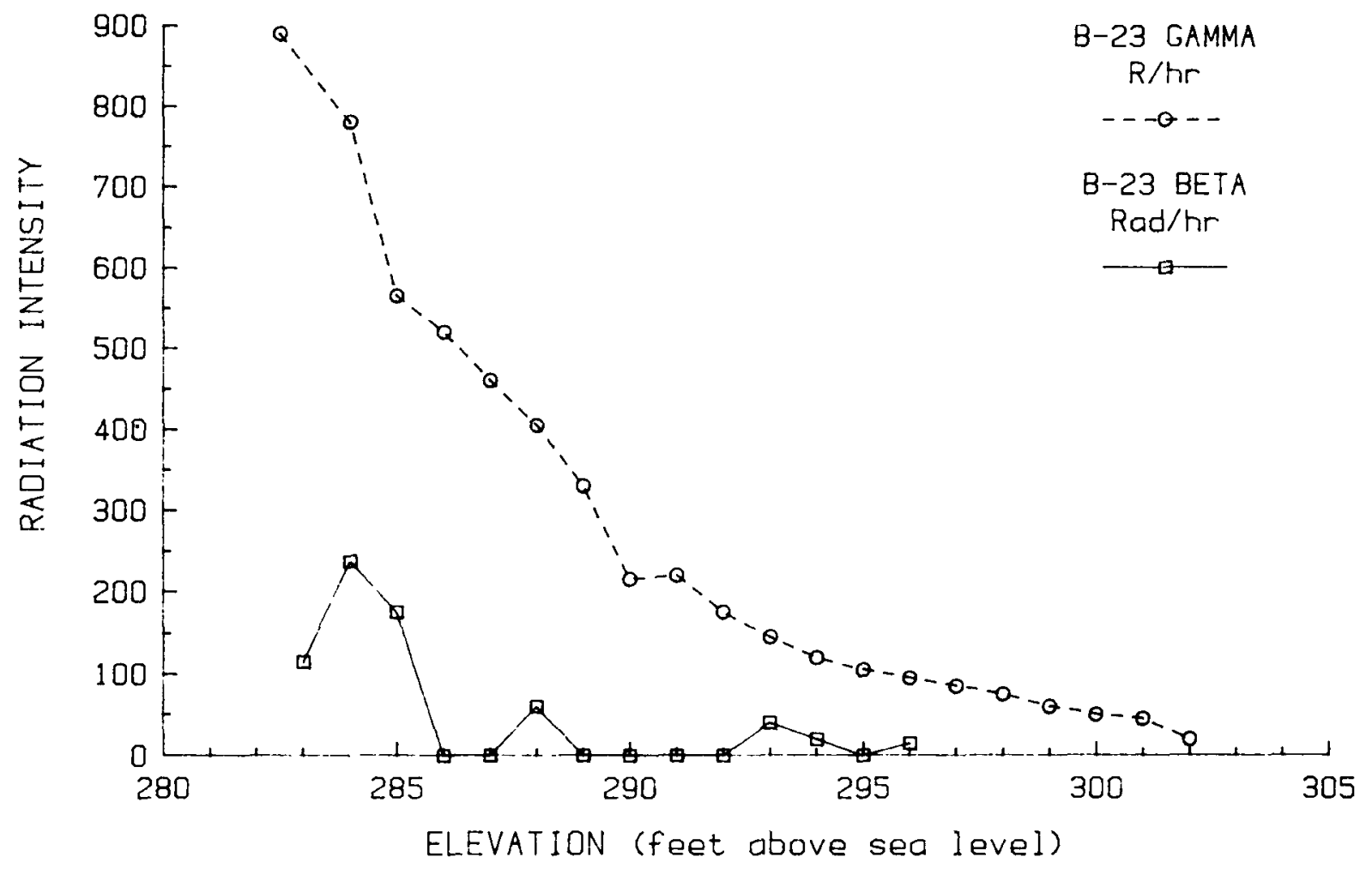

FIGURE 3.7. Dose Rate Profile at Location B-23 


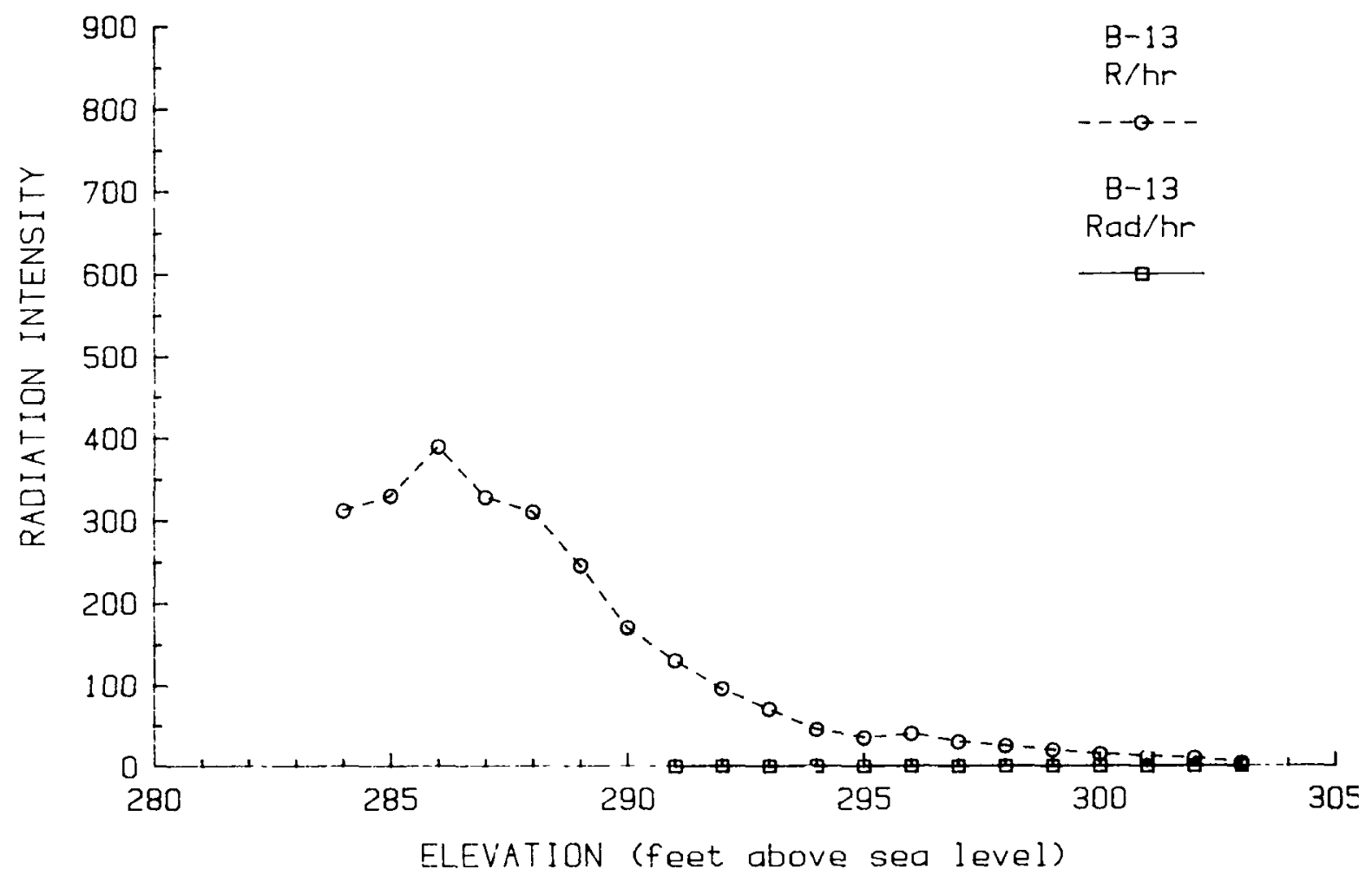

FIGURE 3.8. Dose Rate Profile at Location B-13 


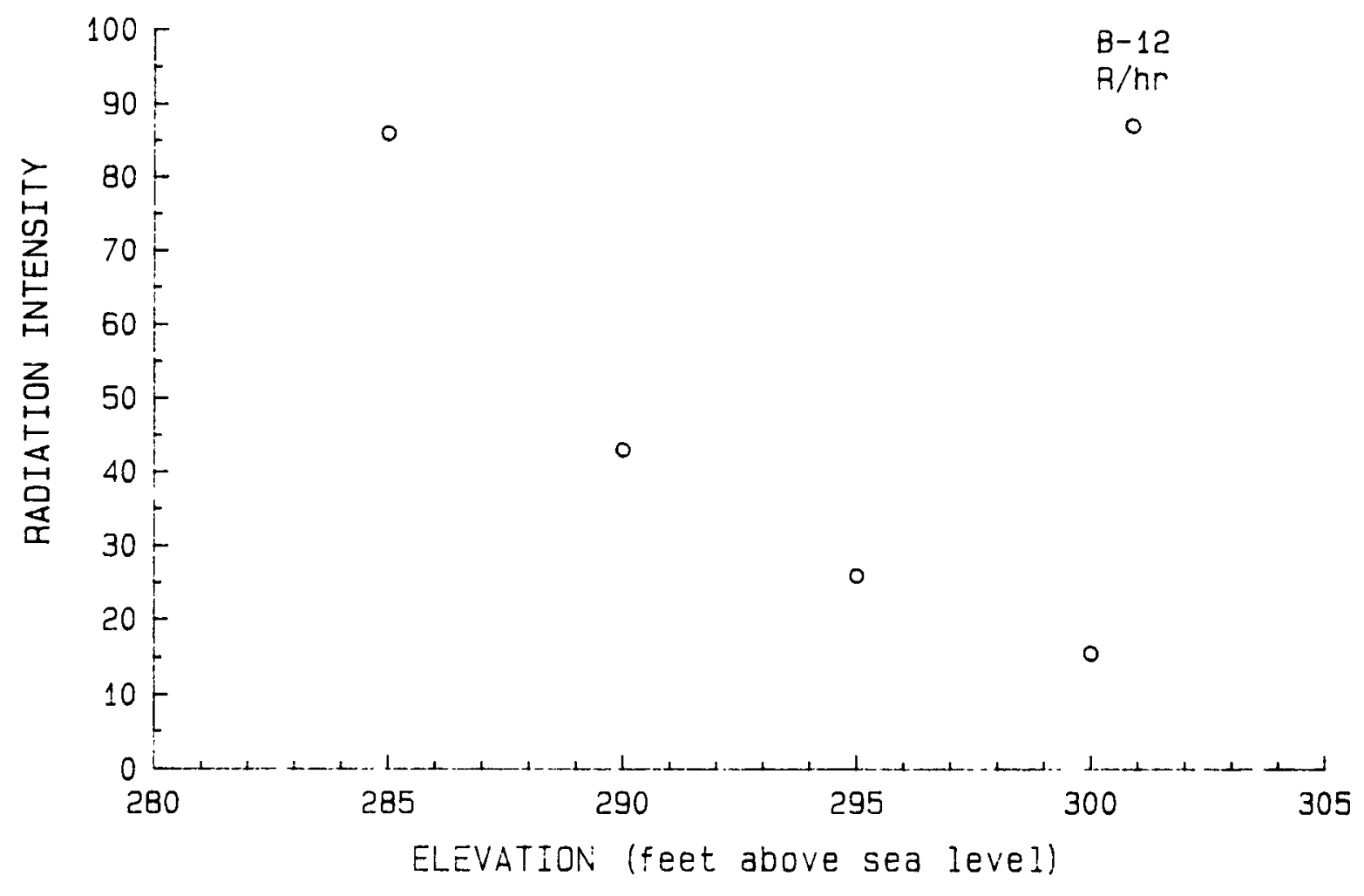

FIGURE 3.9. Dose Rate Profile at Location B-12 


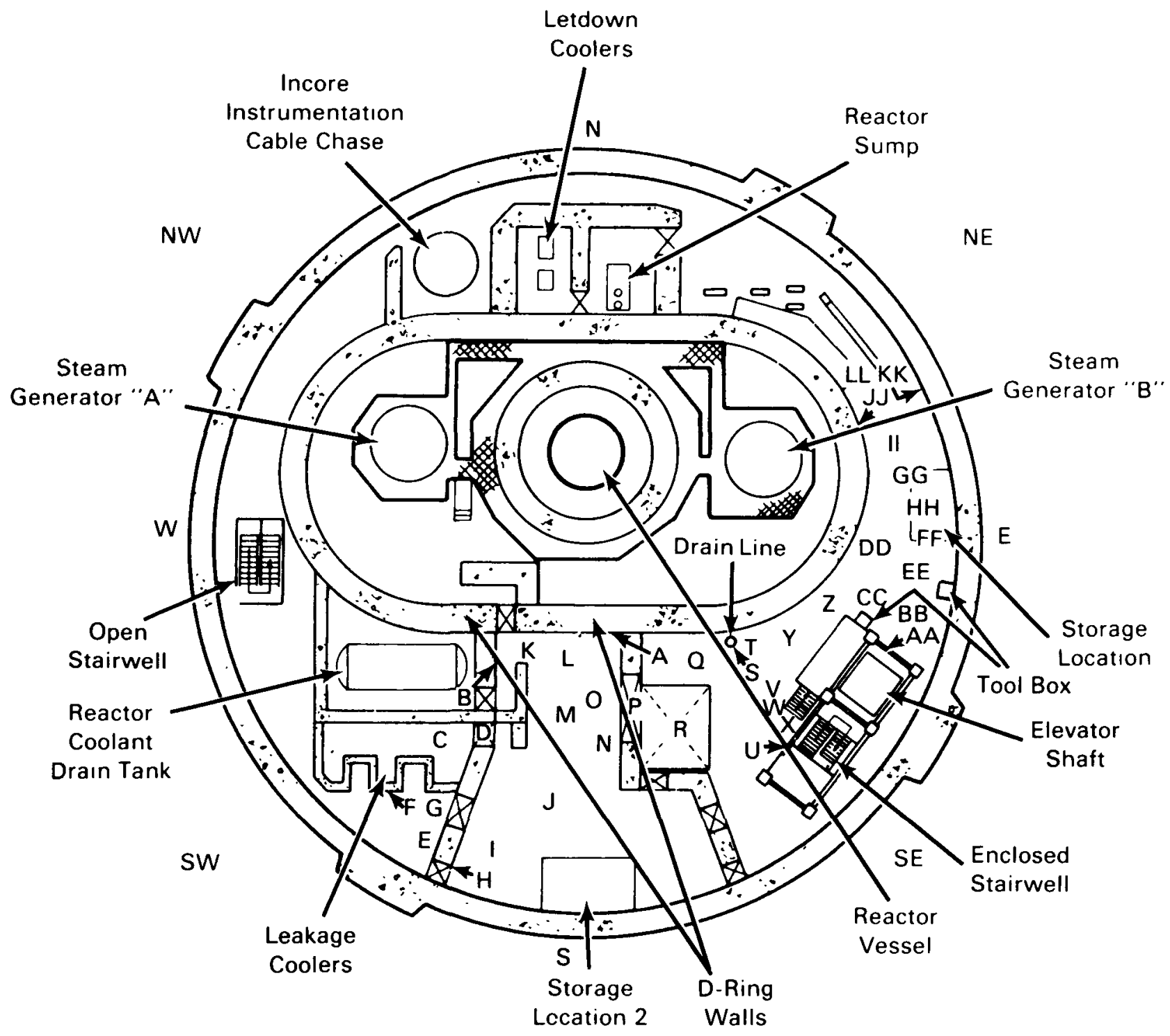

FIGURE 3.10. Locations of Dose Rate Readings by the ROVER Robot 


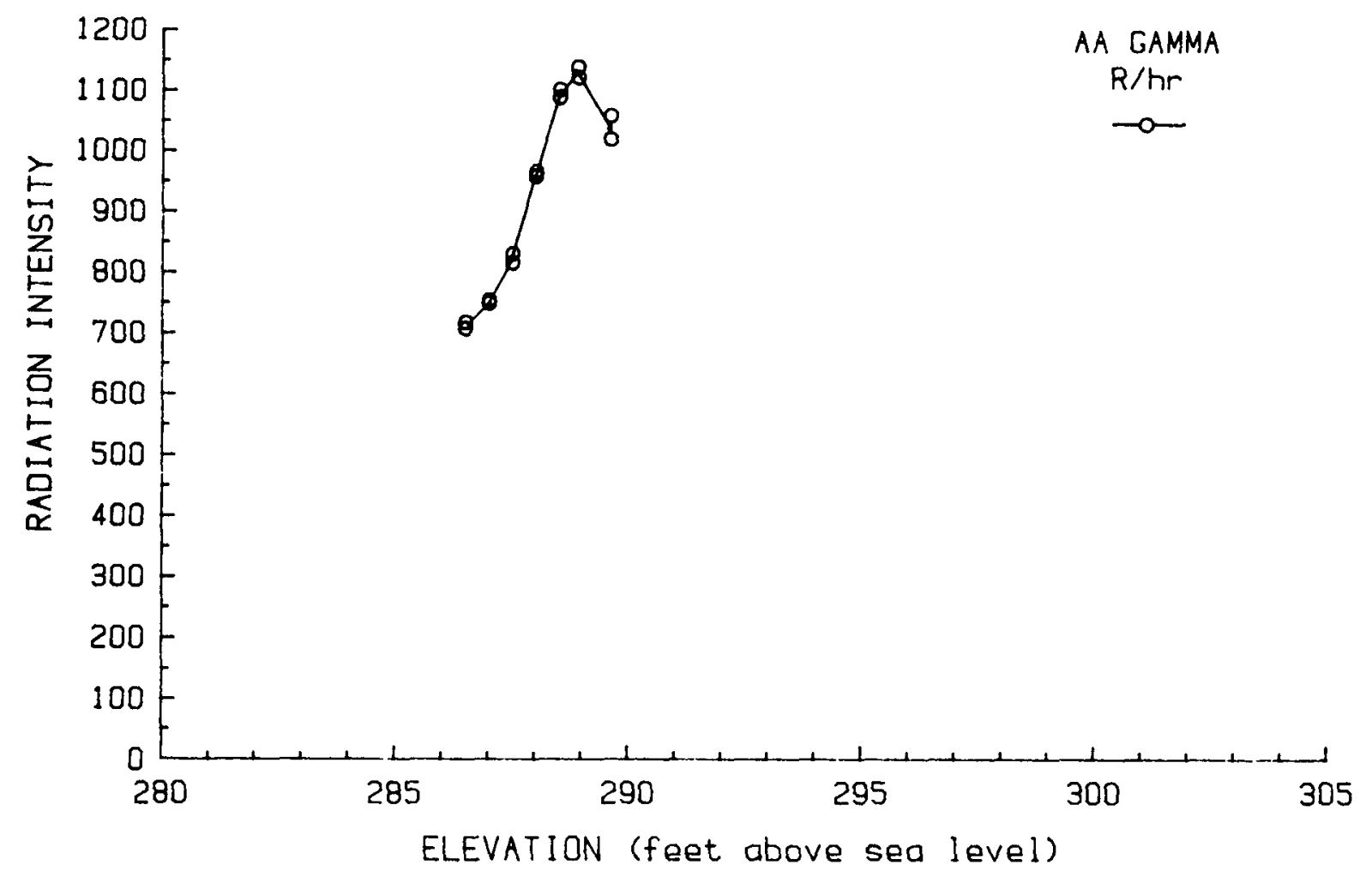

FIGURE 3.11. Dose Rate Profile at Robot Location AA 


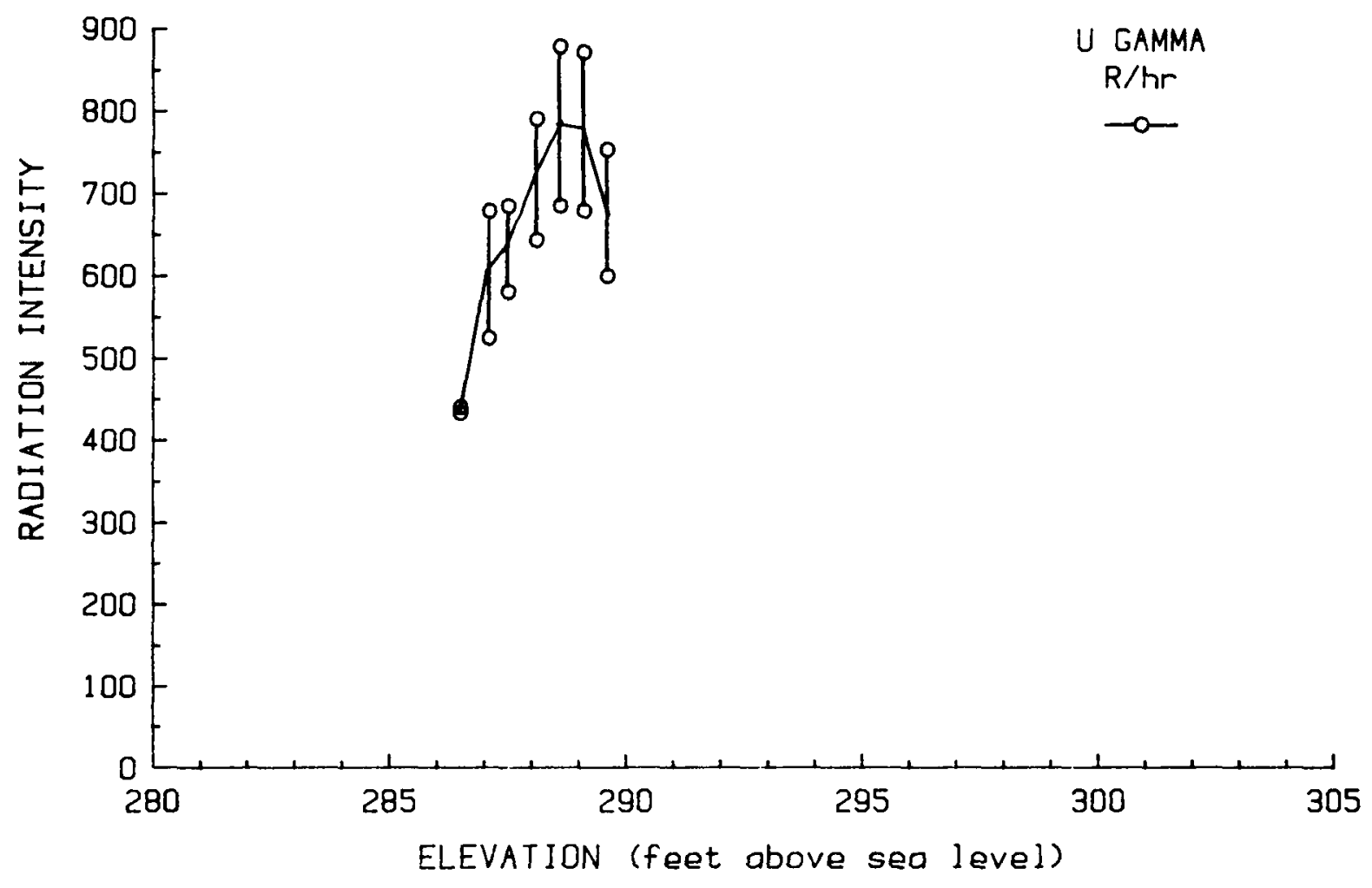

FIGURE 3.12. Dose Rate Profile at Robot Location U 


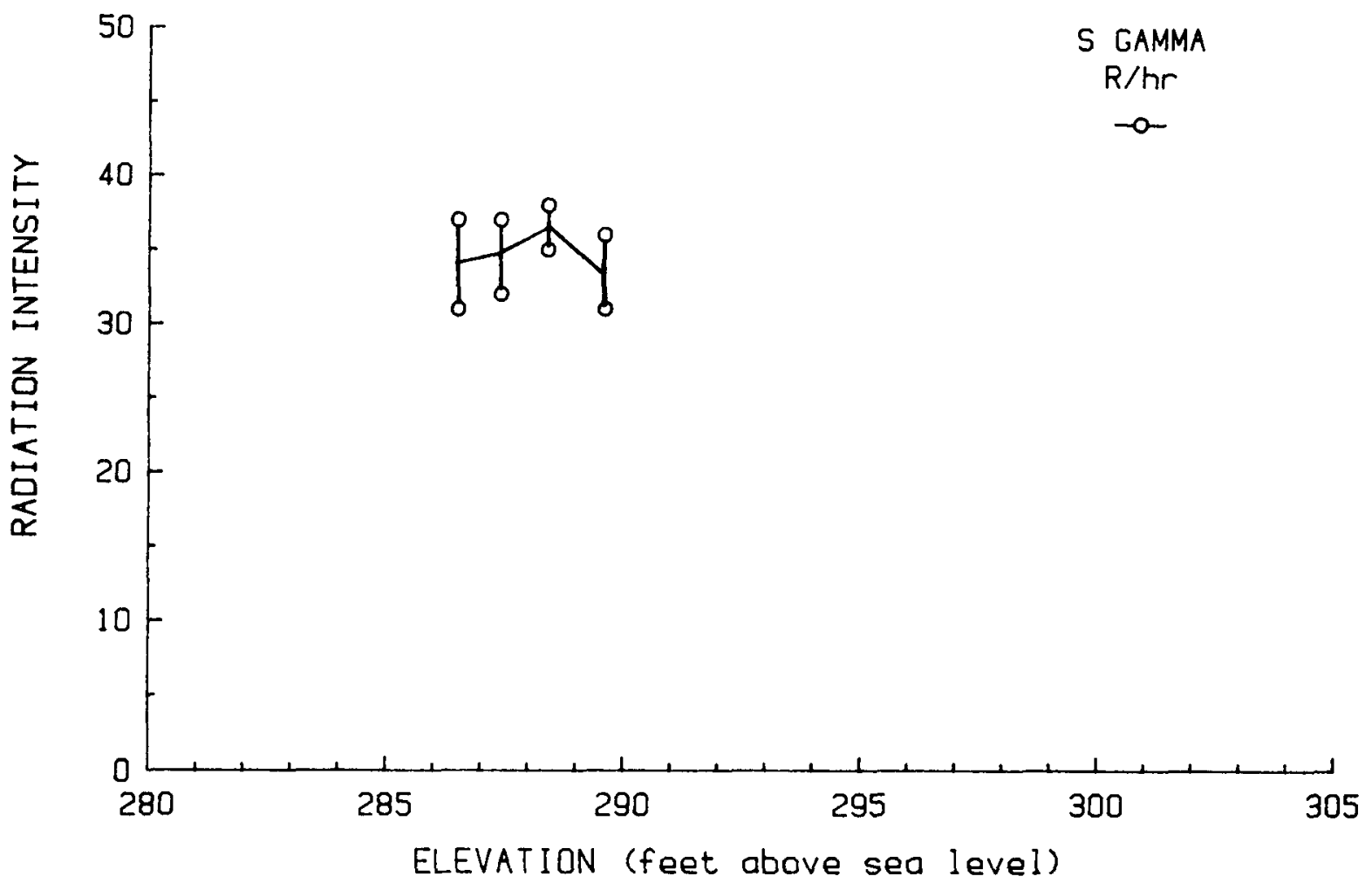

FIGURE 3.13. Dose Rate Profile at Robot Location S 


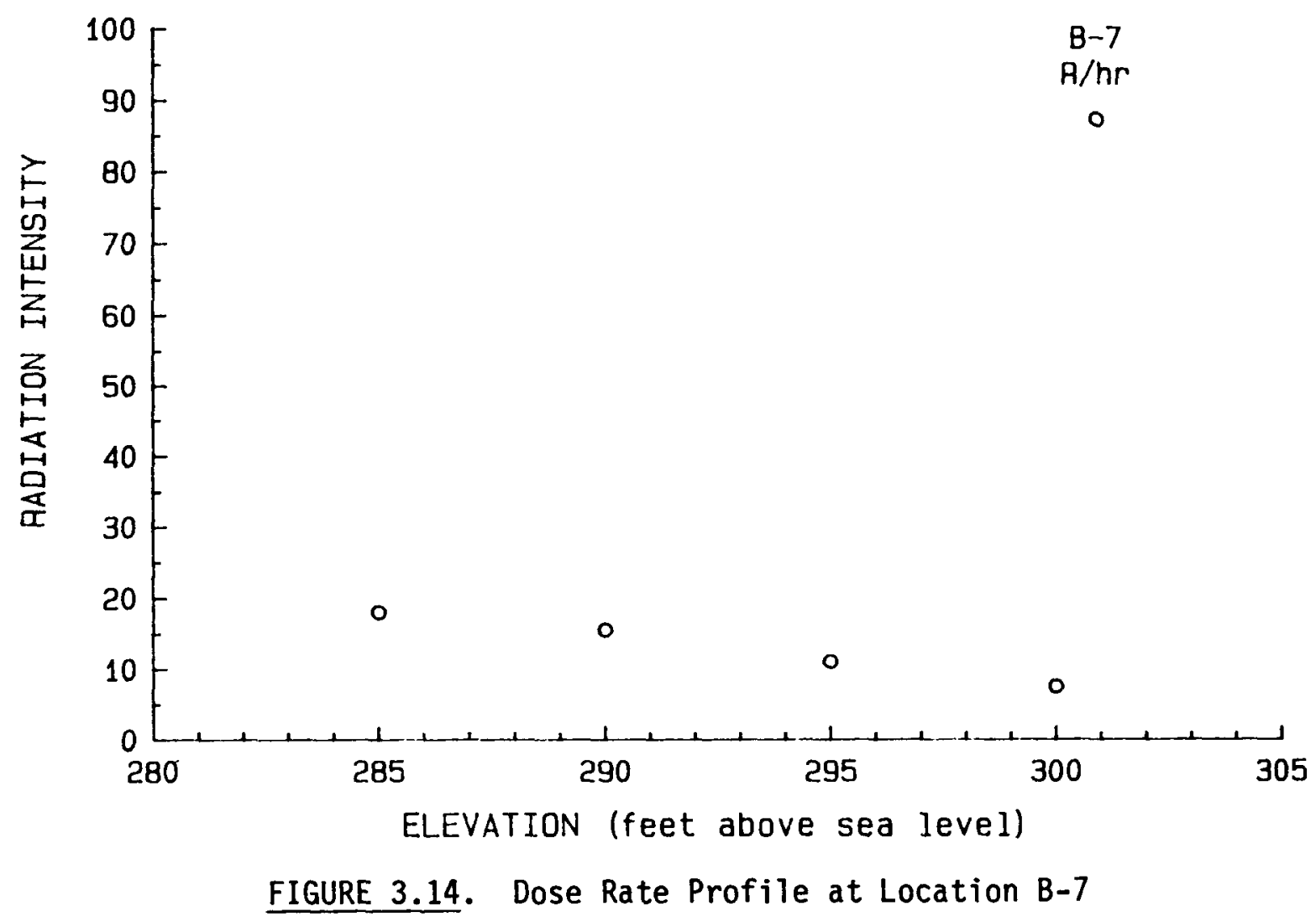




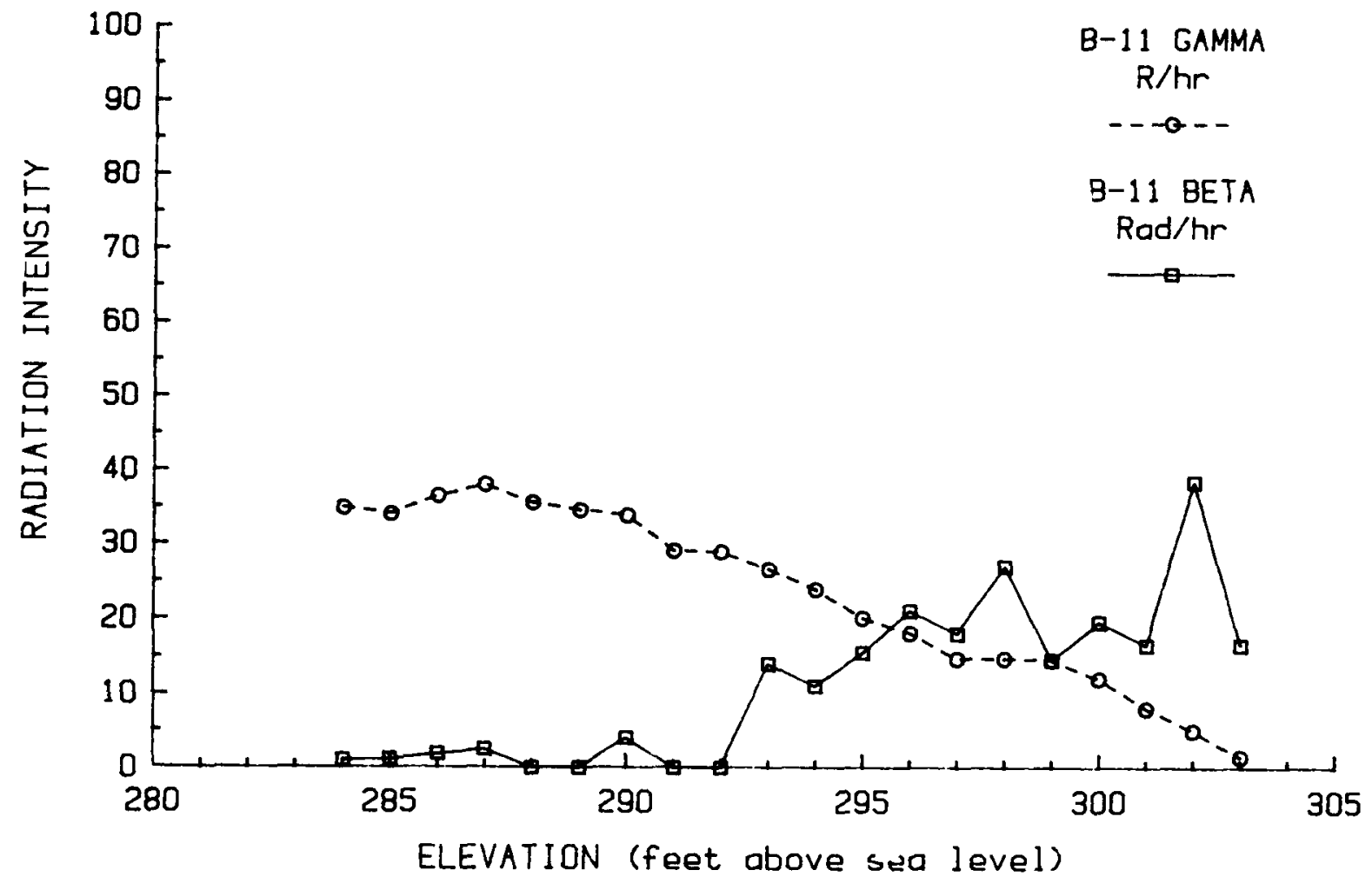

FIGURE 3.15. Dose Rate Profile at Location B-11 


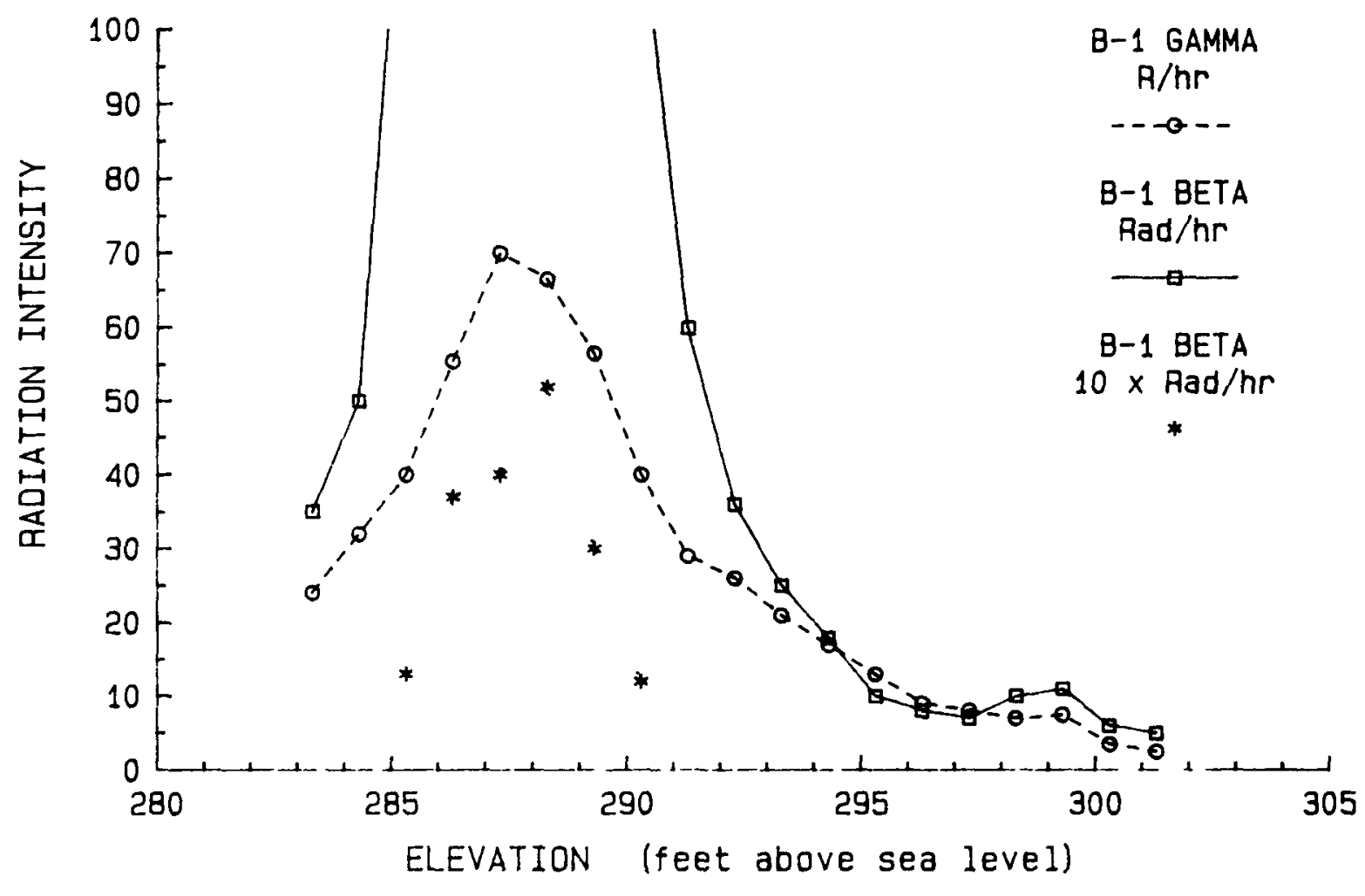

FIGURE 3.16. Dose Rate Profile at Location B-1 


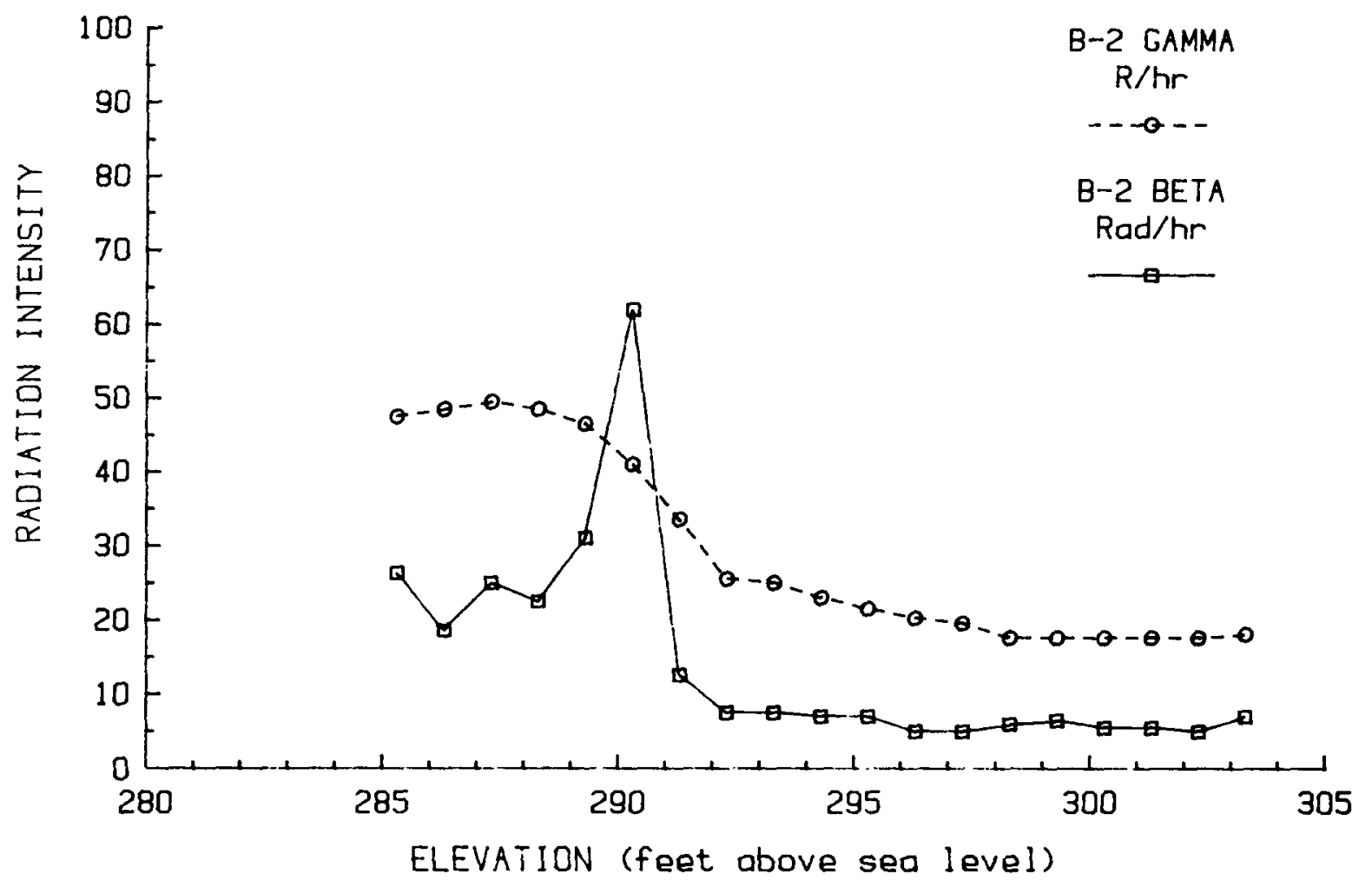

FIGURE 3.17. Dose Rate Profile at Location B-2 


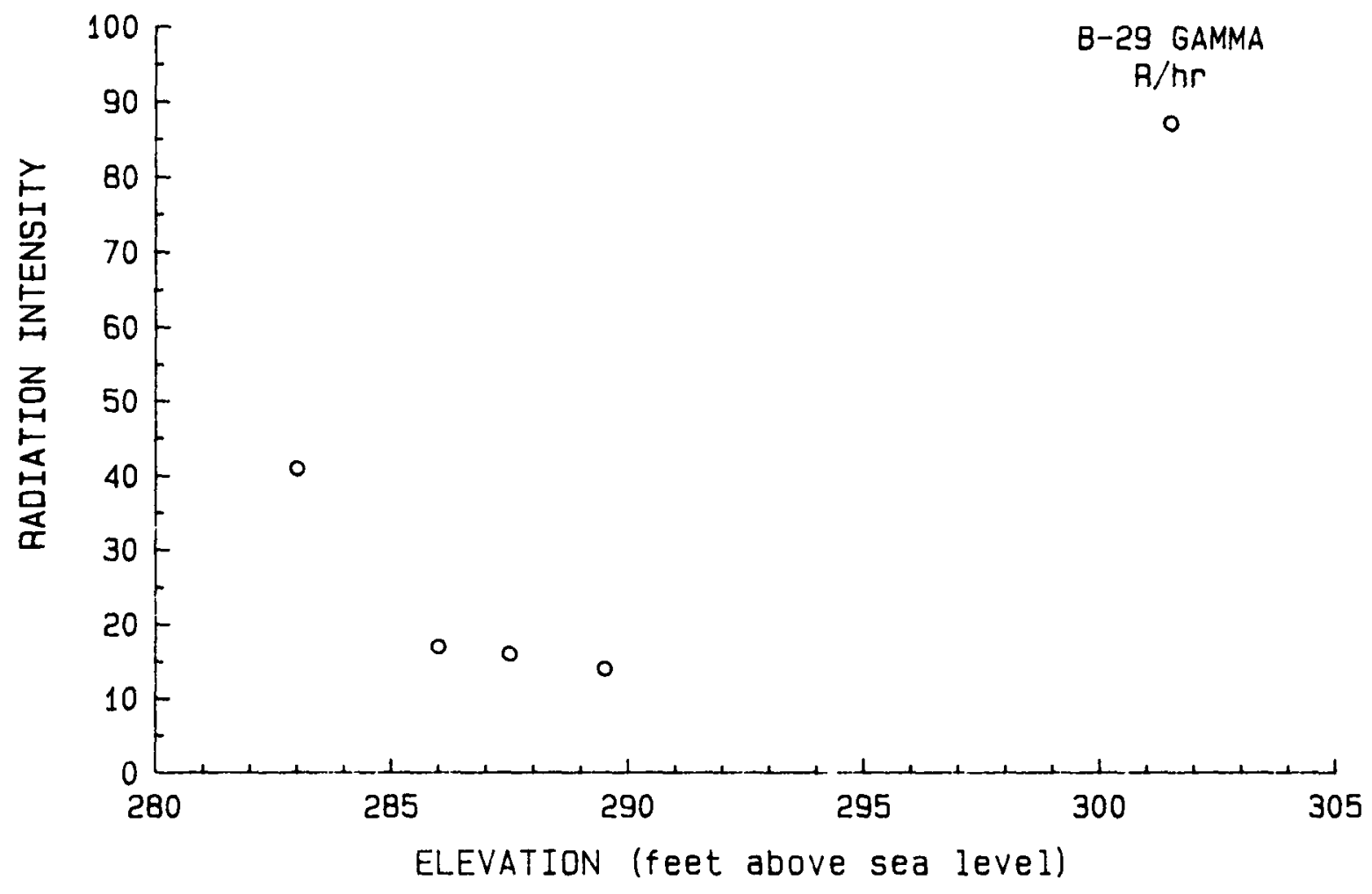

FIGURE 3.18. Dose Rate Profile at Location B-29 


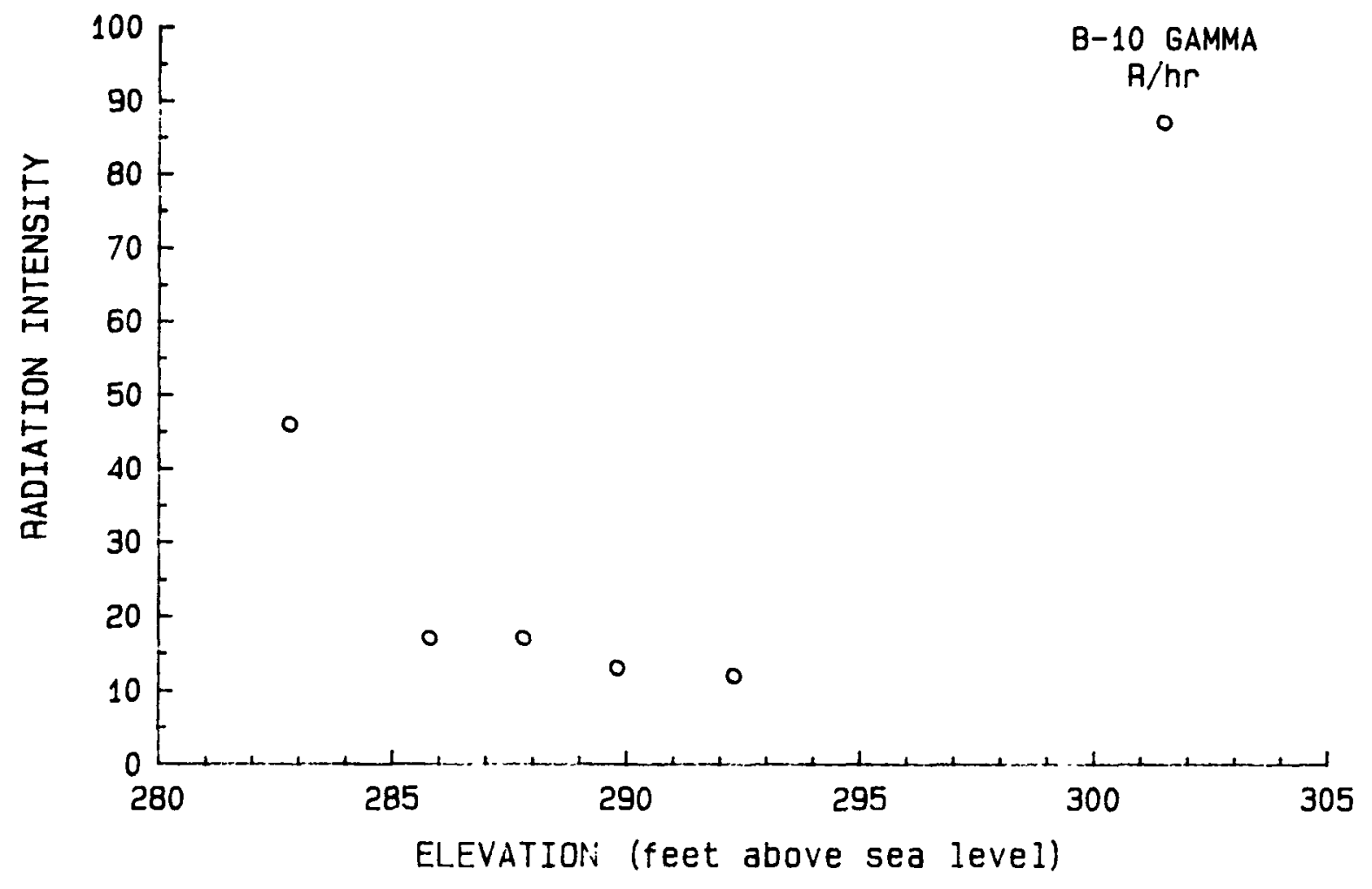

FIGURE 3.19. Dose Rate Profile at Location B-10 


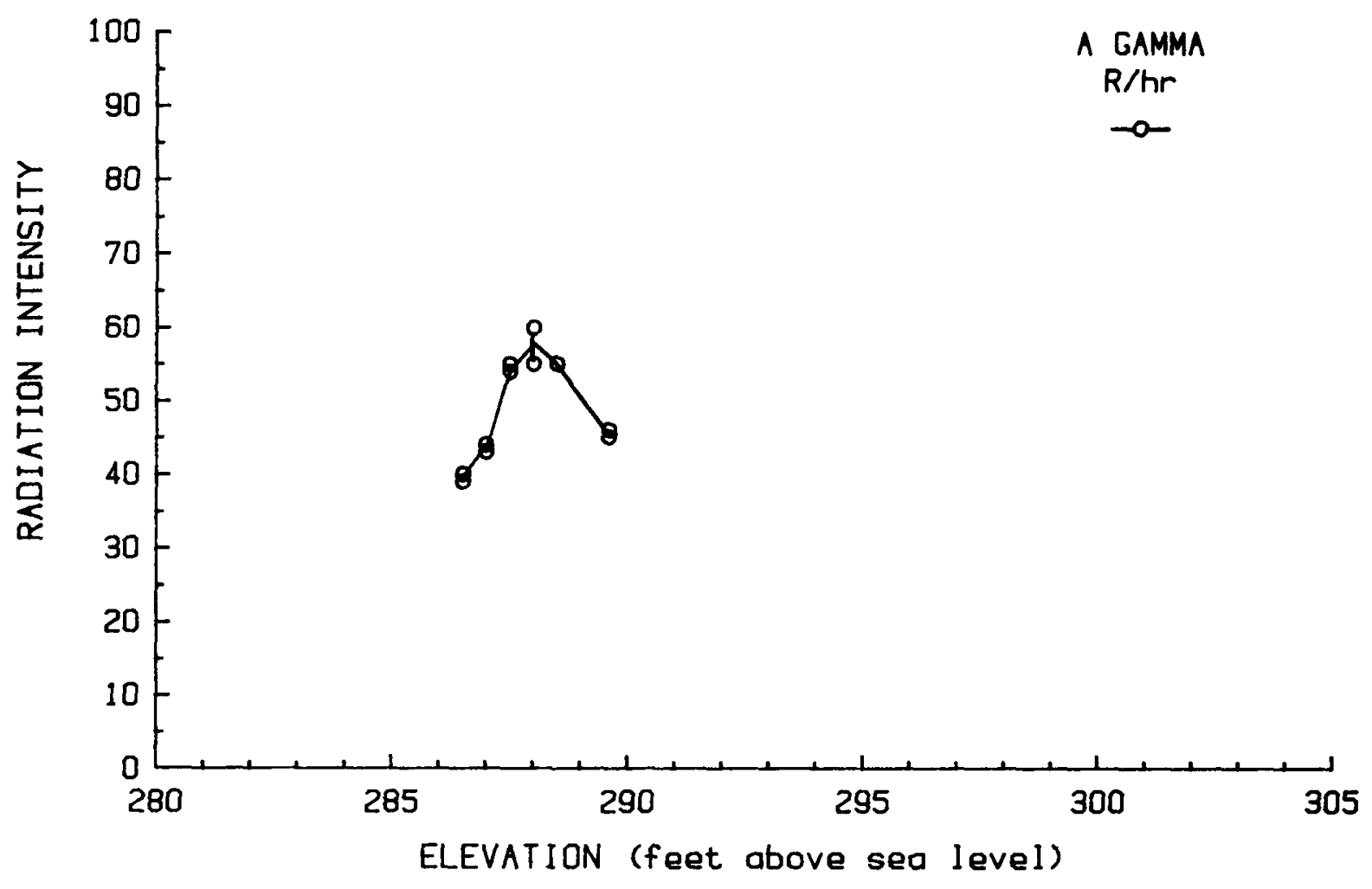

FIGURE 3.20. Dose Rate Profile at Robot Location A 


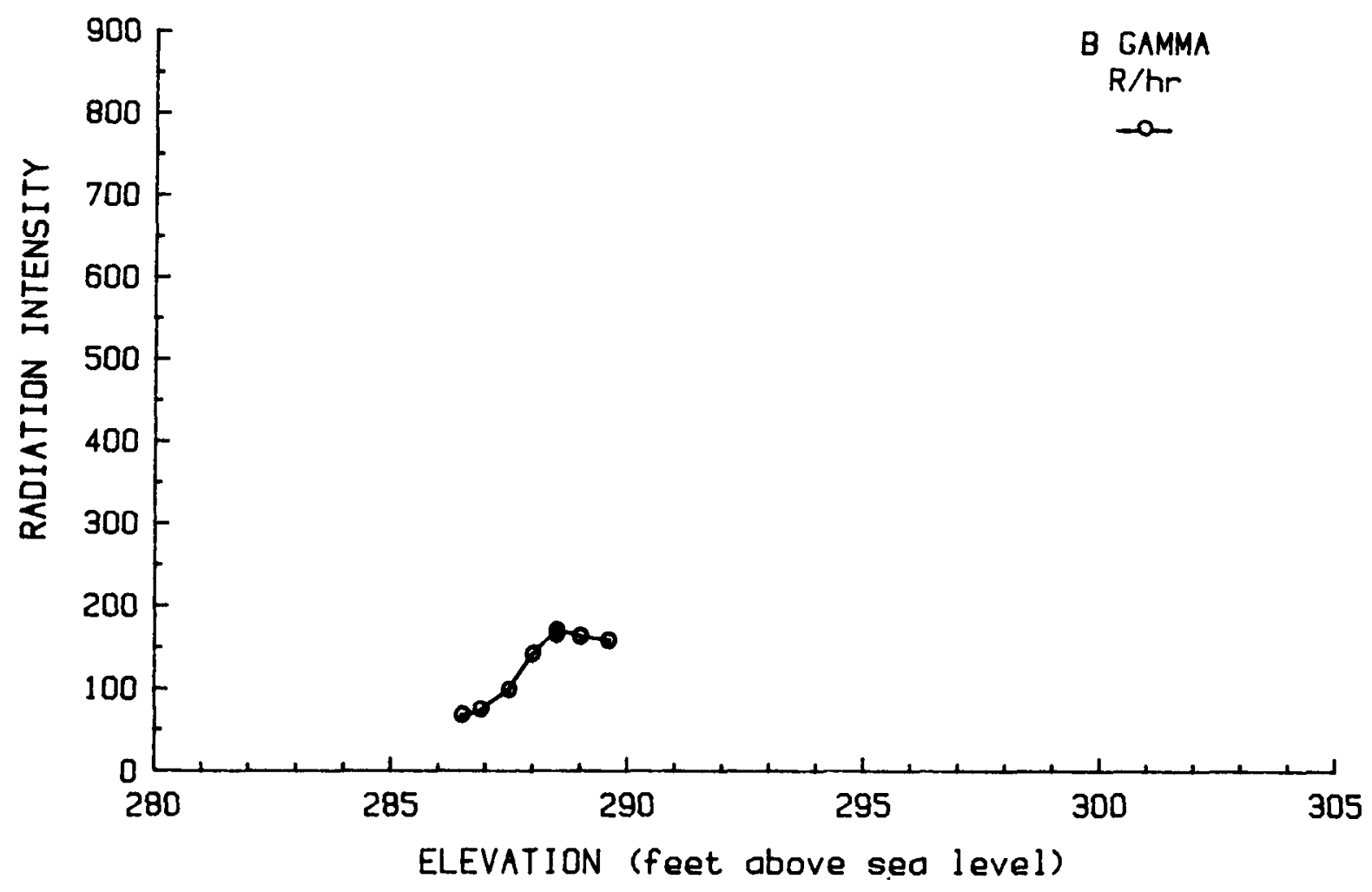

FIGURE 3.21. Dose Rate Profile at Robot Location B 


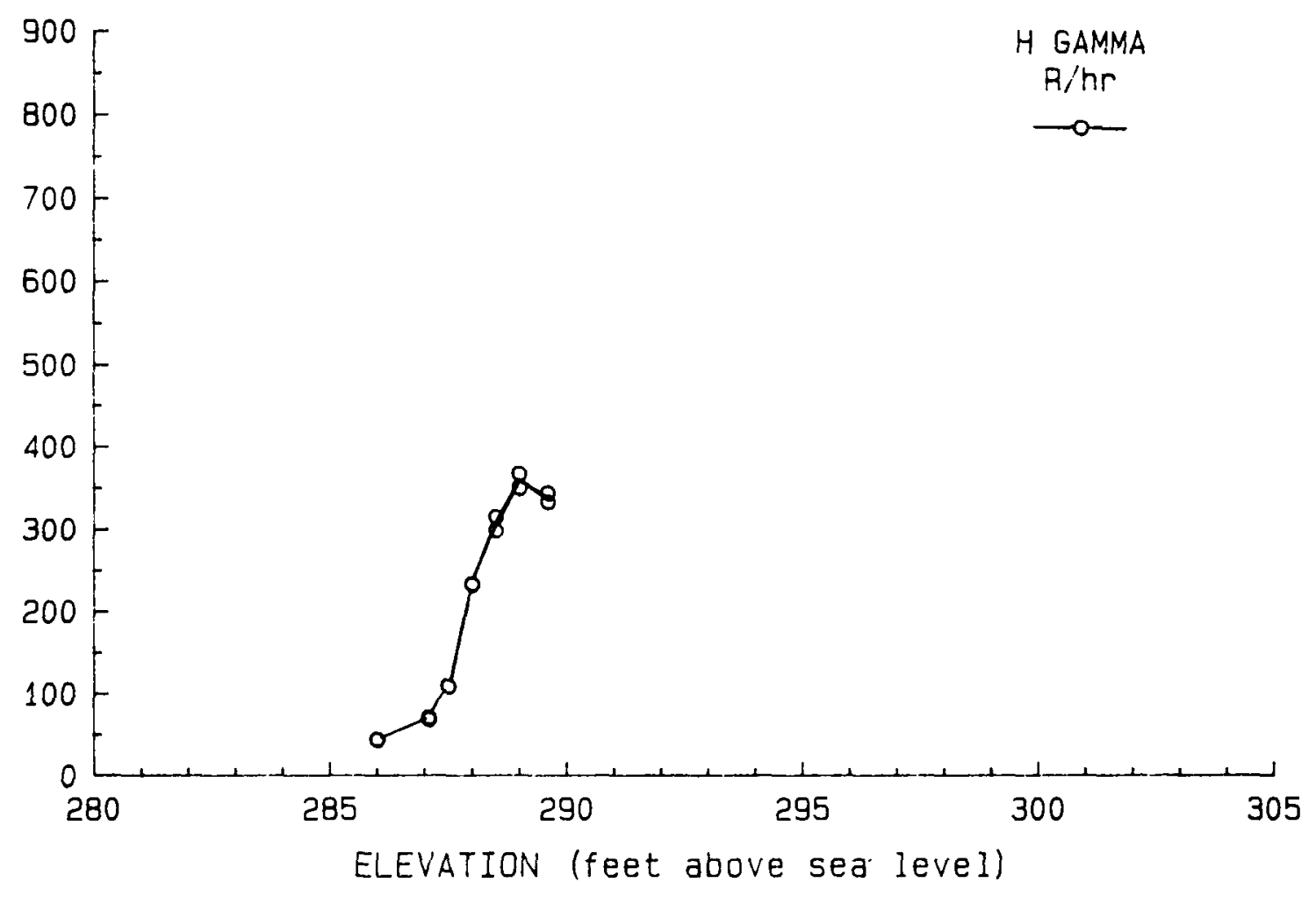

FIGURE 3.22. Dose Rate Profile at Robot Location H 


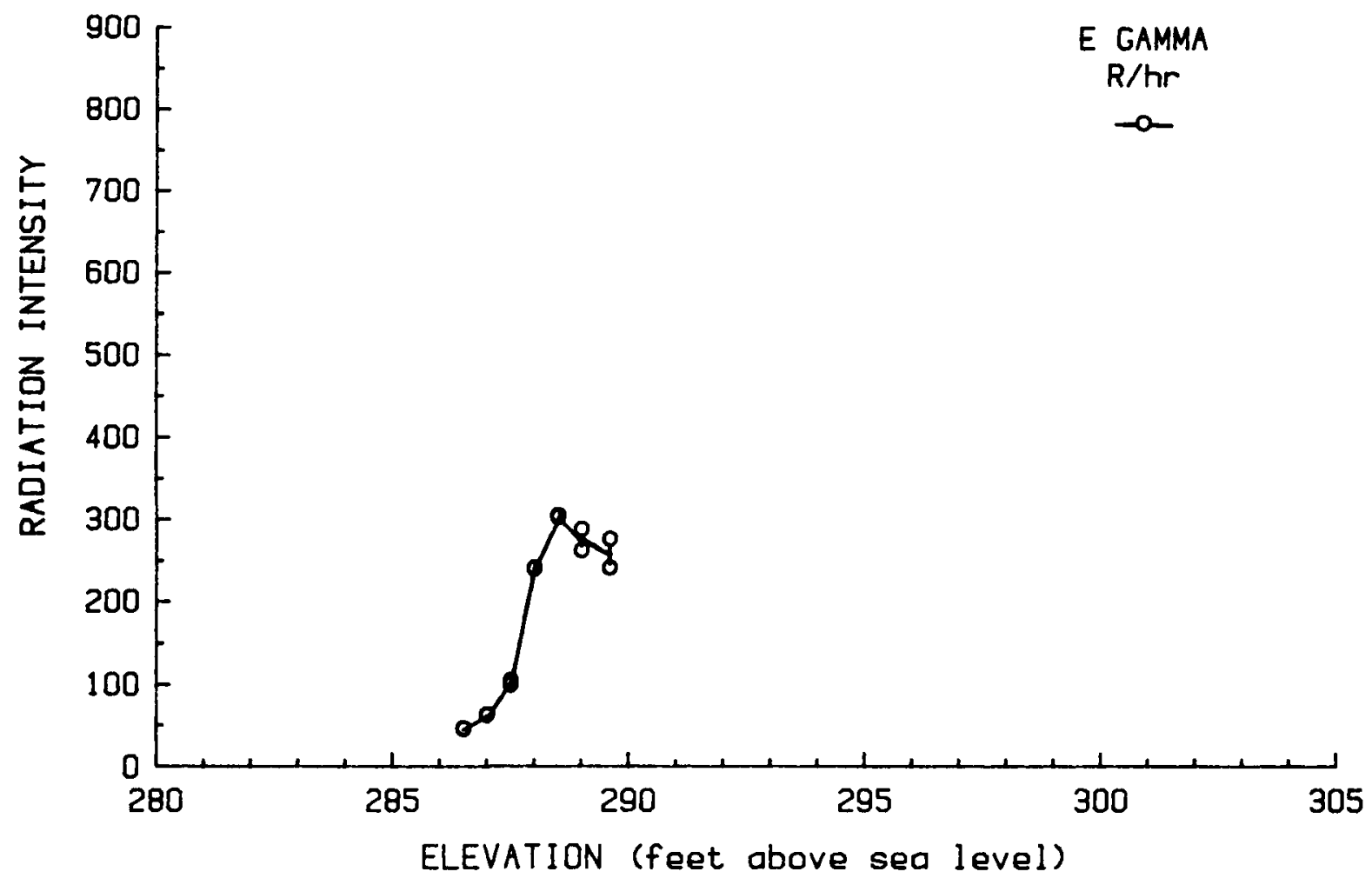

FIGURE 3.23. Dose Rate Profile at Robot Location E 


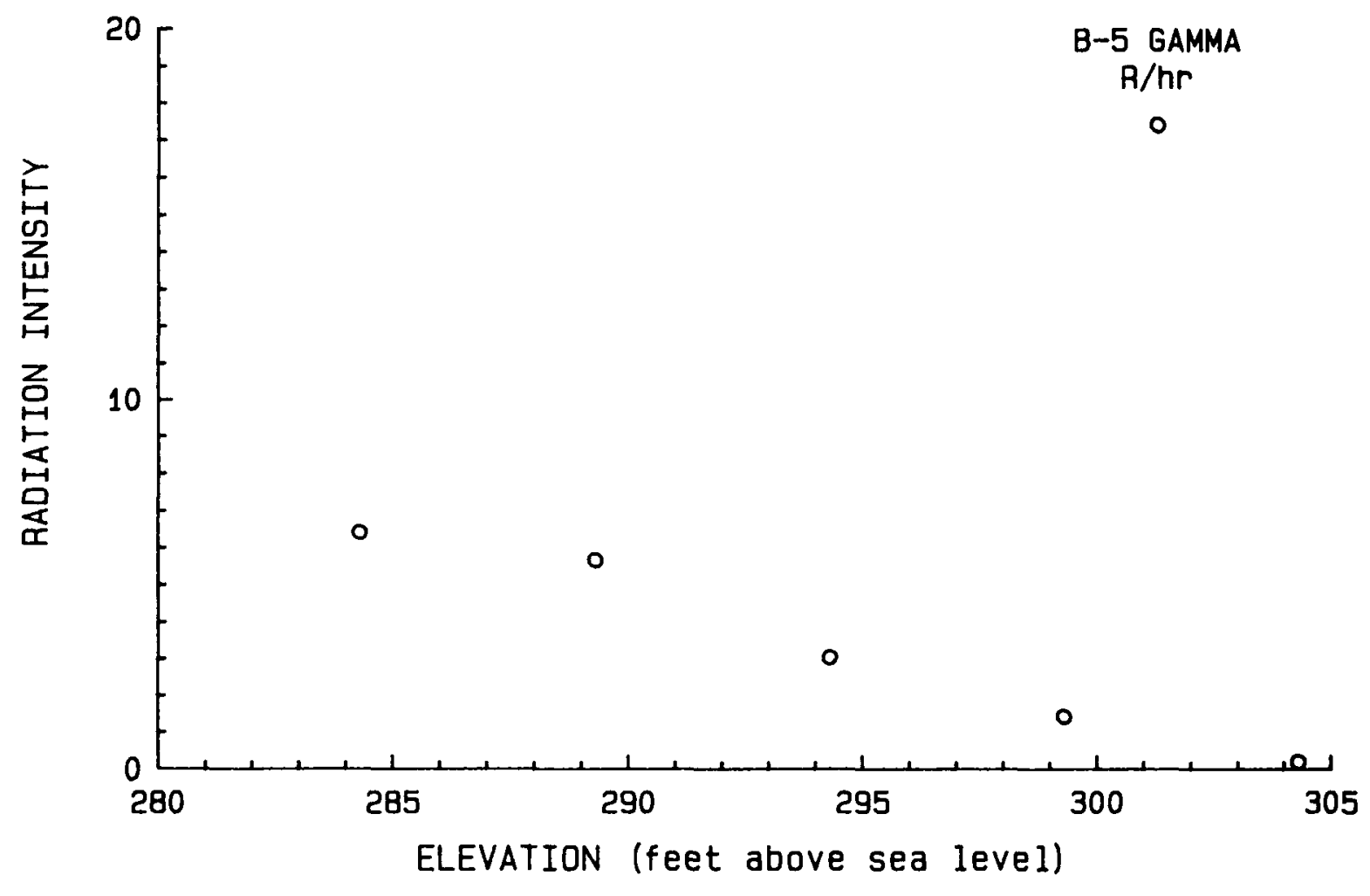

FIGURE 3.24. Dose Rate Profile at Location B-5 

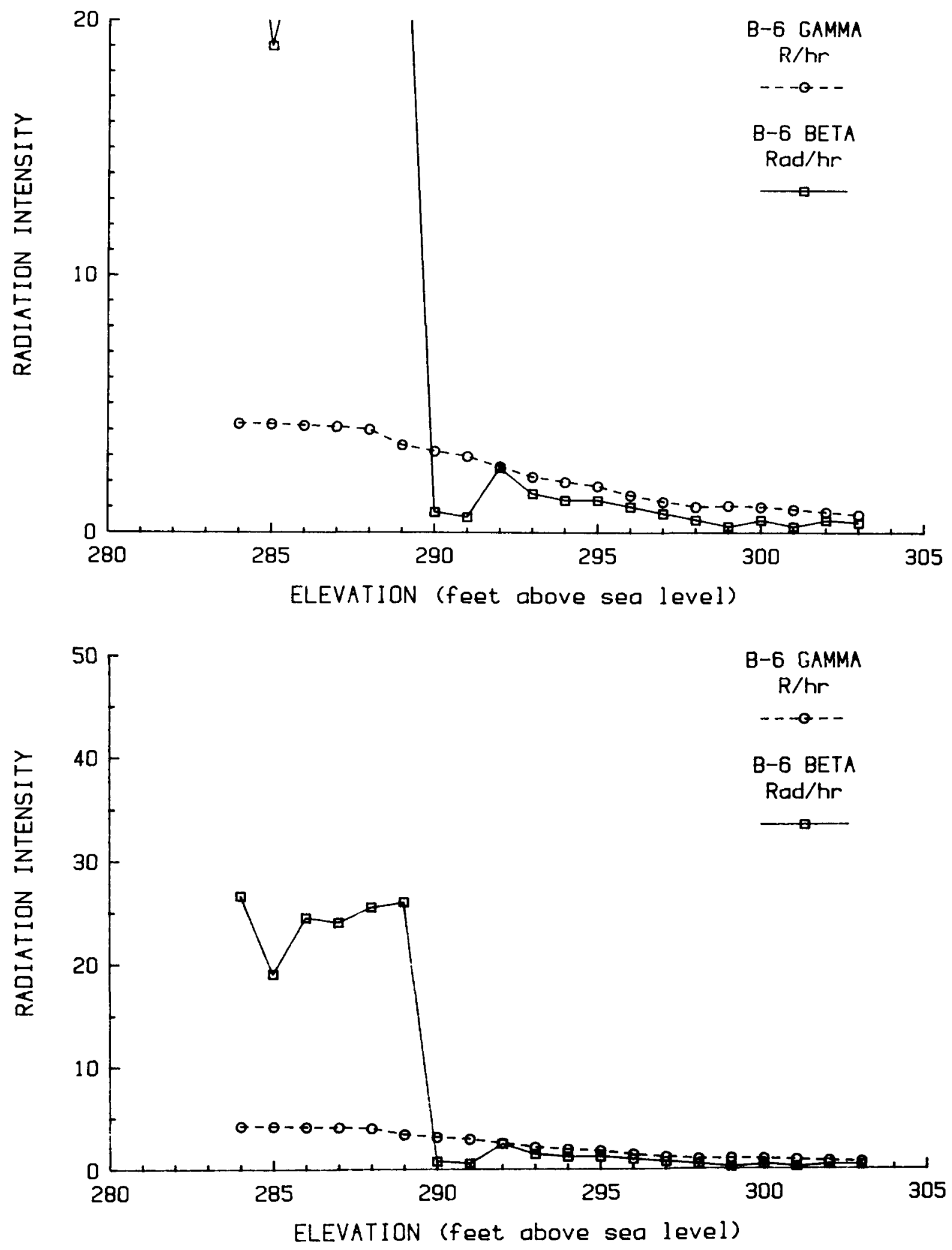

FIGURE 3.25. Dose Rate Profile at TLD Location B-6 


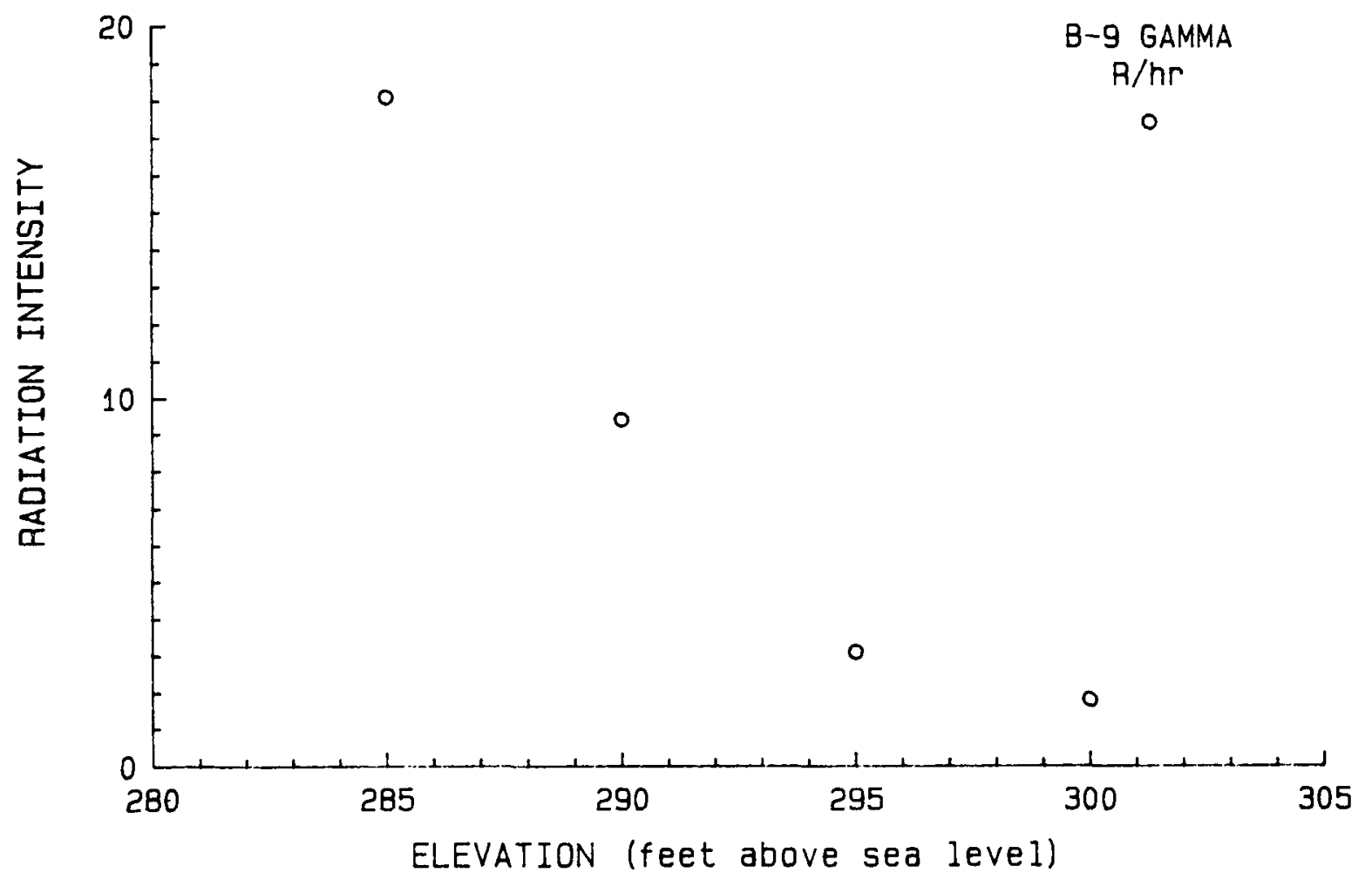

FIGURE 3.26. Dose Rate Profile at Location B-9 

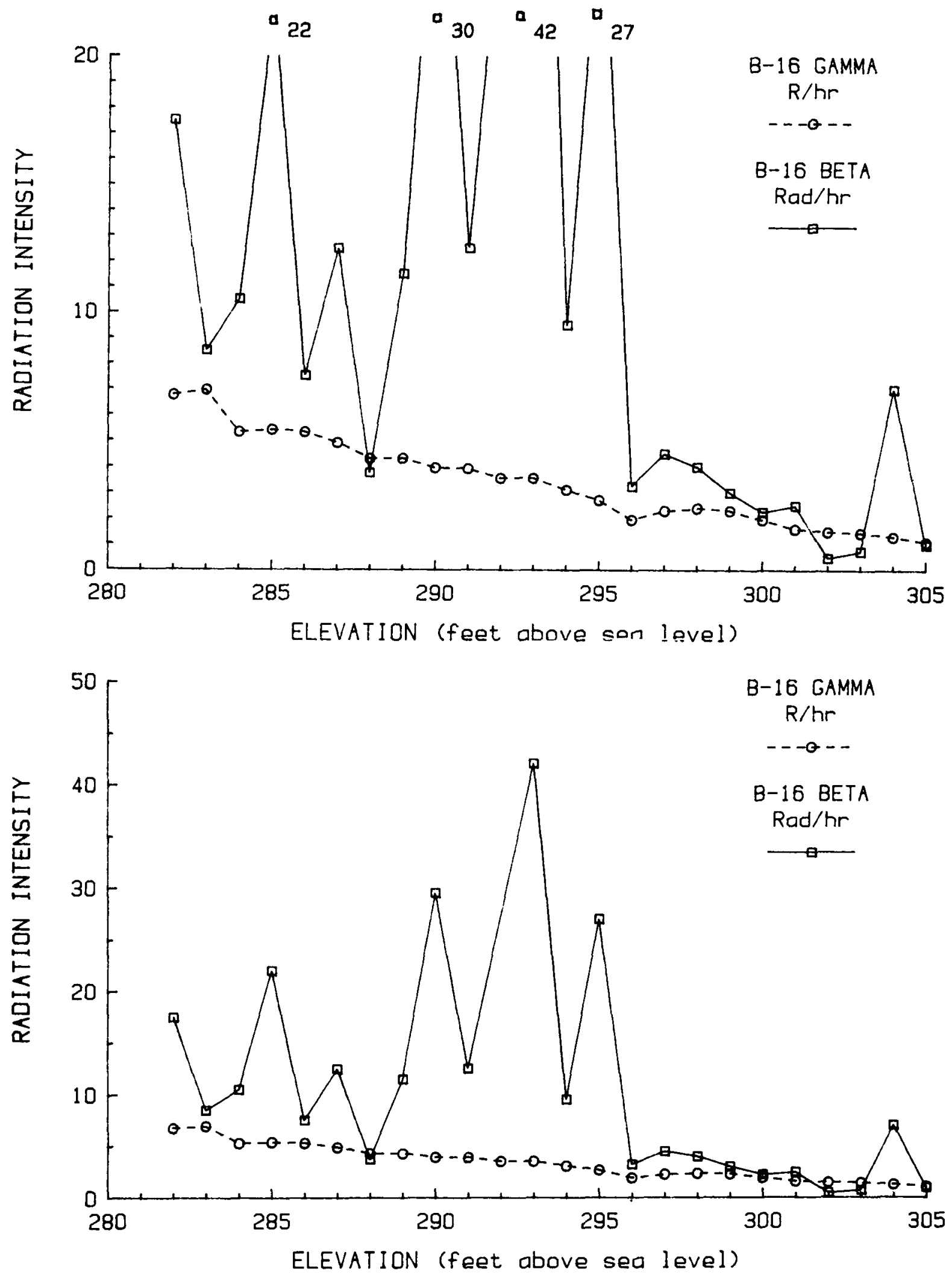

FIGURE 3.27. Dose Rate Profile at Location B-16 


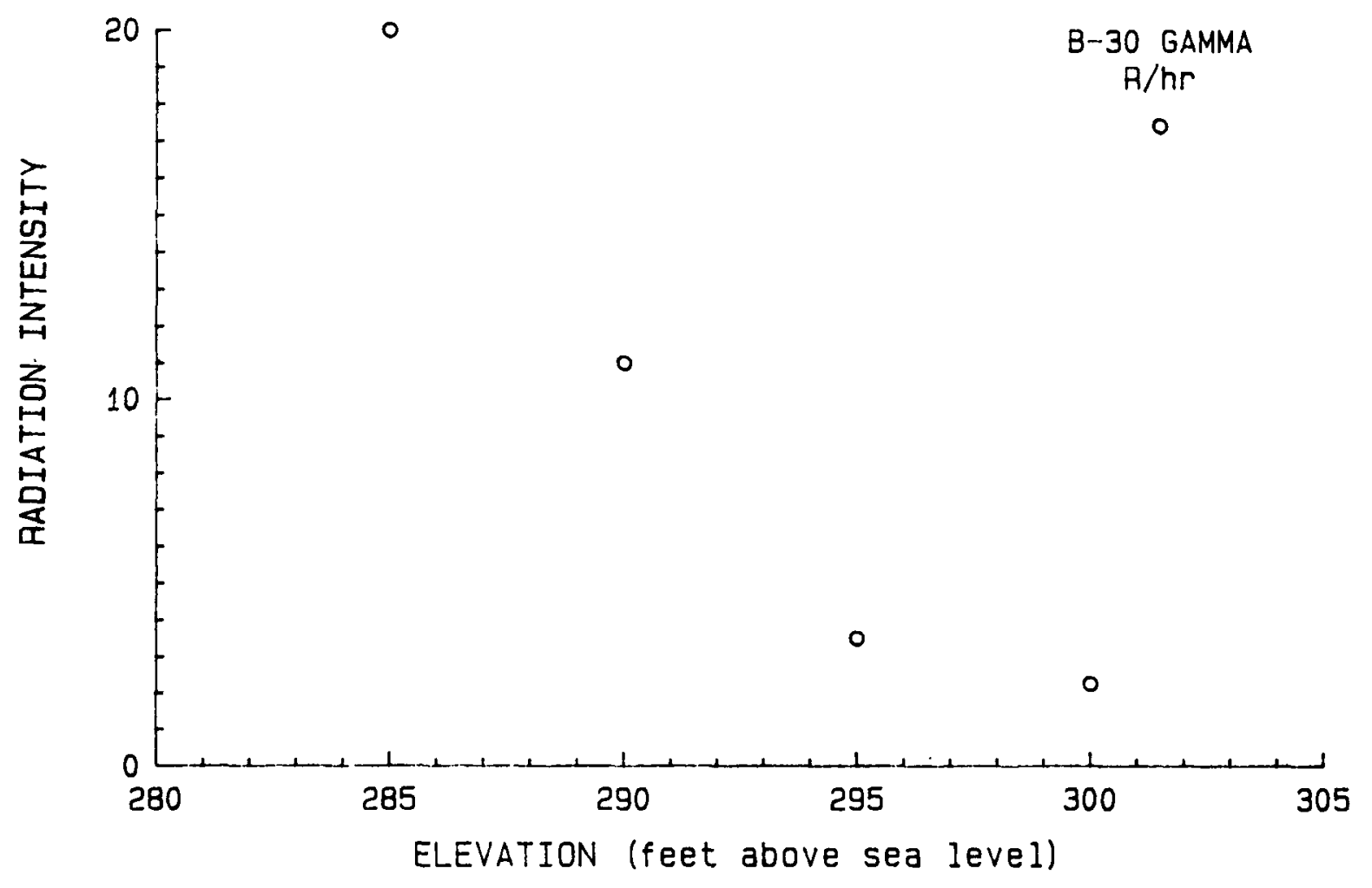

FIGURE 3.28. Dose Rate Profile at Location B-30 

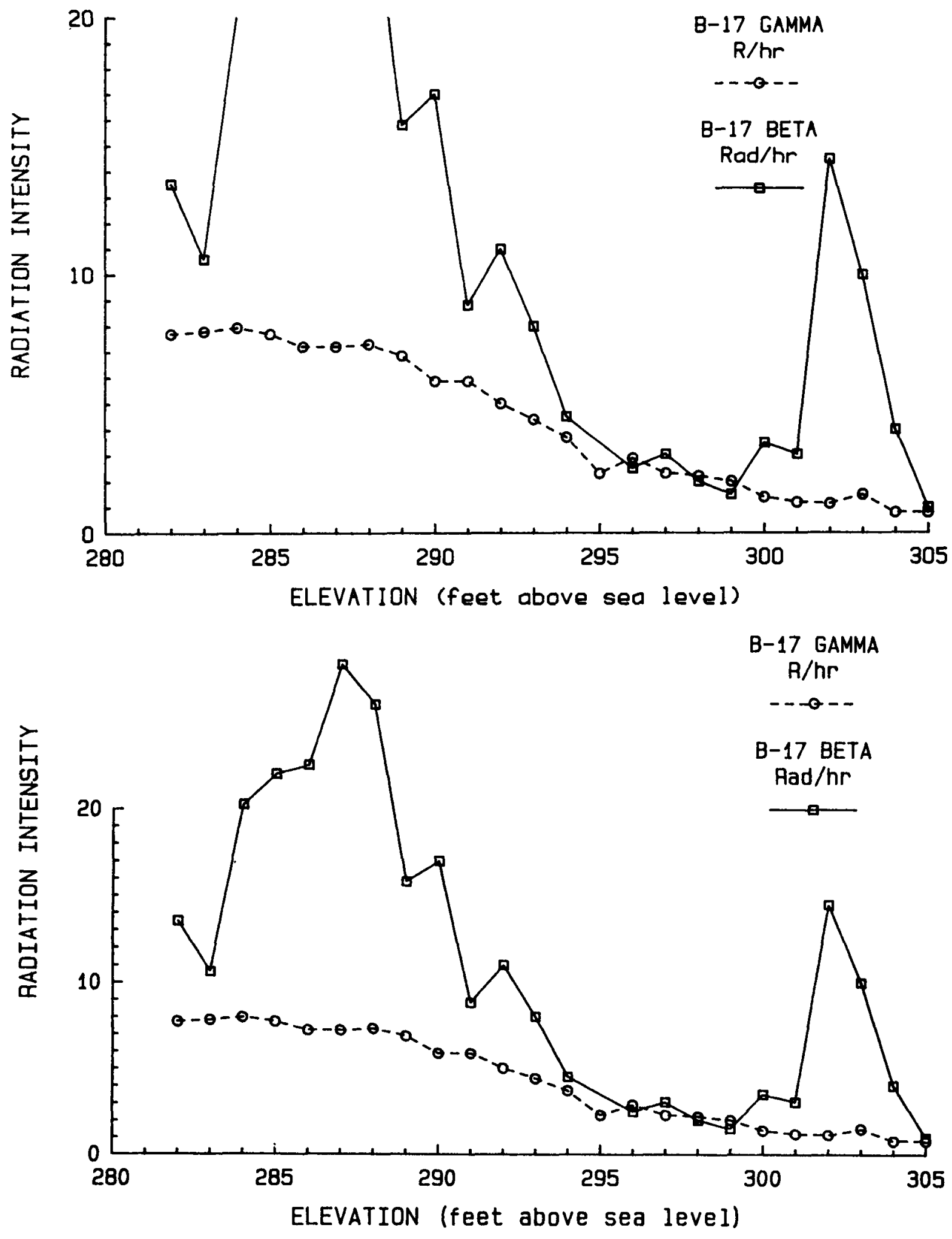

FIGURE 3.29. Dose Rate Profile at Location B-17 

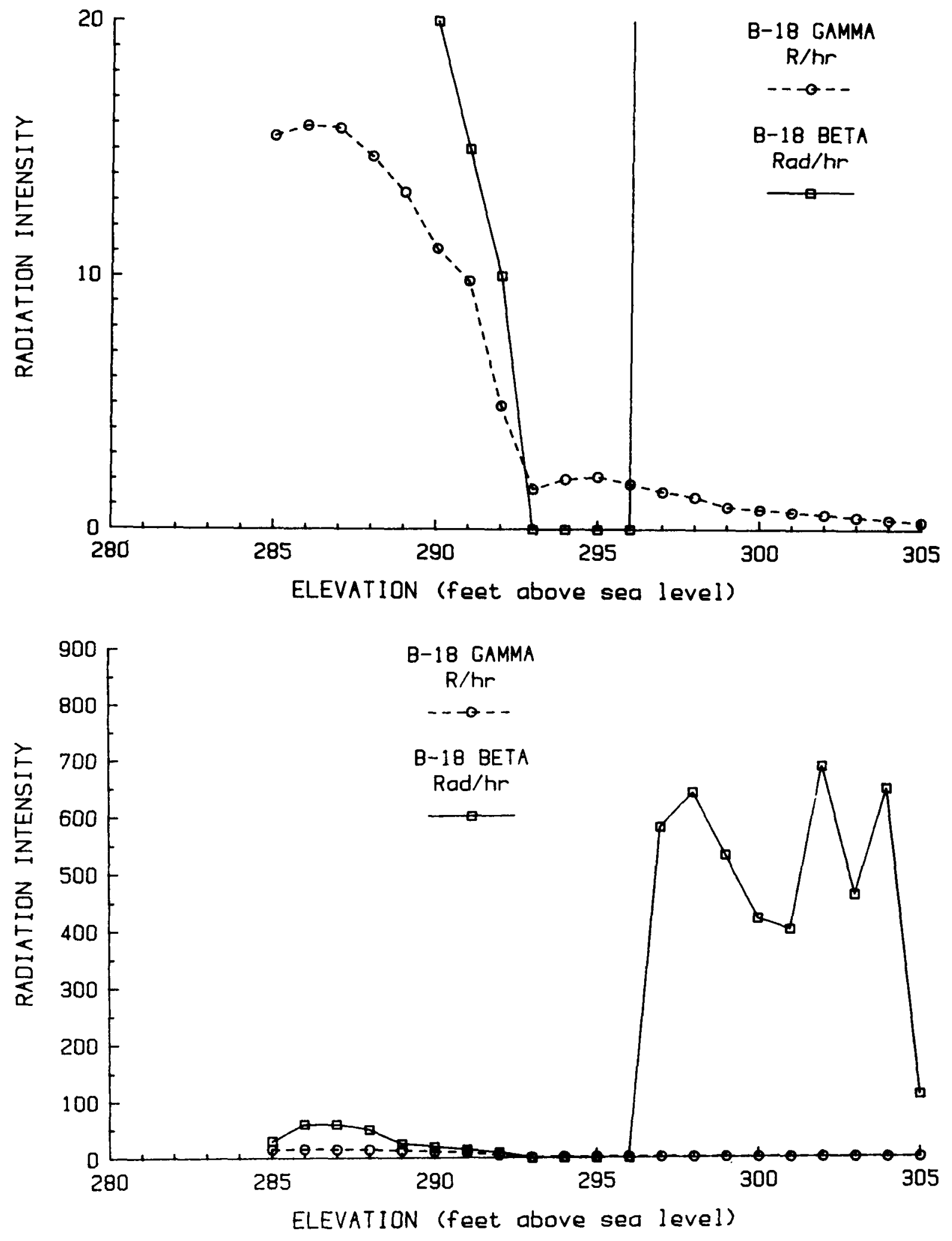

FIGURE 3.30. Dose Rate Profile at Location B-18 

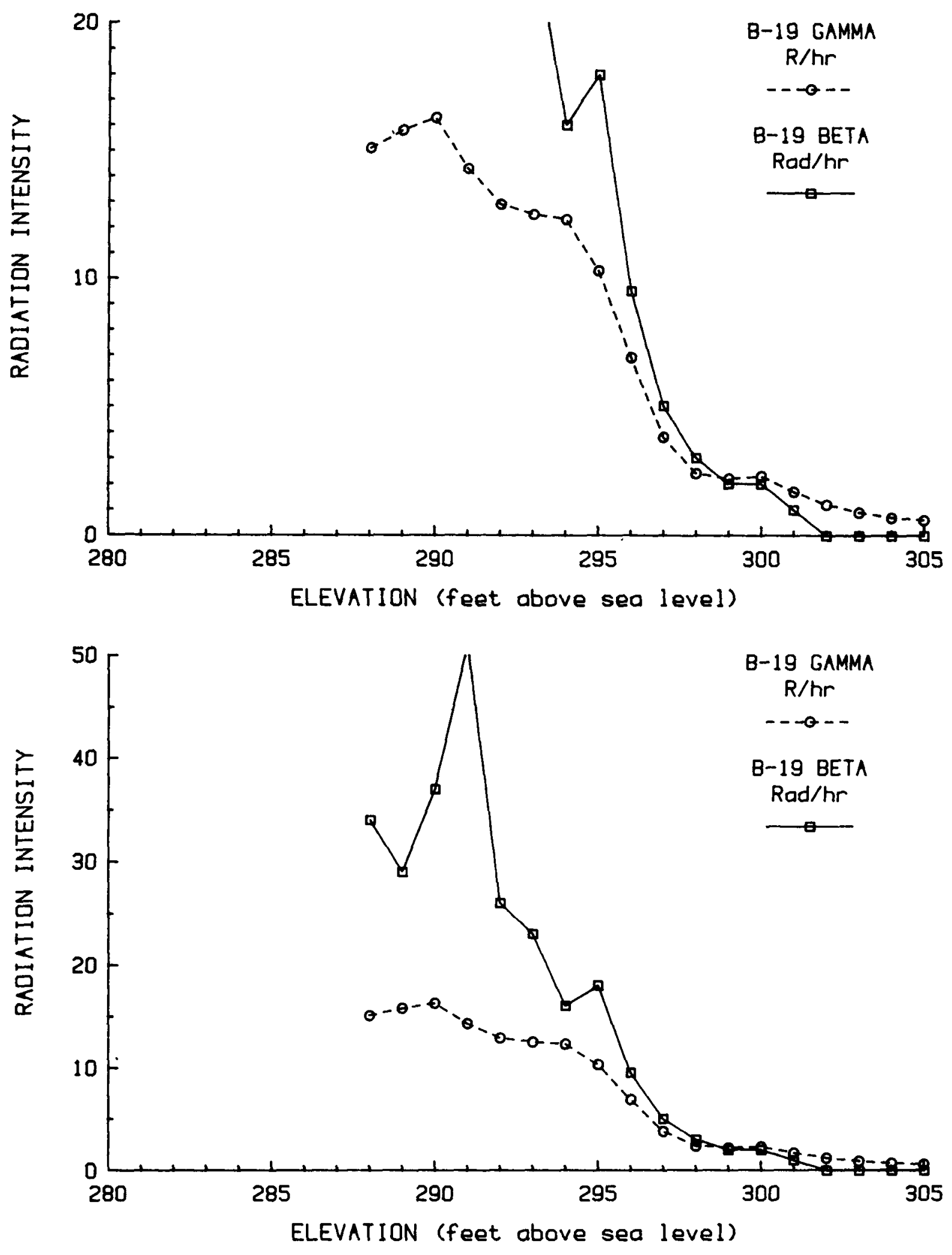

FIGURE 3.31. Dose Rate Profile at Location B-19 


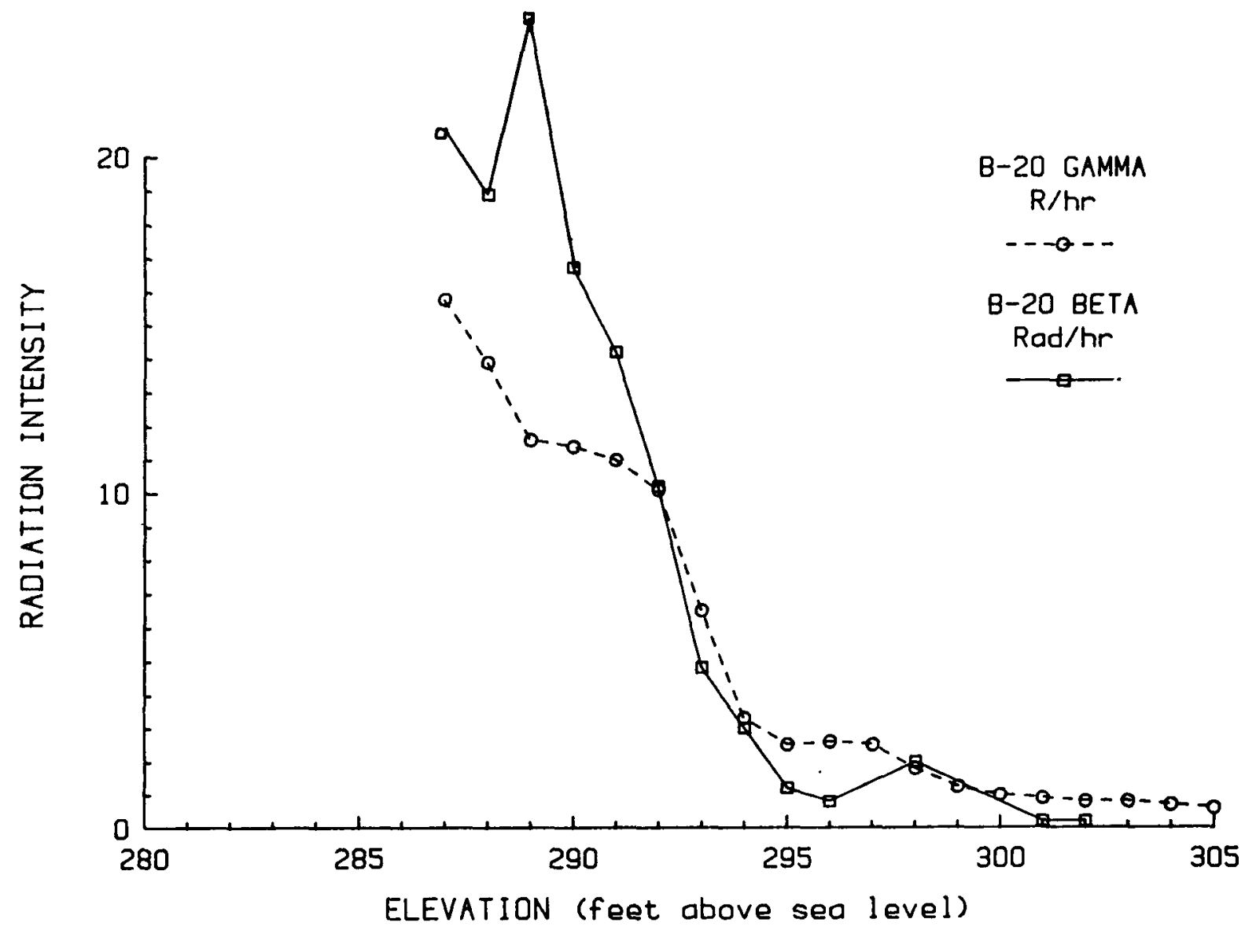

FIGURE 3.32. Dose Rate Profile at Location B-20 


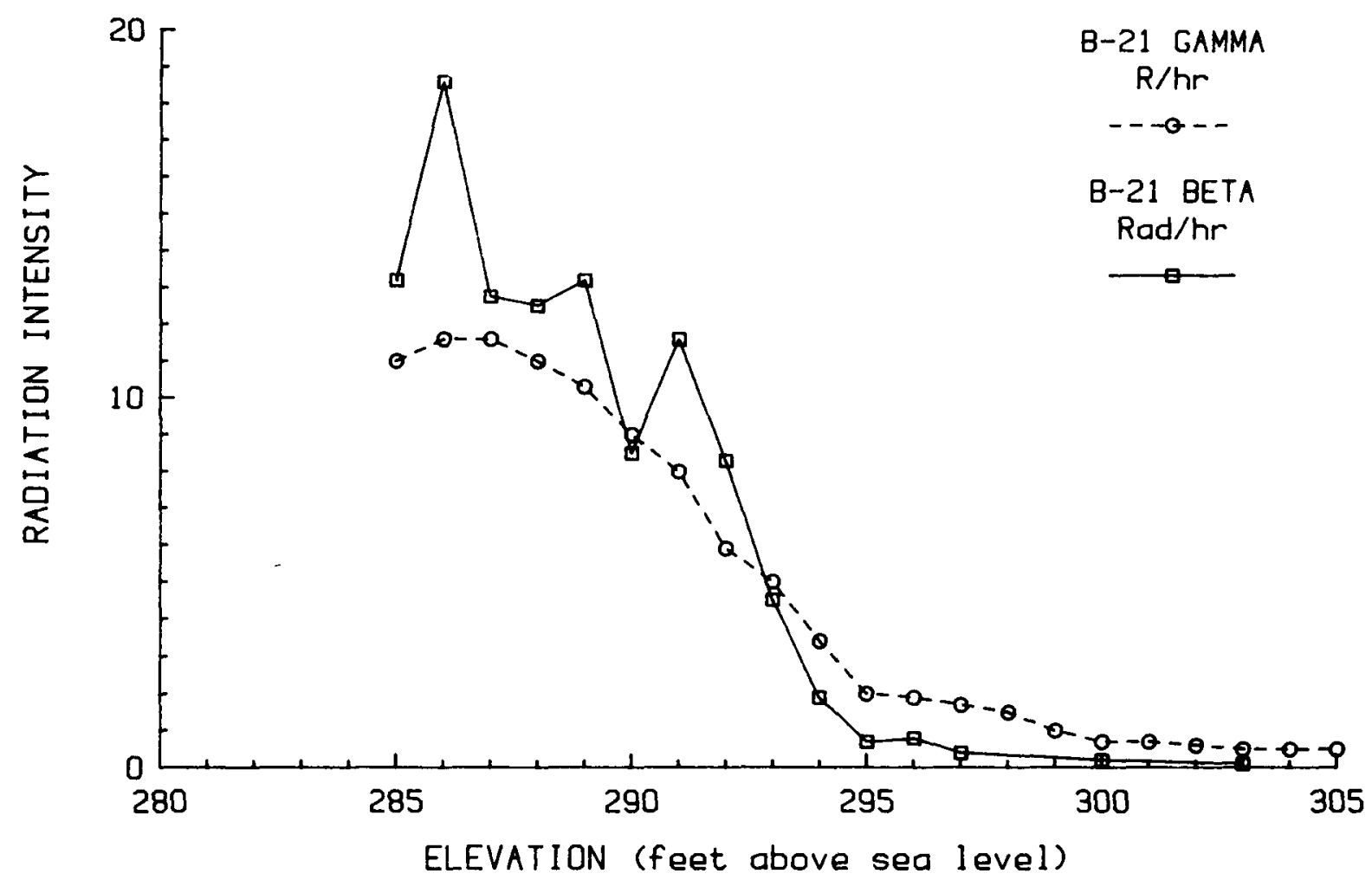

FIGURE 3.33. Dose Rate Profile at Location B-21 

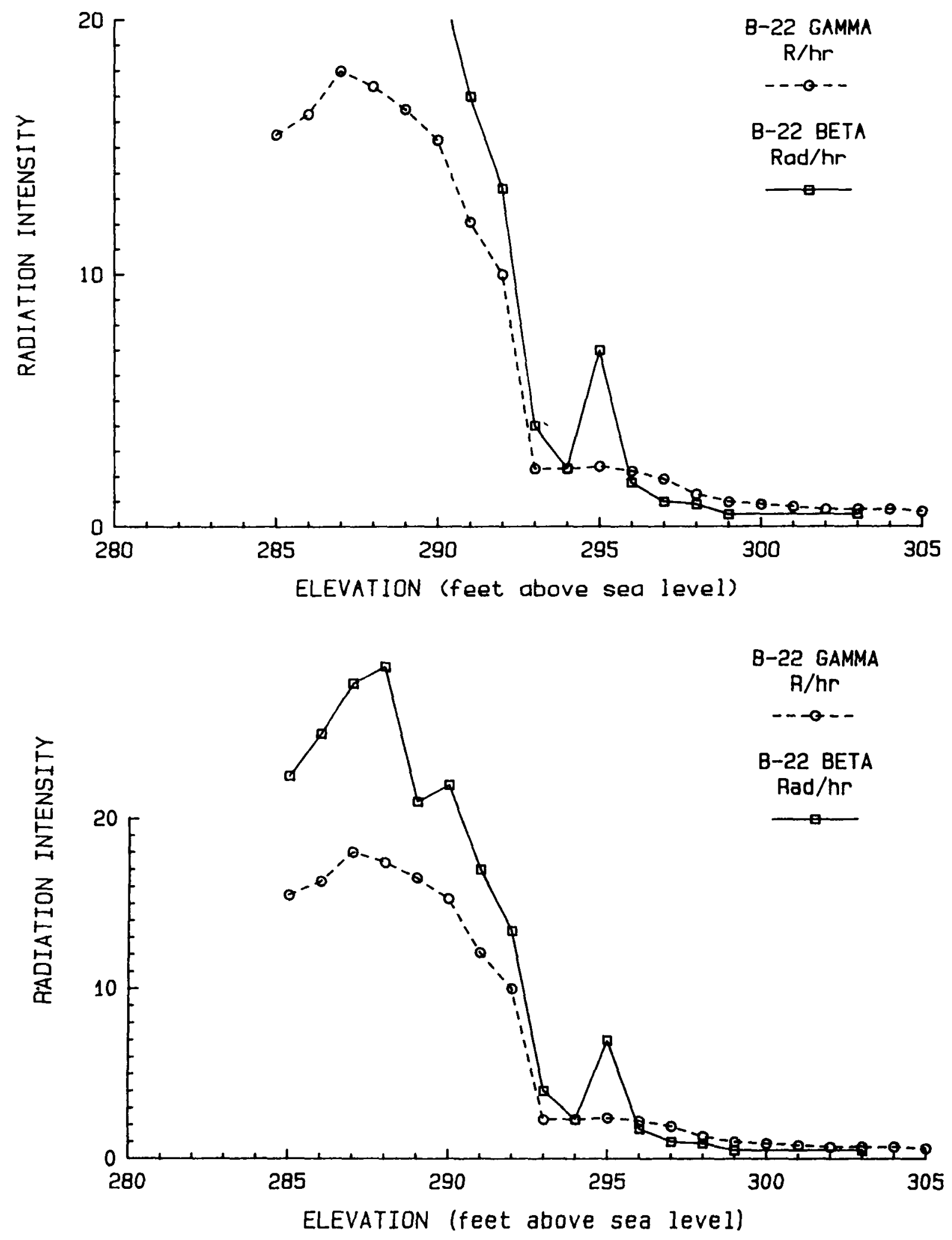

FIGURE 3.34. Dose Rate Profile at Location B-22 


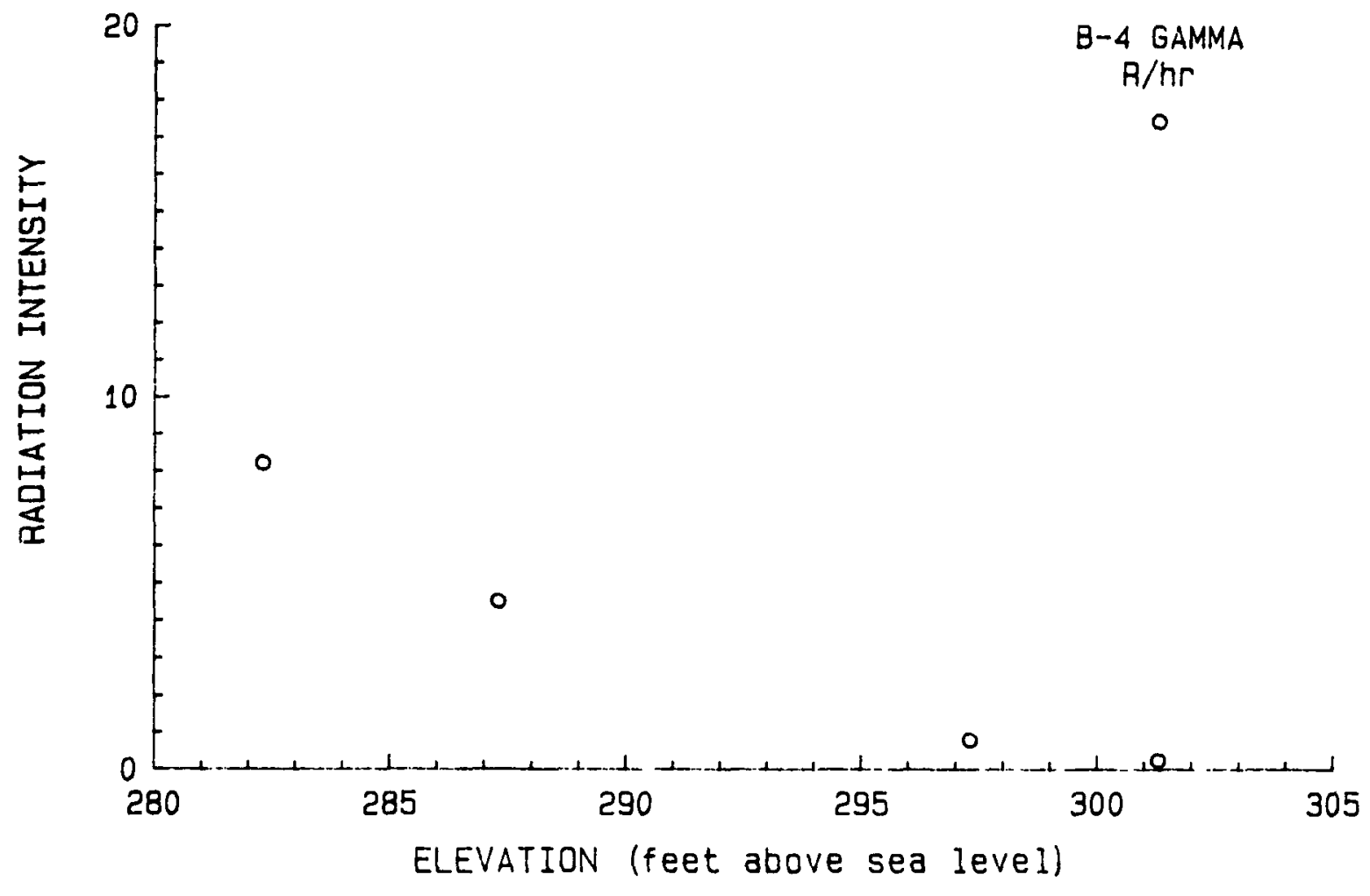

FIGURE 3.35. Dose Rate Profile at Location B-4 


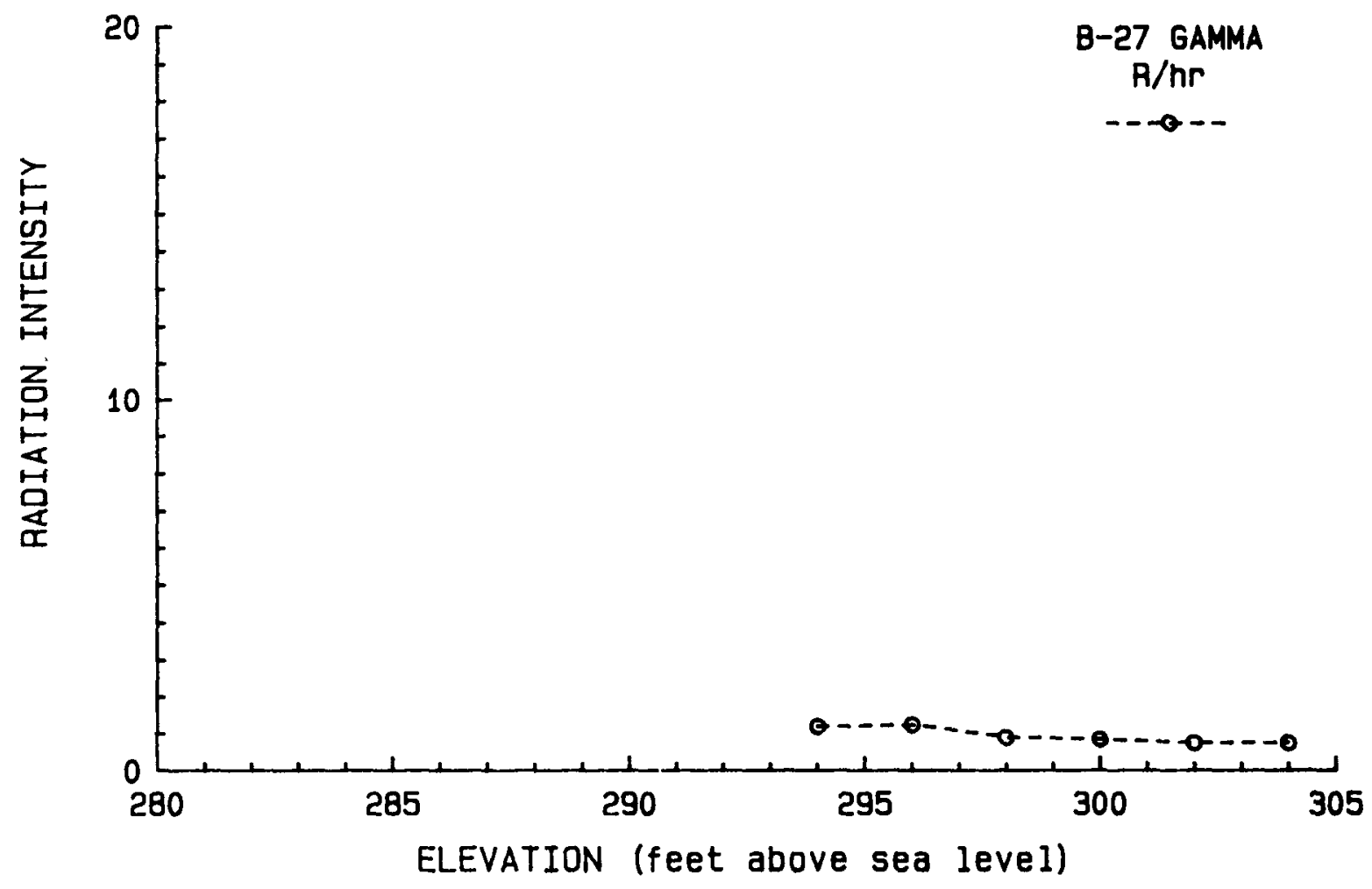

FIGURE 3.36. Dose Rate Profile at Location B-27 
- 46.2

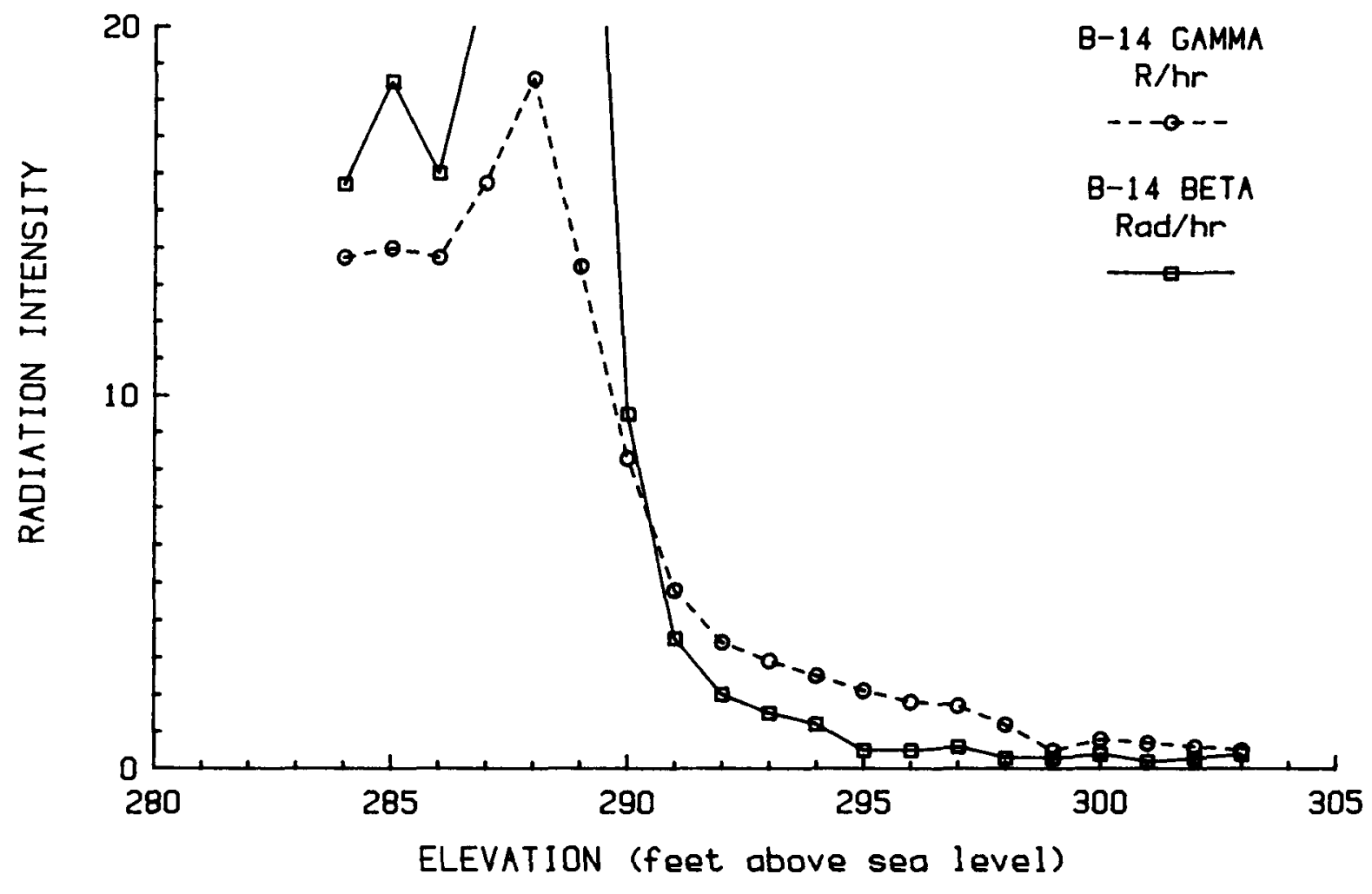

FIGURE 3.37. Dose Rate Profile at Location B-14 


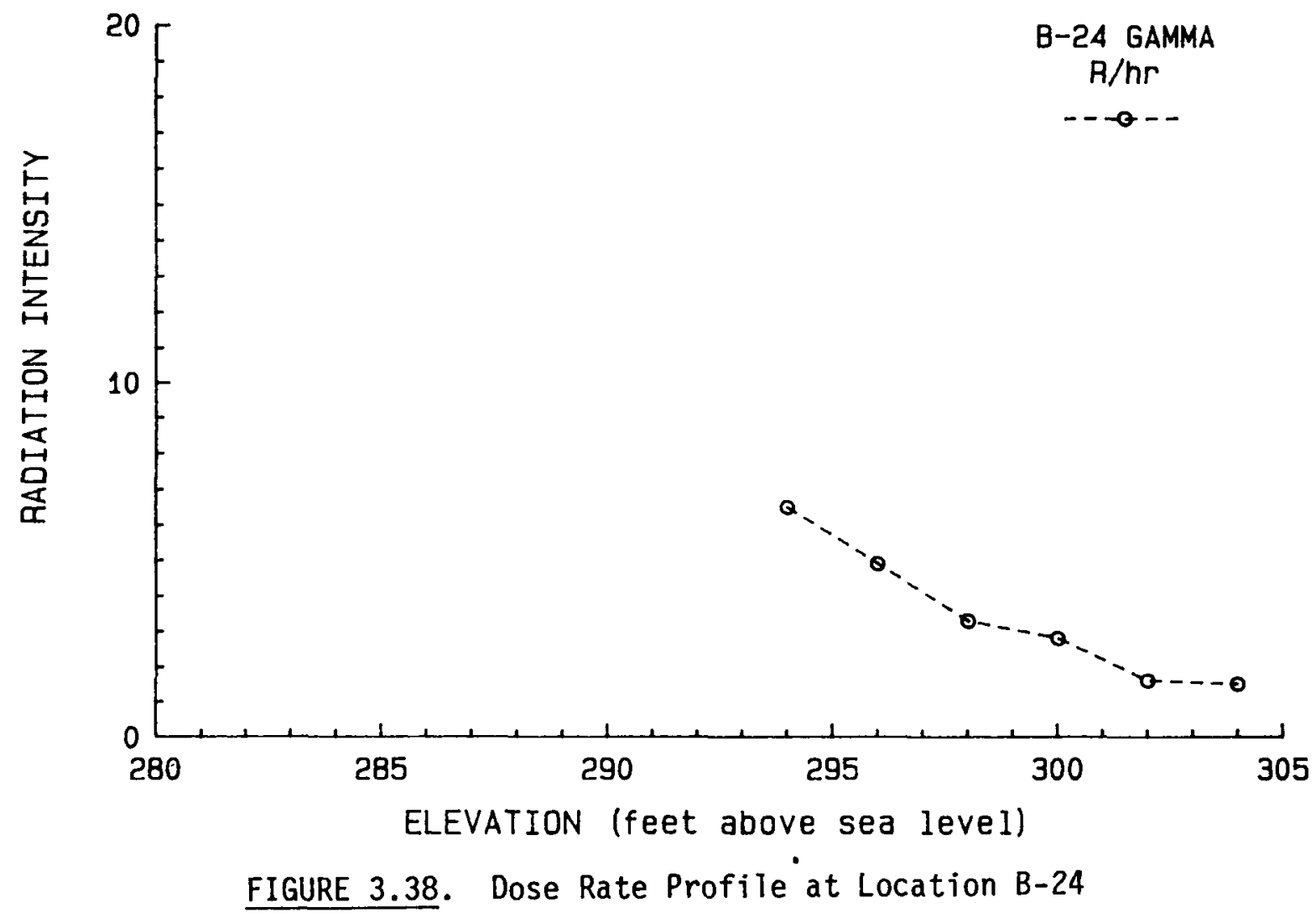




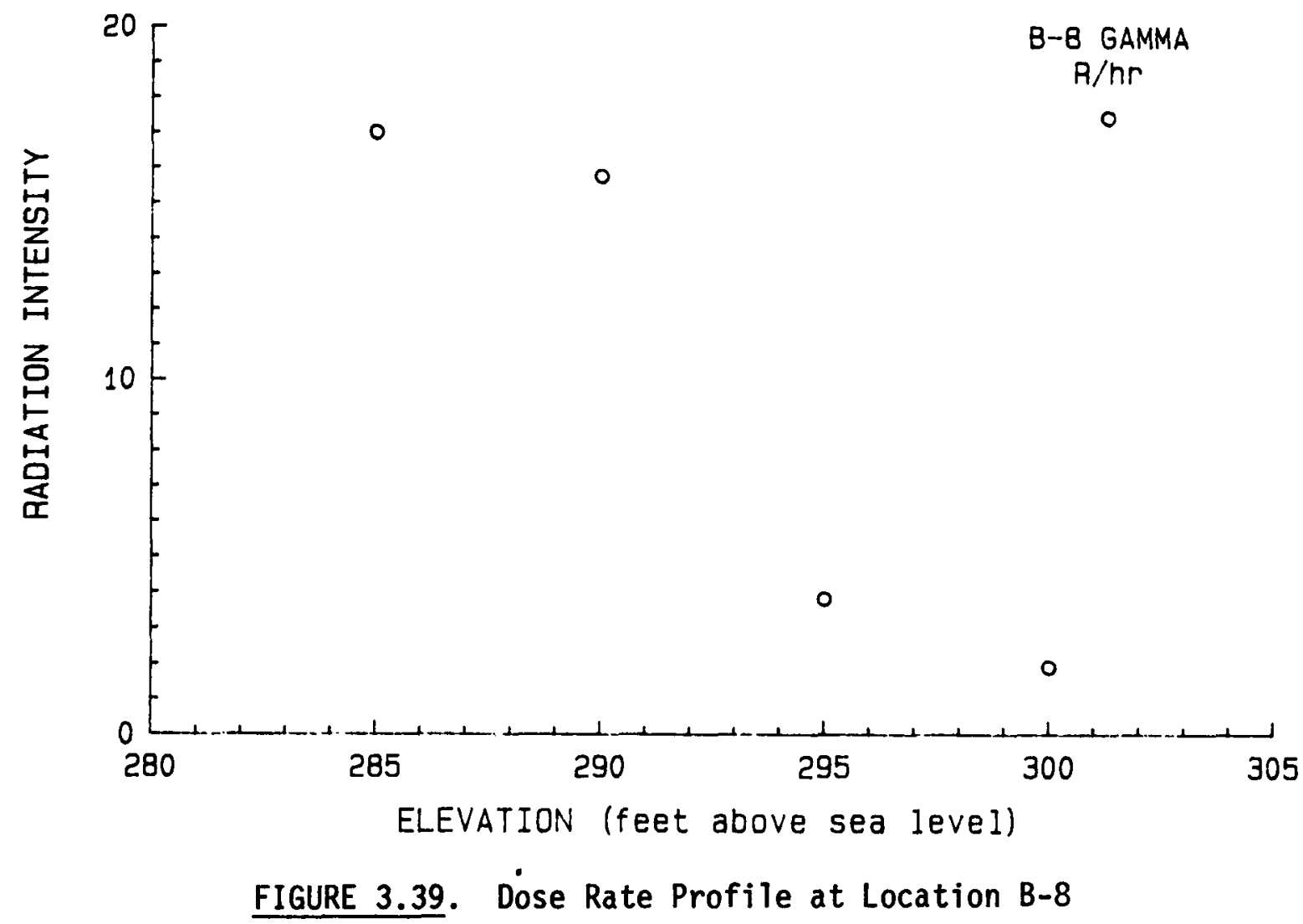




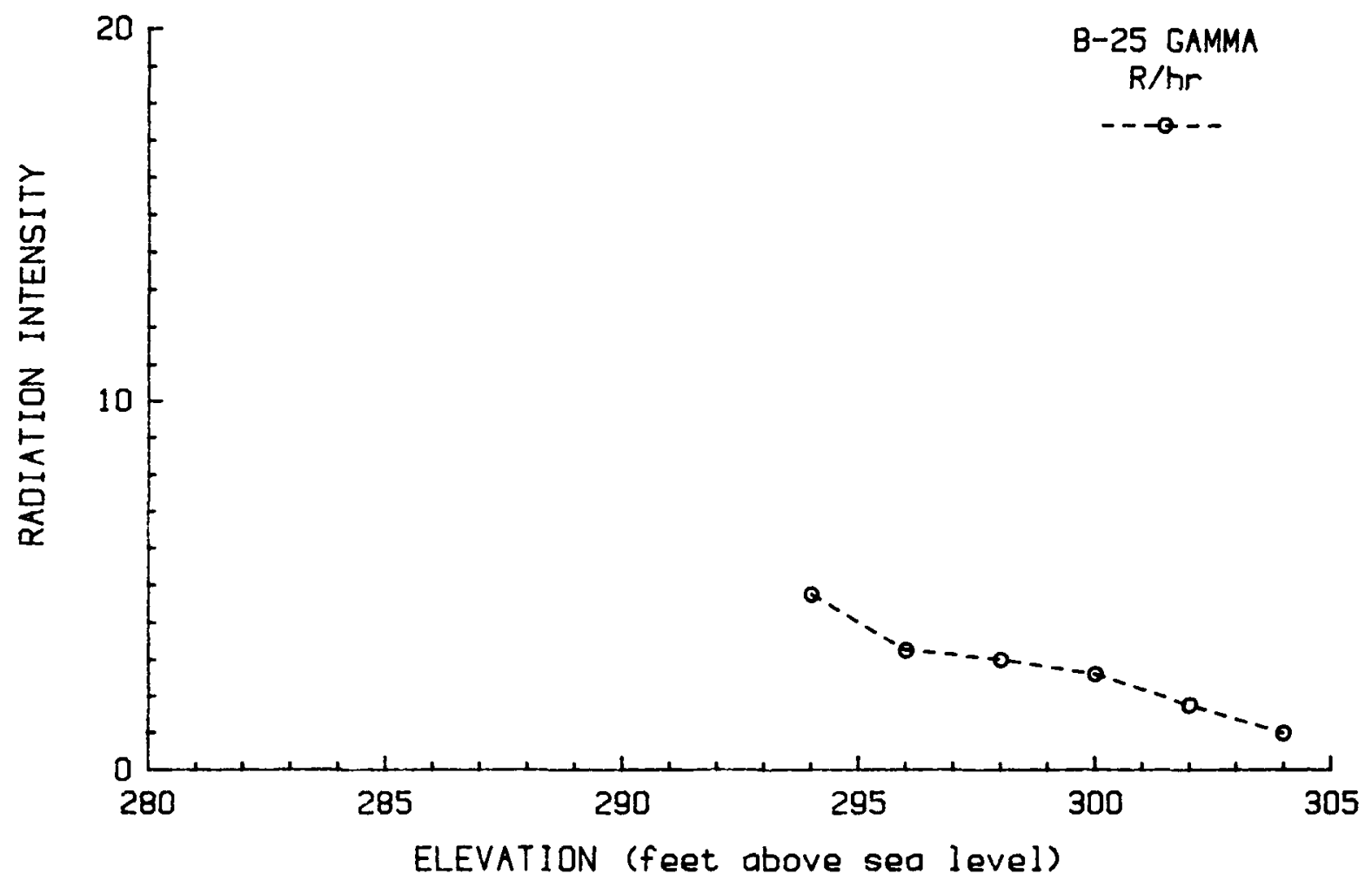

FIGURE 3.40. Dose Rate Profile at Location B-25 


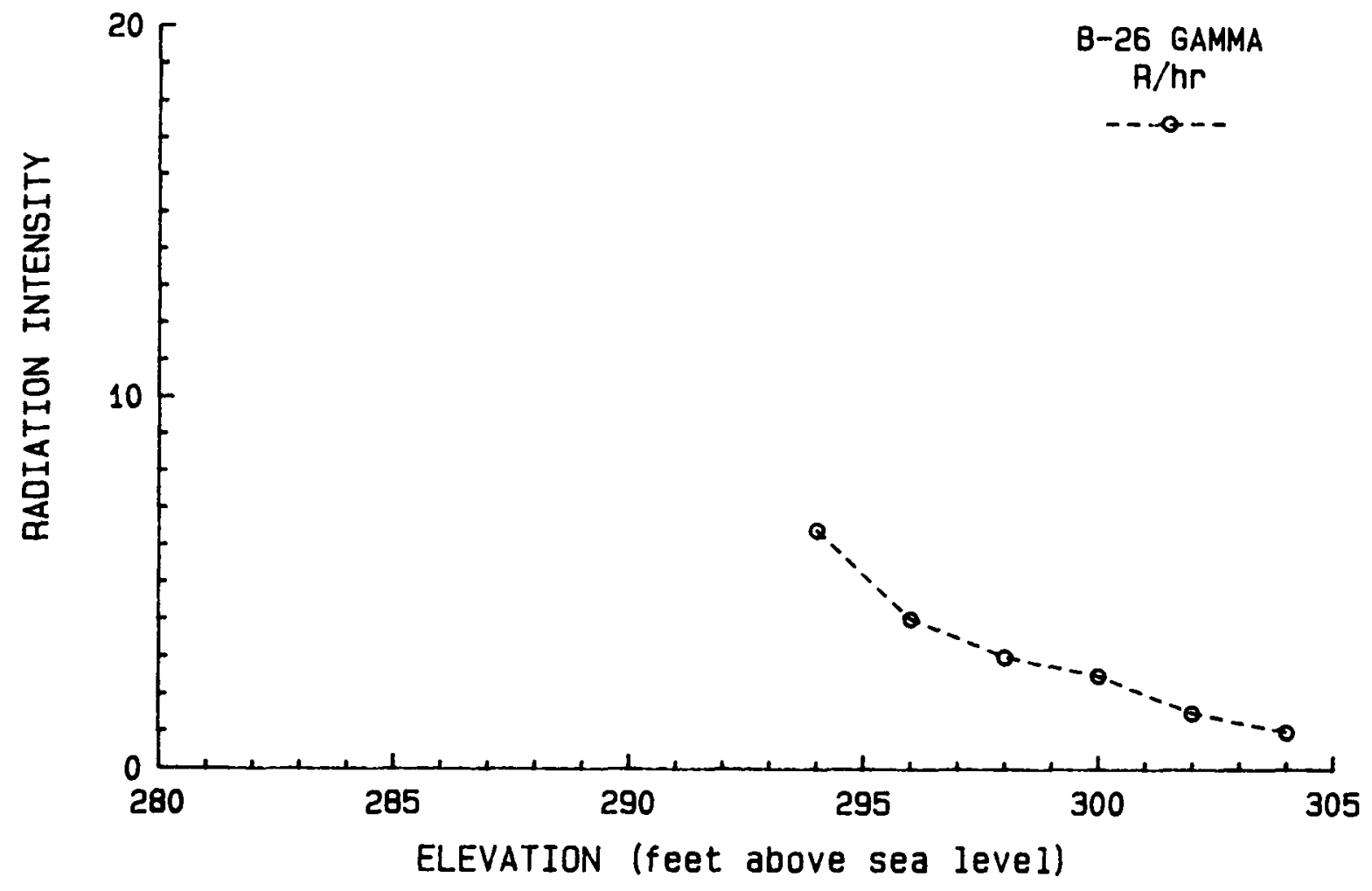

FIGURE 3.41. Dose Rate Profile at Location B-26 


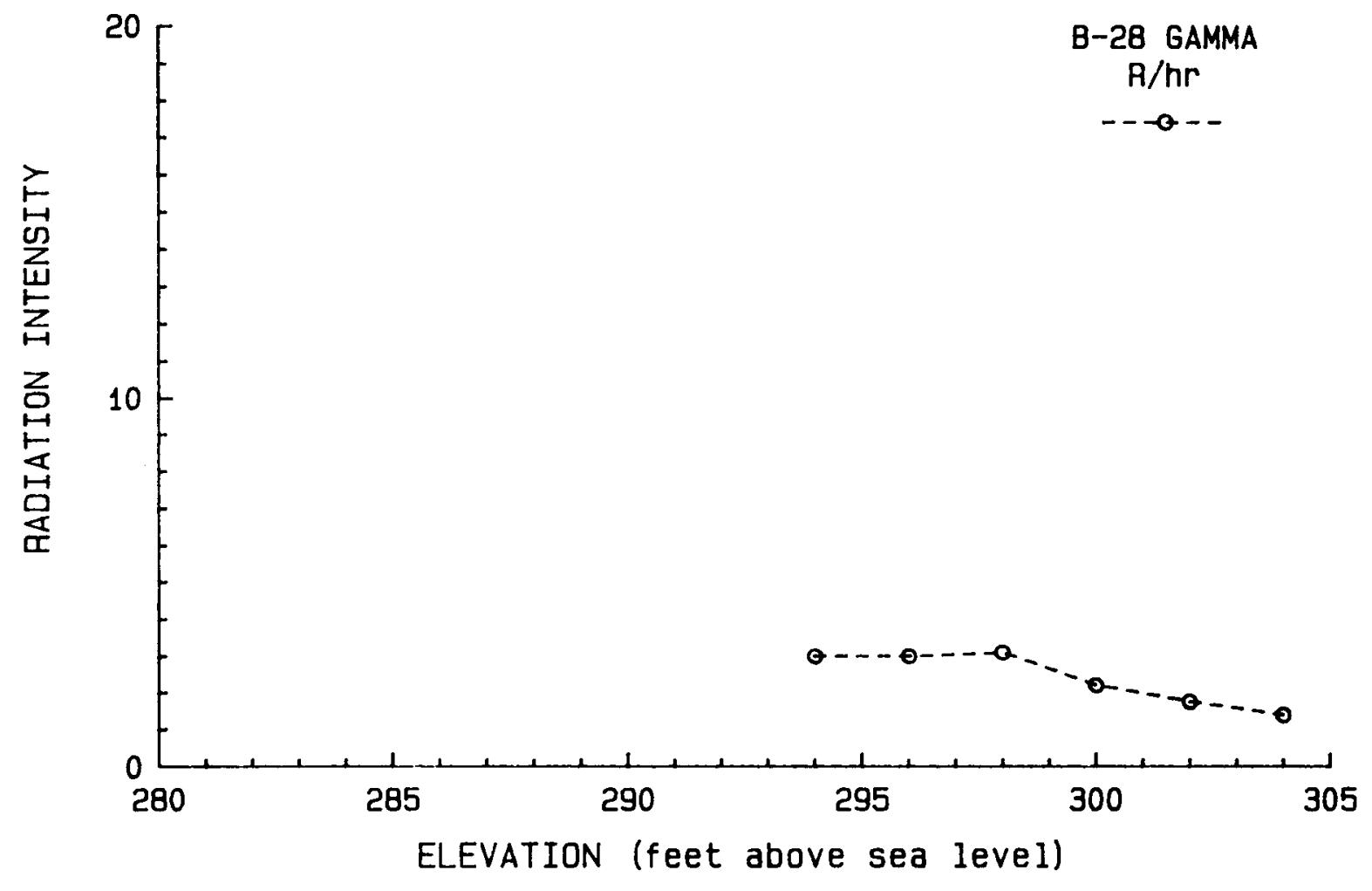

FIGURE 3.42. Dose Rate Profile at Location B-28 


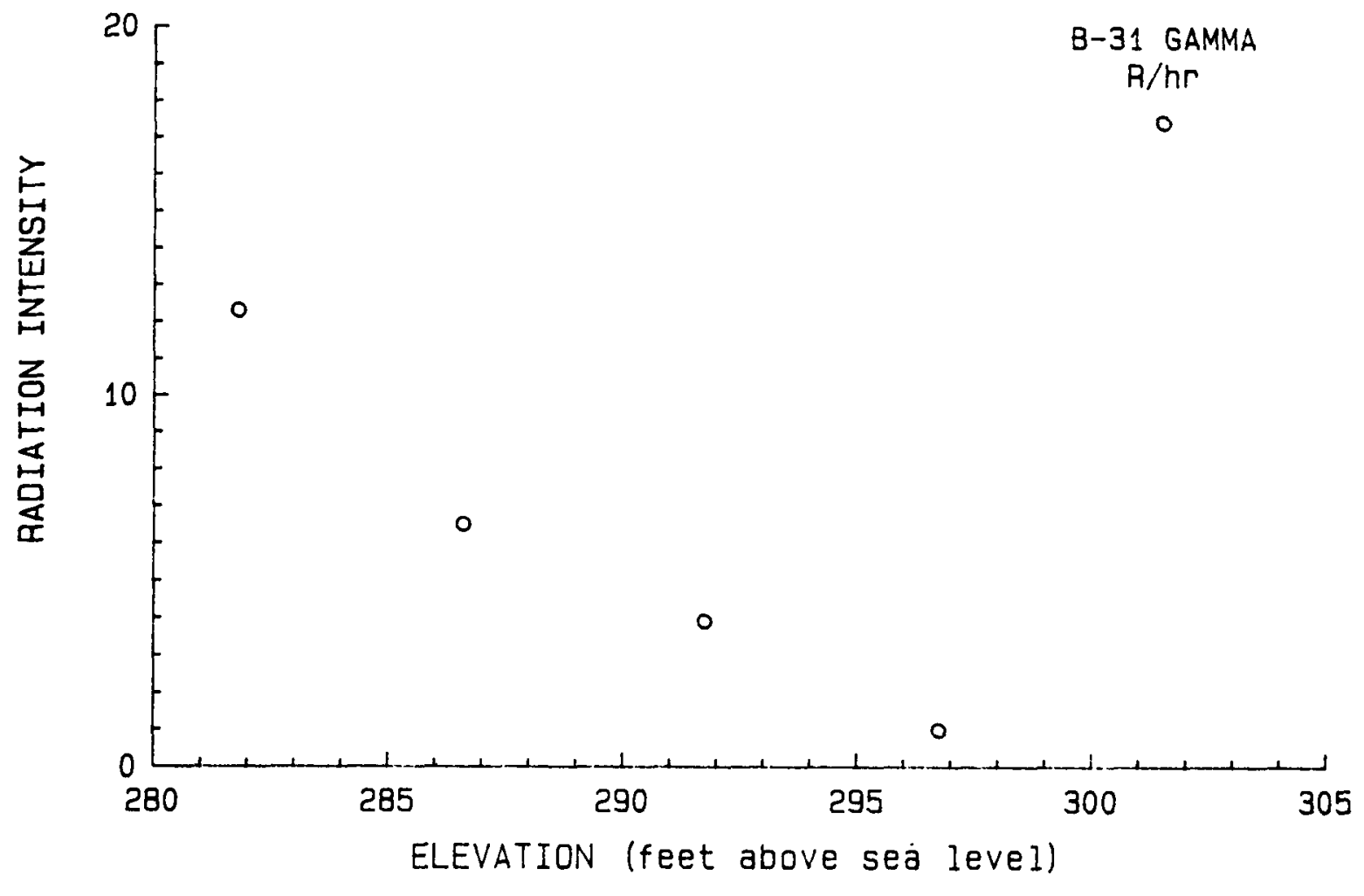

FIGURE 3.43. Dose Rate Profile at Location B-31 


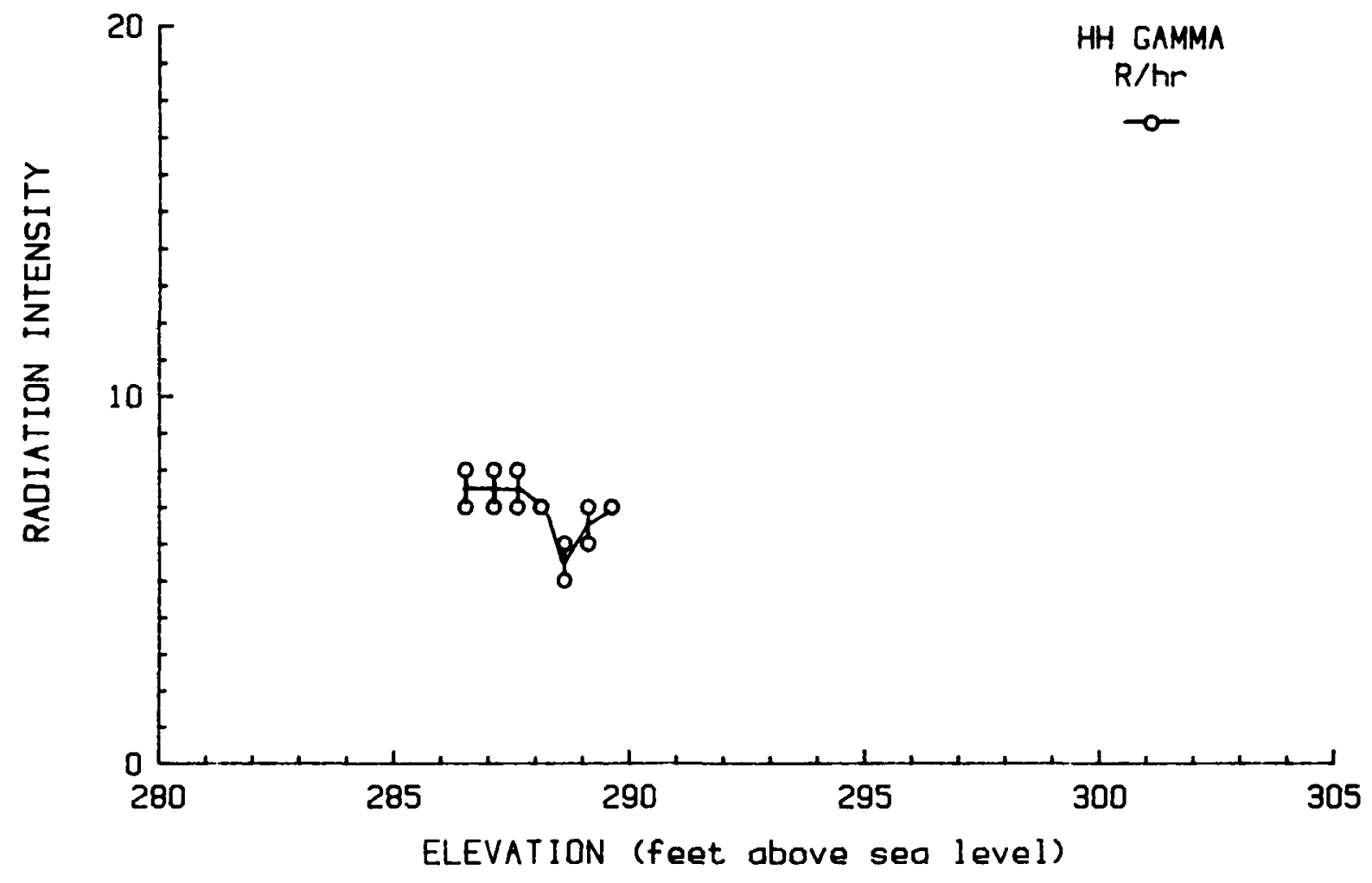

FIGURE 3.44. Dose Rate Profile at Robot Location HH 


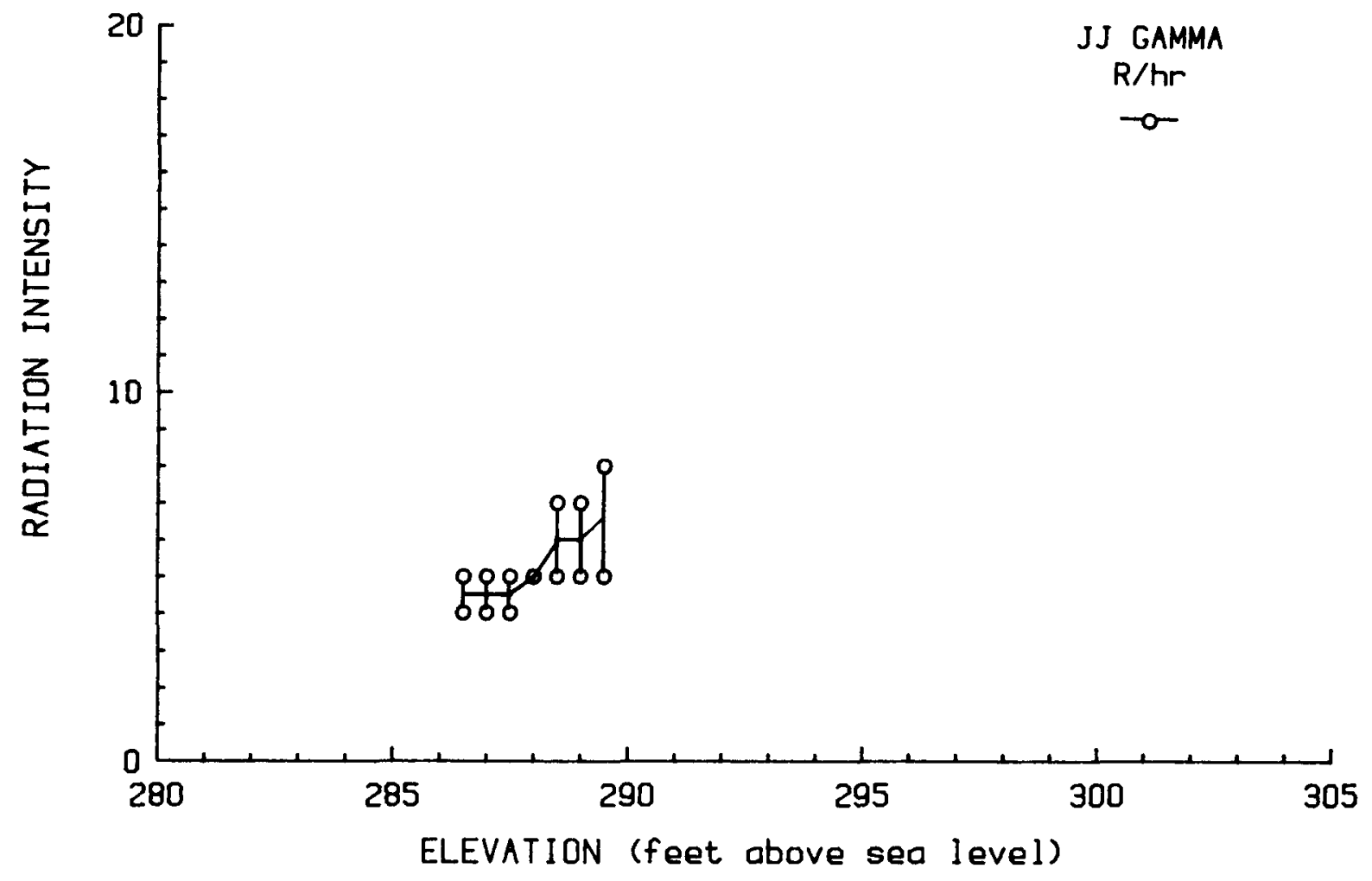

FIGURE 3.45. Dose Rate Profile at Robot Location JJ 


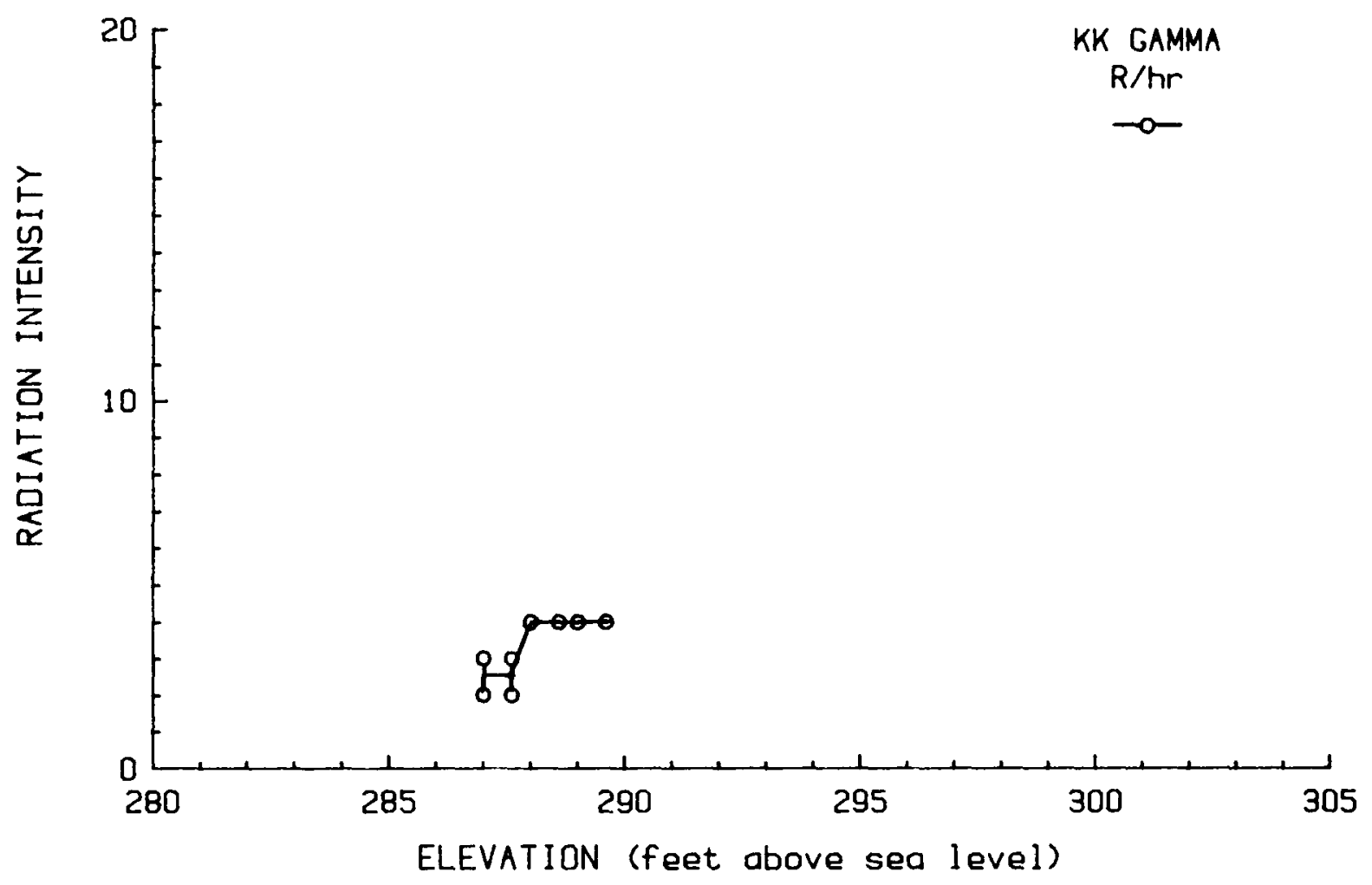

FIGURE 3.46. Dose Rate Profile at Robot Location KK 



\subsection{LOCATION OF RADIOACTIVITY IN THE BASEMENT}

The radioactivity in the basement appears to be in the: 1) reactor coolant drain tank (RCDT) and on the floor and walls surrounding the RCDT vent; 2) water and sludge on the floor and in the sump; 3) loose surface contamination in the paint on various painted surfaces, including the metal exterior containment wall, the concrete interior walls, the floor, and the concrete block walls; 5) concrete floor slab; 6) cast concrete walls; 7) hollow concrete block walls of the enclosed staimell and elevator shaft; and 8) water and sludge trapped in the elevator shaft. The bathtub ring occurs on all of the vertical surfaces.

\subsection{FUEL PARTICLES IN AND OUTSIDE OF THE REACTOR COOLANT DRAIN TANK}

Exposure rates were measured near the RCDT. The average gamma exposure rate was $7 \mathrm{R} / \mathrm{hr}$ at the 18 -inch vent line (using a teletector) and $19.0 \mathrm{R} / \mathrm{hr}$ facing the tank (TLD measurement) (GPU 1982). These exposure rates are due not only to the RCDT source but al so to exposures from nearby sources, such as the reactor building basement floor and walls.

The analysis of a sample taken from the RCDT in December 1983 showed $1.33 \mu \mathrm{Ci}$ of ${ }^{137} \mathrm{Cs}$ and $0.07 \mu \mathrm{Ci}$ of ${ }^{13}{ }^{4} \mathrm{Cs}$ per milliliter of liquid, and $96.7 \mu \mathrm{Ci}$ of ${ }^{135} \mathrm{Cs}$ and $5.7 \mu \mathrm{Ci}$ of ${ }^{134} \mathrm{Cs}$ per gram of solid material. The analysis also showed uranium, both in the liquid phase $(0.003 \mu \mathrm{g} / \mathrm{mL})$ and in the solid phase $(0.09 \mathrm{mg} / \mathrm{g})$ confirming that some fuel had been dispersed from the reactor by the accident (GPU 1982). From these data, we estimate that the inventory in the RCDT is at least 36.5 curies in the liquid phase. (The amount in the solid phase is unknown.)

The cesium in liquids and solids from the reactor building basement was discussed in detail in Section 3.0. Small amounts of uranium and plutonium were also present in both the water and the sludge. The analyses also indicated the presence of control rod material, cladding and structural material (Cox, Horan and Worku 1983). The variability of the sludge activity seems to indicate the presence of fine particulate fuel, control rod, and cladding material. The particulates are, however, nonuniform; there is no consistent ratio between uranium, plutonium, cerium-144 and the two cesium isotopes. However, the two cesium isotopes seem to be in a consistent ratio in all samples.

\subsection{WATER AND SLUDGE ON THE FLOOR AND IN THE SUMP}

The water remaining in the reactor building basement contains at least 440 curies of ${ }^{137} \mathrm{Cs}$. The activity in the sludge is much more difficult to predict because the sludge is extremely nonuniform. Estimates presented previously are based on sample results and range from 2.5 to 2700 curies. Some leaching has no doubt taken place since those samples were taken. The latest series of samples, taken in November 1983, led us to estimate that between 2.5 and 250 curies of ${ }^{137} \mathrm{Cs}$ are present in the sludge on the floor. Most of this activity is probably in a relatively small area between the RCDT vent and the incore instrument cable chase. 


\subsection{LOOSE SURFACE CONTAMINATION}

The primary coolant from the drain tank vent and the receding basement water have left radioactivity on surfaces where it is not chemically or mechanically attached but is smearable and removable by ordinary flushing and washing techniques. No smear surveys have been taken in the basement, but they have been done on upper elevations. A primary consideration on upper elevations has been the deposition, or fallout, of activity from airborne contamination. This is expected to be much less of a problem in the basement where the principal settling surface is covered with water. (Addition to the basement from fallout of airborne contamination is trivial, on the order of $0.02 \mathrm{Ci} / \mathrm{yr}{ }^{137} \mathrm{Cs}$. )

It was originally thought that some of the easily removed contamination was associated with oil that floated on the basement water and was left behind as the water receded. This has not been conclusively confirmed nor disproven. Efforts to remove this contamination by flushing or high-pressure washing from above have not yet made major changes in the dose rate.

Quantifying the loose contamination would help optimize basement cleanup efforts. This could be done by obtaining smears at various elevations above and below the previous water level and in areas where flushing has been attempted and where it has not been attempted.

\subsection{ACTIVITY IN PAINT}

The basement is painted to five feet above the floor surface. Some of the areas above this elevation and some of the overheads (piping, ducts, equipment, ceilings, etc., six or more feet above the floor) are also painted. Many paint and concrete samples from the 305-foot and 347-foot elevations have been analyzed. Cesium-137 activity on seven samples taken on the 305-foot elevation ranged from 0.001 to $5.3 \mu \mathrm{Ci} / \mathrm{cm}^{2}$, with an average of $0.85 \mu \mathrm{Ci} / \mathrm{cm}^{2}$ and a standard deviation of $1.96 \mu \mathrm{Ci} / \mathrm{cm}^{2}$. A similar group of nine samples from the 347-foot elevation ranged from 0.01 to $2.89 \mu \mathrm{Ci} / \mathrm{cm}^{2}$, with an average of $0.68 \mu \mathrm{Ci} / \mathrm{cm}^{2}$ and a standard deviation of $0.932 \mu \mathrm{Ci} / \mathrm{cm}^{2}$. These surfaces had all been flushed, and those on the 347-foot elevation had been extensively decontaminated. Basement paint that was submerged for years is expected to be higher, probably in the range 1.0 to $10 \mu \mathrm{Ci} / \mathrm{cm}^{2}$. The surface area of the paint that was submerged is about $22,000 \mathrm{ft}^{2}\left(20 \times 10^{6} \mathrm{~cm}^{2}\right)$. This paint is expected to contain between 20 and 200 curies of ${ }^{137} \mathrm{Cs}$.

Paint and concrete surfaces above the high-water level will have absorbed less cesium than the submerged surfaces. Cesium concentration in the range of 0.1 to $2.0 \mu \mathrm{Ci} / \mathrm{cm}^{2}$ seems reasonable. Assuming $26,000 \mathrm{ft}^{2}\left(24 \times 10^{6} \mathrm{~cm}^{2}\right)$, these painted surfaces contain between 2.4 and 48 curies of $137 \mathrm{Cs}$.

\subsection{CONCRETE FLOOR SLAB}

The activity contained in the concrete floor slab is partly dependent on the integrity of the floor coating and the integrity of the concrete itself. Concrete samples from upper elevations showed very little penetration of the 
activity into the concrete. This is consistent with data from an old, unpainted fuel storage basin at Hanford, where cesium concentration was shown to have penetrated less than eight millimeters (Bechtold 1981). While penetration of contamination deep into concrete may have occurred enough to affect waste disposal, it is doubtful that it will affect worker dose rates until very late in the cleanup process.

The quantity of radioactivity contained in the concrete floor slab in the SE quadrant was estimated using data obtained from the shielded teletector probe placed on the ROVER robot. Assuming the activity has penetrated to a maximum depth of $8 \mathrm{~mm}$, an estimated 180 to $195 \mu \mathrm{Ci} / \mathrm{cm}^{2}$ of $137 \mathrm{Cs}$ is contained in the concrete floor slab at this location. This estimate corresponds to 500 to 540 curies for the SE quadrant. A range of $60-280 \mu \mathrm{Ci} / \mathrm{cm}^{2}$ (160 to 780 curies for the SE quadrant) was obtained by varying some of the assumptions used in the initial analysis, such as the amount of water or sludge present on the floor or the concentration of $137 \mathrm{Cs}$ in the liquid phase. Details of the analysis are presented in Appendix B.

The activity calculated for the SE quadrant of the basement floor slab should not be extrapolated to other areas of the basement. Variations in water and sludge levels and in dose rates from other quadrants indicate that the distribution of activity on the floor was nonuniform and thus the distribution of activity in the concrete slab is most likely nonuniform.

\subsection{CAST CONCRETE WALLS}

There are both 3000-psi and 5000-psi concrete walls. The 3000-psi walls are those of the impingement area, the RCDT, and the leakage coolers. The 5000-psi walls form shields for the reactor pressure vesse1, the once-throughsteam generators, the pressurizer, and the reactor coolant system (RCS) piping, pumps, and associated equipment (Figure 4.1).

Generally, exposure rates are much higher near the 3000-psi concrete walls than near the 5000-psi concrete walls. The reason for this is not known. However, some of the robot video inspections show what appear to be stripes in some of the concrete, as if it had been poured in lifts of 1 to 2 feet. The surface of this concrete appears rough with some possible voids. Rougher concrete has more surface area than smooth concrete and may entrain some contaminated water.

The licensee's estimate of the amount of activity that has penetrated into concrete walls is based on an assumed uniform penetration depth of 1 inch and an assumed complete saturation. These assumptions yield worst case estimates, and, for dose and curie estimates, we find it more reasonable to assume that significant penetration is about a millimeter below the paint. (For waste volume estimates though, it is reasonable to assume that all the concrete would require disposal as radioactive waste.)

The amount of activity in the loose contamination and in the paint is expected to overshadow the amount in the subsurface concrete. Thus, the source term estimate is not substantially affected by the activity that has penetrated the concrete surfaces. 


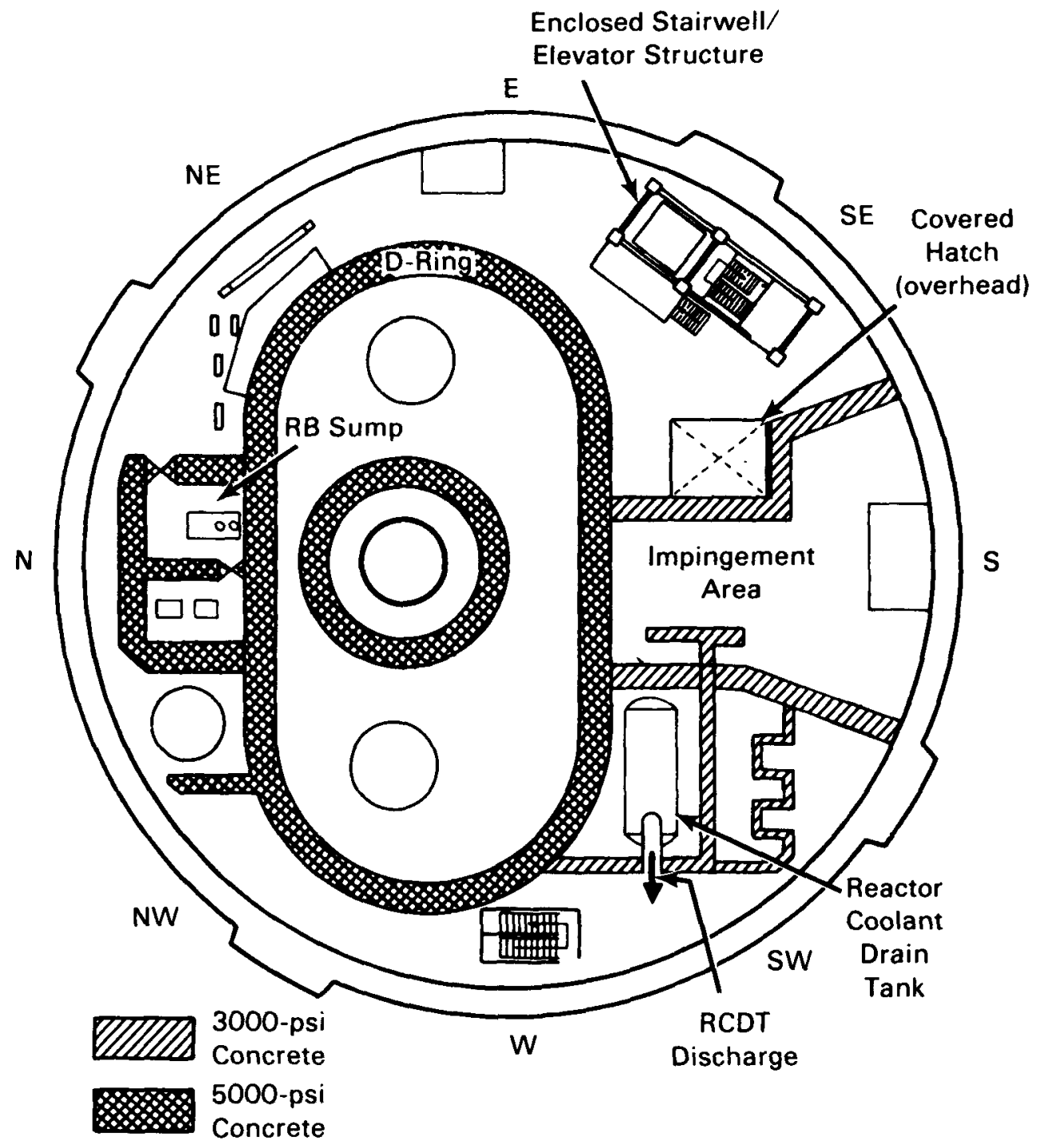

FIGURE 4.1. Types of Concrete in the TMI-2 Basement

\subsection{HOLLOW CONCRETE BLOCK STRUCTURE - ENCLOSED STAIRWELL/ELEVATOR SHAFT}

The licensee has modeled the enclosed stairwell/elevator shaft concrete block structure based on two TLD strings hung near the stairwe 11: B-3 was hung in the center of the stair portion of the stairwell; B-13 was hung 4.75 feet behind the stairwell.

The walls of the enclosed stairwell are hollow concrete blocks, $20.32-\mathrm{cm}$ thick, with some reinforcing material. The structure is painted on the outside (to five feet above the floor) with a nuclear grade paint. The licensee modeled the blocks of the structure as a homogeneous substance composed of concrete and air with a density of $1.07 \mathrm{gm} / \mathrm{cm}^{3}$. The stairwell itself, consisting of stairs, platforms and support steel, was modeled as a homogeneous substance of steel and air, neglecting attenuation by treads and platforms. The 
source was assumed to be uniform horizontally through the thickness of the concrete. The variation of activity vertically was based on the exposure rate variation from the TLD strings. Contributions from other radiation sources were considered negligible. The activity in the elevator pit was neglected. The calculated activity in the enclosed stairwell/elevator shaft was estimated to be approximately 11,000 curies of $137 \mathrm{Cs}$ and 700 curies of $134 \mathrm{Cs}$. (The ${ }^{134} \mathrm{Cs}$ activity is based on the ratio of ${ }^{137} \mathrm{Cs}$ to ${ }^{134} \mathrm{Cs}$ in the basement water.)

The authors also modeled the enclosed stairwell/elevator shaft structure with an inhouse point kernal shielding code. Appendix C contains a description of the model. We estimated approximately 19,000 curies in the concrete blocks. The assumptions used in both models are reasonable. We believe our estimate is conservative. Between 11,000 to 19,000 curies is a likely range for the activity in the enclosed stairwell/elevator shaft.

The volume of the submerged concrete blocks is about $400 \mathrm{ft}^{3}$. If this volume were occupied by the most contaminated water $(174 \mu \mathrm{Ci} / \mathrm{mL})$ in the reactor building, it would include 2,000 curies. Some concentration or absorption would have had to occur for there to be 11,000 to 19,000 curies in this source, as was estimated for the enclosed stairwell/elevator shaft. This is possible considering the surface area of the concrete blocks, the time that the blocks were submerged, the penetration of contamination into paint, as was observed elsewhere in the reactor building, and the unpainted blocks on the inside surface of the stairwell/elevator shaft structure.

\subsection{WATER AND SLUDGE IN THE ELEVATOR SHAFT}

Because the entrance to the elevator shaft is about four feet above the bottom of the elevator shaft and three feet above the basement floor and there is no drain, water and contamination from the accident remained trapped in the shaft following the accident. The shaft was flushed and pumped out but some contamination probably remains. The elevator equipment in the shaft may be internally contaminated. At the very least, contamination levels on the shaft walls will be as high as they are on the other walls and vertical structures in the basement, and contamination levels on the shaft floor will be as high as they are on the floors of the other portions of the basement that were filled with accident water.

\subsection{SUMMARY OF THE LOCATION OF THE ACTIVITY IN THE BASEMENT}

Based on the preceding analysis, we estimate that the roughly quantified basement sources contains between 12,000 and 21,000 curies of ${ }^{37} \mathrm{Cs}$. This information is summarized in Table 4.1 . 
TABLE 4.1. Cesium Activity in the Basement

\begin{tabular}{|c|c|}
\hline Location & Curies of $137 \mathrm{Cs}$ \\
\hline Reactor coolant drain tank & $\begin{array}{l}36.5 \text { (minimum in } \\
\text { liquid phase) } \\
\text { unknown (solid } \\
\text { material) }\end{array}$ \\
\hline Water on the floor & $440 \pm 20 \%$ \\
\hline Sludge on the floor & 2.5 to 250 \\
\hline Loose surface contamination & unknown \\
\hline Paint (below water level) & 20 to 200 \\
\hline Paint (above water level) & 2.4 to 48 \\
\hline $\begin{array}{l}\text { Concrete floor slab } \\
\text { in SE quadrant }\end{array}$ & 160 to 780 \\
\hline $\begin{array}{l}\text { Concrete floor slab in } \\
\text { other quadrants }\end{array}$ & unknown \\
\hline Cast concrete walls & unknown \\
\hline Hollow concrete block & 11,000 to 19,000 \\
\hline $\begin{array}{l}\text { Water and sludge in the } \\
\text { elevator shaft }\end{array}$ & unknown \\
\hline
\end{tabular}




\subsection{CLEANUP OF THE TMI-2 BASEMENT}

This section discusses the work that must be done to clean the reactor building basement and the occupational dose consideration that will effect that cleanup. Possible cleanup approaches are then discussed and evaluated.

\subsection{BASEMENT CLEANUP}

The basement condition is not particularly important to the activities that are being conducted in the reactor building at the present time, except as it may affect the radionuclide concentration in air. However, full cleanup from the accident will require that the basement be cleaned (most partial cleanup scenarios being discussed also require some basement cleanup). At the present time, it is thought that cleanup will be complete when the radiation levels in the building are no higher than they would be at an operating reactor. For the basement, this probably means that most areas must be cleaned to between 10 and $100 \mathrm{mR} / \mathrm{hr}$.

Cleanup will require the removal of basement sludge, the decontamination or removal of essentially all surfaces that were exposed to accident water, and the removal of other contaminated structures, such as ventilation ducts and overhead lighting fixtures that were exposed to accident conditions. Nonporous, nonabsorbent surfaces, such as polished stainless steel, may be decontaminated by scrubbing or high-pressure water blasting, but most basement surfaces are expected to require much more extensive decontamination methods. Electric motors, electrical conduits, fire hoses, and other structures with inaccessible contamination will require aggressive decontamination or, more likely, removal and disposal as radioactive waste. At least the outside surface of the concrete will have to be removed, and the hollow concrete block will have to be removed completely.

As indicated previously, if this work were performed manually, it would result in several thousand person-rem of radiation dose to the workers, and it is not certain that without innovative approaches all of the work could be done without exceeding NRC quarterly occupational dose limits. This fact accounts for the NRC's interest in the alternatives for dealing with the basement.

\subsubsection{Removal of Sludge and Fuel Particulates}

Probably one of the first cleanup tasks is removing sludge and fuel particulates. The licensee is now planning this work but no firm schedule has been established. The sludge contains some radioactivity and would be an industrial safety hazard if it were present when workers enter the basement.

Sludge and fuel particulates may be removed by rinsing them to the sump and pumping them out or by vacuuming. Moving the sludge to the sump will require that the water level in the basement be dropped below the present level. Vacuuming techniques may not require this. Any sludge removal 
technique is likely to miss some of the sludge but should effectively remove the majority of it. The primary impediment to sludge removal is the need for a system to filter or settle large quantities of solids out of solution.

Fine fuel material is primarily associated with sludge on the floor. There may also be fuel particulates on the walls and overheads in the vicinity of the reactor coolant drain tank (RCDT) vent. Any desludging technique such as moving the sludge with low pressure to the sump or vacuuming would also remove the fuel particulates from the floor. Low-velocity flushing may remove the overhead fuel particulates, or high-velocity flushing may be required.

Sludge and particulate fuel material will be subject to leaching, even with only a few inches of water in the basement. As these particulates have been in an aqueous environment for the last several years, the present rate of leaching is expected to be relatively low, but it may be enhanced by effective rinsing. Even with several years of leaching, the dose rate from fuel particulates probably would not decrease significantly, although the particulates might contribute significantly to the number of curies removed.

Leaching with cesium-free or low-cesium water is expected to be effective for removing cesium from the sludge that does not contain fuel particulates, provided there is good contact between the solids and the water.

Routine pumping from the sump might accelerate the transport of siudge to the sump. Because the sump has two parts, where solids settle on one side and the normal outlet is on the other side, the installed sump pump is not expected to efficiently transport sludge and fuel debris out of the building. The licensee is considering putting a small-diameter well-type pump through a line into the settling side of the sump to remove solids. There are no plans to do this until a solid separation and solidification system is ready. This should be more effective than pumping with the installed system, but it is expected that there still will be highly contaminated solids in the sump until late in the basement cleanup process.

\subsubsection{Hollow Concrete Block}

There is little doubt that the hollow concrete block of the elevator shaft and enclosed stairwell is highly contaminated throughout (not just on the surface). It will be the major contributor to basement dose rates until it is removed, cleaned, or shielded. Flushing, scrubbing, scabbling, or other surface approaches are not expected to be effective. The quality of the paint on the outside of the structure and the relatively small interstitial spaces in the blocks will make leaching very slow. Leaching might be faster if the concrete were broken to expose a greater surface area and to allow better water contact.

Concrete block, which is reportedly of the same composition as the concrete block in the basement, was removed from the auxiliary building. This block is being tested for unusual cesium ion exchange properties that might account for the observed dose rates. If the block is determined to be relatively leachable, it could be broken up in the basement, covered with 
water, and leached. If, however, it proves to be a highly selective cesium ion exchanger, such action might make working conditions in the basement much worse than they are now, because newly exposed concrete block material would pick up cesium from the water and from any other sources that were being leached. The results of the test on the block are pivotal to making any recommendation regarding the elevator shaft and enclosed stairwell.

The hollow concrete block section of the elevator shaft does not extend beyond the 302-foot elevation. At the point where the 305-foot-elevation floor above begins, the structure of the elevator shaft changes. (Between the 302-foot elevation and the 305-foot elevation is a solid support structure that is part of the 305-foot-elevation floor.) Although the elevator shaft below the 302-foot elevation is constructed of hollow concrete block, it does have some seismic restraining devices. Methods of remotely dismantiing it have not yet been engineered but are likely to include hydraulic expansion devices, plasma arc or mechanical cutting devices, and shaped explosives. Explosives have been used successfully at other nuclear facilities. There are specially shaped pipe-cutting explosives and other shaped charges that can be accurately controlled. The biggest problem with using explosives is expected to be the generation of airborne contamination within the reactor building. Damage to safety systems or breach of containment is not expected.

Whether demolition of the elevator shaft is done with conventional devices or with explosives, it must be done entirely remotely. This will require considerable planning and preparation.

\subsubsection{Vertical Surfaces}

Once the concrete block has been removed and/or leached, the next largest dose contributor may be either miscellaneous contamination traps, such as tool boxes and insulation, or it may be the vertical concrete surfaces, some of which appear to be extremely porous. Tool boxes and pipe insulation will be removed remotely or possibily semiremotely and disposed of. Attachment to tool boxes might be done robotically or with long-handled tools through the open hatch. Vertical painted and unpainted surfaces have a bathtub ring that contains both oil (or dirt) and relatively high levels of contamination. The ring on the painted metal outside wall of containment seems resistant to low-pressure flushing, and past attempts at high-pressure flushing have not been very satisfactory. However, if pressures are high enough and distances optimized, high-pressure water should be able to remove this material; but then it might also remove the paint and allow rusting of the metal. Removal of the paint from the concrete D-rings and walls will not have this effect. Scrubbing would probably help loosen contamination except on very rough surfaces. However, normal scrubbing methods are labor intensive. The Navy uses a magnetically attached device to remotely scrub the outside of metal vessels. Such a device (with minor modifications) might be applicable to the inside of containment, which is also metal. D-ring walls and other concrete surfaces would require other methods.

If the contamination is physically or chemically associated with oil, then detergents, steam, or solvents would probably be beneficial. 
Experiences on the upper levels of the TMI-2 containment structure indicate that the nuclear grade paints used in TMI-2 may pick up cesium when exposed to aqueous cesium solutions over long periods of time. The cesium is not readily released by flushing unless the paint is removed. A prolonged leach in clean water is expected to result in a slow but measurable reduction in cesium activity. A prolonged leach in highly contaminated water (that might result from leaching other sources) could incorporate additional cesium into the paint layer.

The scabblers presently in use on the upper elevations are not adapted for work on vertical surfaces, and removal of the bathtub ring may require either extensively modifying the equipment or drilling holes and inserting an expansion head to spall off the surface. The latter operation is quite slow and if performed manually might be a significant source of radiation exposure. However, the process is probably one that could be adapted for robots. This process might also be an acceptable alternative to core boring for sample collection.

The 5000-psi concrete is quite smooth and contains much less activity than the 3000-psi concrete. The activity in the 3000-psi concrete is much deeper, and more of the concrete will require removal. It is also possible that contamination has penetrated much deeper into the unpainted concrete and that surface removal will have to go beyond the 2 inches achievable in a single pass by most of the available scabbling equipment.

\section{1 .4 Floors}

At some time, probably well into the basement cleanup, the floor will become an important potential contributor to occupational doses, just as the floor of the 347- and 305-foot elevations were found to be. The floor of the basement is coated. The coating will probably be intact in most locations and is likely to be contaminated. Scabbling of the floor should take care of the majority of the contamination on the floor. At the expansion joint where the floor meets the wall, there is a caulking or joining compound, which is likely to be contaminated. If this material is a significant radiation source, conventional jack hammers could be used to remove it.

\subsection{OCCUPATIONAL DOSE CONSIDERATIONS FOR BASEMENT CLEANUP}

The NRC limits the maximum permissible occupational dose to an individual to $3 \mathrm{rem} / \mathrm{calendar}$ quarter for whole-body radiation dose, provided that certain conditions regarding lifetime dose limitations are met. To date, the licensee has established even stricter control limits (NRC 1984). The radiation dose rates in the basement are so high that the quarterly maximum permissible wholebody dose would be reached in a short period of time ( 21 seconds at $500 \mathrm{R} / \mathrm{hr}$, 18 minutes at $10 \mathrm{R} / \mathrm{hr}$ ). The time constraints essentially preclude hands-on work in areas around the enclosed stairwell and severely limit work in other areas. Federal limits on the dose to the skin and extremities may be more restrictive for work in some basement locations, further limiting the time a worker may spend. 
Three methods can be used to decrease the dose that a worker receives: decreasing the time of exposure to radiation; increasing the distance between the worker and the radiation source; and increasing the shielding between the worker and the radiation source. These basic techniques, including some highly engineered and sophisticated applications, have permitted much of the progress to date in the cleanup of TMI, and they will most certainly be important in cleanup of the basement. Past and possible future applications are enumerated briefly in the remainder of this section.

Time to do radiation work has been minimized by training, the use of mockups, and by air conditioning the reactor building. Time spent in the basement was minimized by careful planning and training to reduce radiation dose to the worker who entered the basement down the open stairwell. Future entires can be made quickly by well-practices and we11-trained workers.

Distance has been used to reduce radiation dose on the many occasions when long-handled tools have been used for sample collection in both the containment and auxiliary buildings. The practice of observing and instructing workers by video camera and communicating by head sets also employs distance to reduce doses. Distance is expected to play a useful role in the placement and removal of equipment in the basement and for waste handling (probably in conjunction with the other two techniques).

Shielding of floor drains and penetrations has prevented considerable occupational exposure in the cleanup performed on the upper elevations and the use of shielded enclosures saved dose during head and plenum lift operations. Shielding (possibly placed by robots) will probably be an important dose reduction tool in basement cleanup.

Some specific techniques that might prove beneficial for cleanup of various parts of the basement are discussed in Appendix D.

\subsection{POSSIBLE CLEANUP APPROACHES}

Any particular approach to cleanup of the basement must be an integrated approach that takes into account the current basement conditions, the fina? cleanup objective and the available dose reduction methods and techniques. The approach so far, which has centered on using robots and working remotely from the upper elevations, is expected to continue, at least until the dose rates have been reduced sufficiently to permit workers to enter the basement. Other approaches might be used following or in conjunction with the robotic approach. Several of the approaches discussed below will probably be needed to clean the basement. We expect that basement cleanup can be completed within the 4,800 to 17,000 person-rem estimate in NUREG-0683 (NRC 1984).

\subsubsection{Robotics and Work From Above}

Basement cleanup may be continued using a combination of robotics and work through penetrations from the upper elevations. The characterization program is proceeding this way now, and the robot will probably be able to handle a hose nozzle to help desludge the basement. Some cleaning of metal 
components with high-pressure water could also be done by the robot or through penetrations from the 305-foot elevation. With sufficient planning and programming, the present or some other currently available robot should be able to detach tool boxes, fire hose racks, wood frame doors and other basement debris and attach cables to drag them to the hatch for removal. The occupational dose resulting from raising and lowering robots and from handling the waste in this way (even if the wastes were rinsed off on the way up) would still be significant.

Robots could be programmed to do vertical scabbling of walls, although it would be a slow process that would probably require periodic hoisting of the robot for replacement of drill bits and other equipment. The removal of scabbling debris would be time consuming, requiring picking up large chunks and vacuuming smaller ones. Again, the dose at the 305-foot elevation from hoisting and handling the waste would be considerable, but could be minimized by good ALARA practices.

So far, the robot has been able to reach only the NE, SE, and portions of the SW quadrants. It is extremely unlikely that the present robot or most others could pass between the 3000-psi concrete baffle wall surrounding the leakage coolers in the SW quadrant and the outer wall of the basement. The passage from the NE quadrant to the NW quadrant is only slightly less difficult. The robots used to date at TMI cannot negotiate stairs that have landings, and this is expected to continue to be a problem in reaching the NW quadrant and portions of the SW quadrant.

Just how far cleanup could progress with robots and remote work is uncertain. Significant reductions in dose rates are expected to be slow and time consuming.

\subsubsection{Shielded Locations Within the Basement}

One method for worker access to the basement in the near future is the beachhead approach of constructing a shielded area within the basement, eliminating sources within the shield and slowly enlarging it. It might, for instance, be possible to lower 6-foot columns into the area directly below the covered hatch and then fill them with water to create a low-dose island within the basement. From this area, workers could be lowered to perform tasks such as scabbling the floor and adding additional columns to enlarge the area (in a possible labyrinth design). Workers would also need to eliminate overhead sources or erect overhead shielding. The area could be gradually expanded to include a small portion of the D-ring wall, which could then also be scabbled. Continued progress could be made in this way. The most important operational consideration in such an approach would be the elimination of waste. Radiation doses for waste handling would also be significant.

This approach would probably be satisfactory for all areas except the elevator shaft. The dose rates in the shaft vicinity are so high that including any part of it in an occupiable area is expected to be unacceptable. 


\subsubsection{Reflooding the Basement}

Reflooding the basement could achieve a variety of objectives, including reducing dose rates on the 305-foot elevation, removing cesium, and eliminating airborne contamination. The flooding approach, that has been considered from time to time during cleanup, would only slightly lower the dose rates on the 305-foot elevation. Dose to cleanup the basement would also be reduced only slightly by a prolonged leach because most of the cesium that would be removed by the process would probably come from the hollow concrete block of the stairwell and elevator shaft. The reduction in dose rate around the structures would not be sufficient to permit hands-on demolition and the reduction in area dose rate would not permit prolonged occupation of other parts of the basement without additional shielding.

There is, however, another possible flooding approach to the cleanup. The basement could be flooded, and divers could work within the shielding provided by the water. While nuclear divers have been used at other facilities, generally in fuel storage basins, deliberately flooding a high-dose-rate area to use divers would be new to the industry. Divers would receive essentially no radiation dose from any source farther than about 3 feet away, except for the dose from immersion in contaminated water. However, it should be possible to keep the dose rate from the water below $1 \mathrm{mR} / \mathrm{hr}$. Airborne contamination from cleanup activities would not be a problem in the basement, and exposure to beta radiation would be eliminated by both the water and the design and construction of the diving suits. However, health physics procedures for such an operation are not well established; and monitoring extremity dose and controlling contamination so that it does not get on the skin are extremely important.

Underwater workers are likely to be less than half as efficient (at most tasks) as workers in ordinary anticontamination clothing and respirators. There is no currently available equipment for procedures such as concrete scabbling underwater, so considerable equipment modification and equipment development would be required. Recontamination of cleaned surfaces could be a problem if the radioactive materials taken from surfaces were not promptly removed. Survey methods to determine if an area has been adequately cleaned might also pose some difficulty. Lighting and water clarity are important to diver safety and are expected to be difficult to maintain in these circumstances. Training the divers in diving safety, radiation protection and work performance would be necessary. Water processing costs would be significant.

The elevator shaft would still be a problem in the flooded basement but relatively simple long-handled tools would suffice to keep exposures to tenable levels.

Waste removal would still be a source of radiation dose, but it could be minimized by carefully packaging the waste in drainable containers underwater and lifting these into shielded transport casks. 
The total radiation exposure from underwater cleanup of the basement to the levels of an operating reactor would be much less than with any other identified technique except robotics, and the robots required to do the cleanup are not currently available. Decontamination equipment and health physics instruments could be modified to do the basement cleanup underwater. 


\subsection{CONCLUSIONS}

Tentative conclusions from the available data on the TMI-2 reactor building basement are discussed below. These are based on limited data, and if actual basement conditions are found to be different from those described in the preceding sections, these conclusions would have to be reconsidered.

1. Radiation sources in the TMI-2 basement are expected to have only a minor effect on doses to defuel the reactor. Doses for defueling are expected to be toward the lower end of the 2,600 to 15,000 person-rem predicted in the first supplement to the PEIS.

2. Core drilling planned for the basement will require several entries by the robot, because currently available concrete coring bits are capable of drilling only one or two holes before replacement. Raising and lowering the robot requires about 10 person-rem, so it would be advantageous to obtain sample data with as few cores as possible. We believe that data from smear surveys, as have been taken by robots in some of the cells of the auxillary building, would be beneficial and should be considered. We also believe that setting up a robot to do concrete spalling (by drilling a hole, inserting an expansion head, expanding the head hydraulically, and collecting the large pieces) might be acceptable and would have the added advantage of developing a possibly useful cleanup method.

3. The greatest reduction of the dose rate on the 305-foot elevation from basement sources will be from decontaminating the upper portions of the basement walls, penetrations, and structures, not from removing the sources on the floor or the bathtub ring. Decontamination efforts should concentrate on the flow path of the contaminated air during the accident.

4. There are unknowns and uncertainties in the basement radiation levels but it is probably not extremely important to characterize them until the initial work of bulk sludge removal and hollow concrete block removal has been completed. At that time care should be taken to assure that TLDs are sufficiently close together that sources can be identified.

The TLD measurement program could be expanded and the data could be used to mathematically model or mathematically construct isodose curves or, because there are significant variations in dose rate with elevation, isodose surfaces. Lines perpendicular to the surfaces will then pass through and thus identify the significant sources. This modeling would be premature with the existing data. We strongly recommend such a program after the major sources, such as the elevator shaft/enclosed stairwell and accessible bathtub ring, have been dealt with remotely.

5. The requirement that only borated water be used in the basement increases water processing cost (if radionuclides other than cesium are removed) and leads to the formation of borate crystals on surfaces that have been 
flushed. Borated decontamination solutions are also thought to contribute to airborne contamination in the building. Although there is no conclusive proof that deborated water would work better for decontamination and leaching, we believe a program to resolve the remaining uncertainties and use water that does not contain boron should be vigorously pursued.

6. Maintaining 10,000 gallons of water in the building may not be the best course of action. Controlling airborne contamination is, of course, important, but a complete pumpdown would cause sludge and fuel particulates to be transported to the sump where radioactivity could be removed. When there are occasions to remove water from the basement over the next few years, we believe that it should be removed from the reactor building sump to facilitate the flow of water and maximize the removal of solids from the sump.

7. The hollow concrete block of the elevator shaft and enclosed stairwell is expected to contain between 11,000 and 19,000 curies of ${ }^{137} \mathrm{Cs}$. Surface dose rates may exceed $1000 \mathrm{R} / \mathrm{hr}$. Removal of this source is required before routine entry to the basement. Remote removal is virtually a necessity.

8. Other quantified basement sources contain between 570 and $1800 \mathrm{Ci}$ of ${ }^{137} \mathrm{Cs}$. There are numerous unquantified sources as well.

9. The concrete block should be tested for the possibility of significant reductions in the dose rate from breaking up the hollow concrete block structures and then leaching them on the basement floor.

10. While the majority of solids in the basement are not contributing significantly to the dose rate, there appear to be some highly radioactive solids deposited through the reactor coolant drain tank vent. Flushing these from the walls and upper elevations and then from the floor to the sump (or removing them from the floor by wet vacuuming) would be beneficial. This might also help establish the quantity of fuel to be expected in the basement and therefore be important in eliminating the requirement for using only highly borated water for the cleanup.

11. Any decision about basement cleanup should be based on an evaluation of the options of constructing shielded work areas and flooding the basement for divers as well as using robots and other devices that can be manipulated from above. 
APPENDIX A

REACTOR BUILDING WATER LEVEL DATA 
. 
TM] UNIT*2 REACTOR BUILDING SUMP LEVEL (1981)

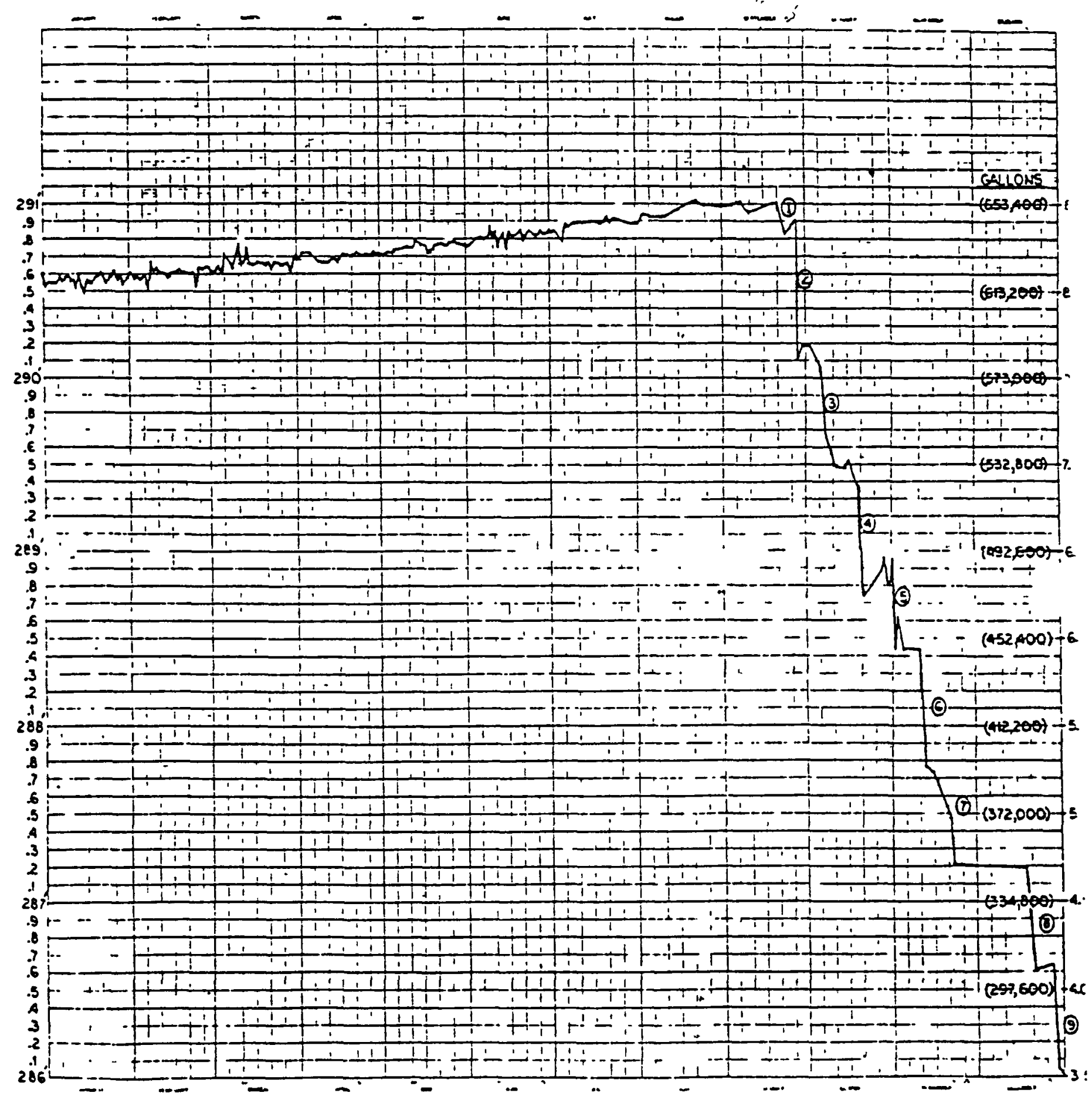


IMI UNIT* 2 REACTOR BUILDING SUMP LEVEL (1984)

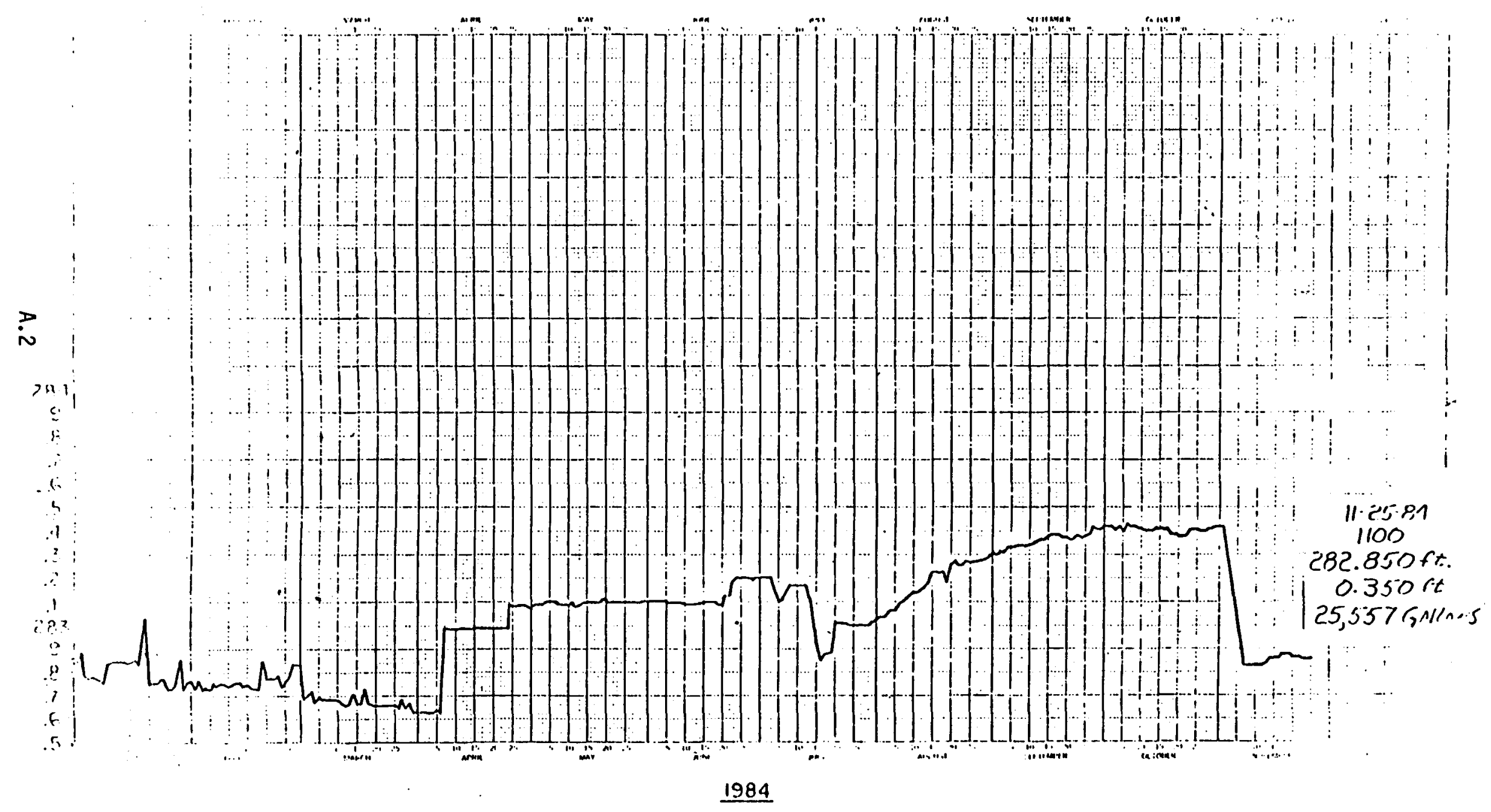




\section{TMI UNIT 2 REACTOR BUILOING SUMP LEVEL (1982)}

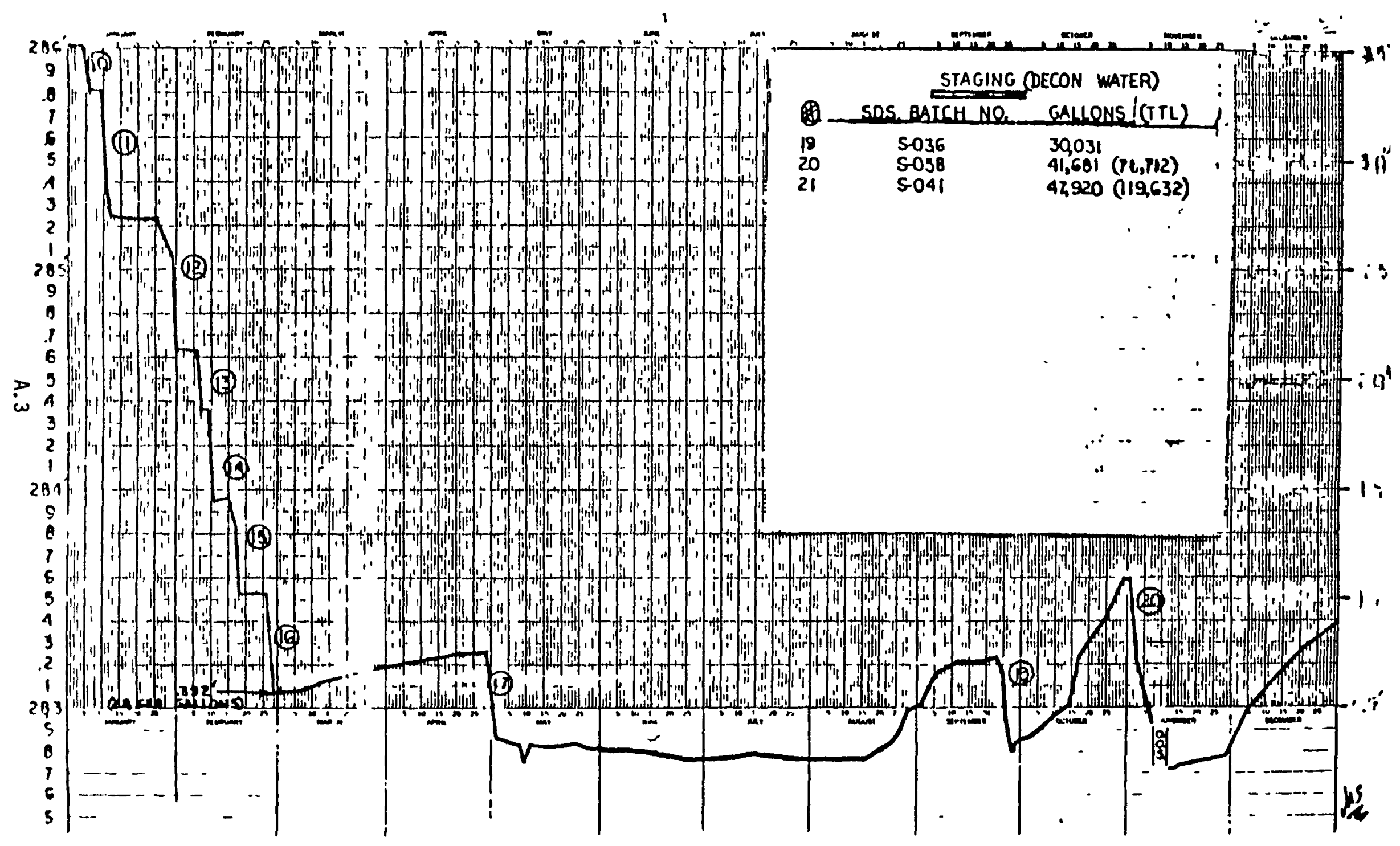




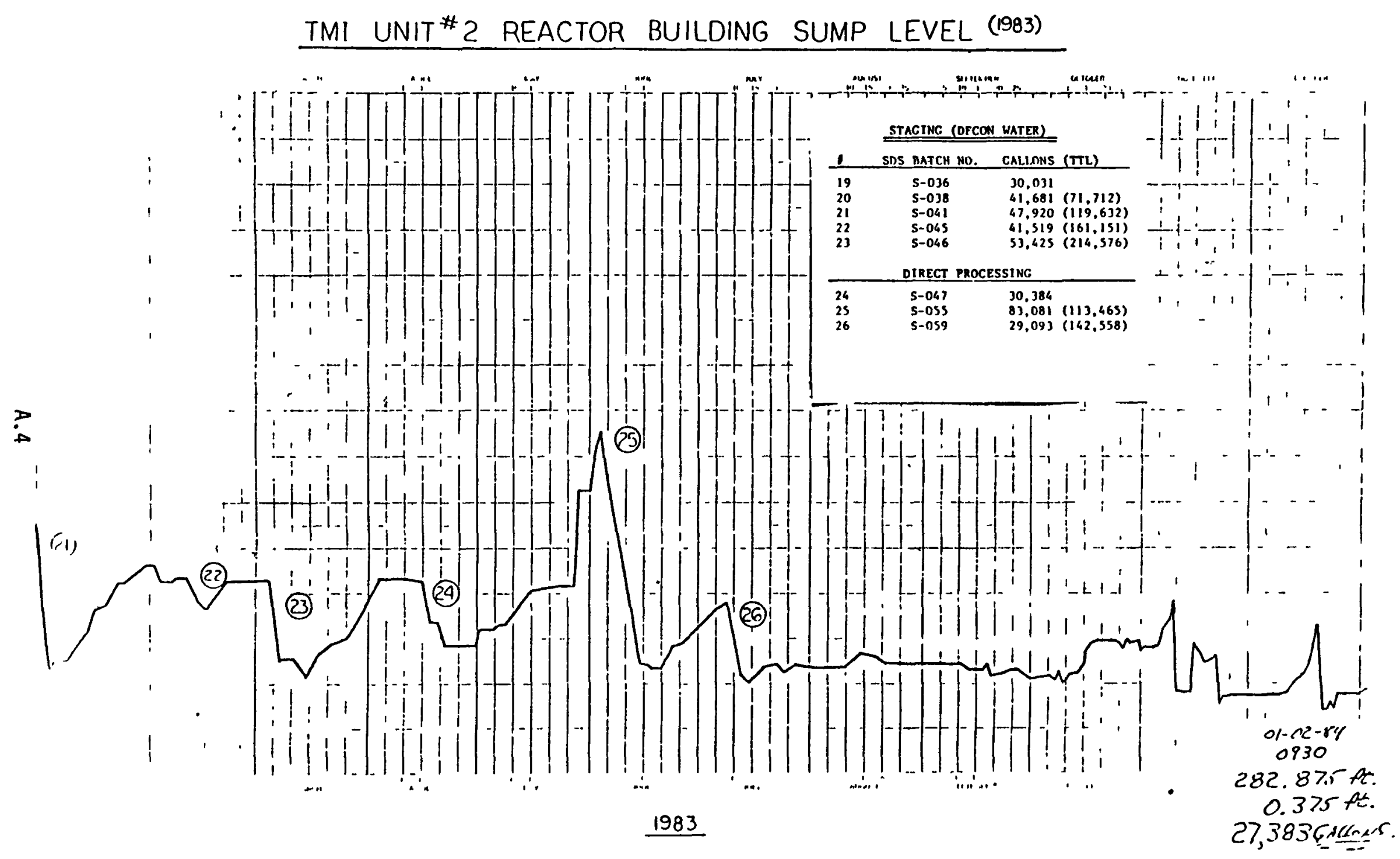


APPENDIX B

MODEL OF THE CONCRETE FLOOR SLAB 
. 
APPENDIX B

MODEL OF THE CONCRETE FLOOR SLAB

The amount of activity contained in the concrete floor slab in the SE quadrant was estimated using data obtained from the shielded teletector probe placed on the ROVER robot. The shield was positioned above the detector. The probe was located 5 inches above the floor.

On 15 November 1984, data was obtained at seven locations in the SE quadrant of the basement. The locations are shown in Figure 3.10 (main text). The teletector readings at points $T, U, V, W$ and $X$ were $2-3 \%$ of the general area dose rate. At points $Q$ and $S$, the teletector read 12-14\% of the general area dose rate.

An angular response study indicated that the detector responded to sources located above the shield by reading $2 \%$ of the actual dose. The dose from the floor at points $T$ through $X$ was considered to be negligible compared with the high background readings. The proximity of the enclosed stairwell/ elevator shaft structure accounts for the high general area dose rates at locations $T$ through $X$. The data from locations $Q$ and $S$ were used for this analysis. The measurements from these locations were adjusted to account for the $2 \%$ contribution to the dose from the general area dose.

The floor slab was modeled as a solid cylindrical disk with a height of $0.8 \mathrm{~cm}$. The depth of penetration of ${ }^{137} \mathrm{Cs}$ was assumed to be $0.8 \mathrm{~cm}$ or less based on the data from an unpainted fuel storage basin at Hanford (Bechtold 1981). A layer of sludge covers the concrete floor. The sludge was assumed to have a density of $1.5 \mathrm{~g} / \mathrm{cm}^{3}$ and a depth of 2 inches. This assumption was based on observing the videos of the sludge and water being perturbed by the cable on the ROVER robot. A layer of water covering the sludge to a depth of 4 inches above the surface of the floor was assumed to contain an average activity of $4.9 \mu \mathrm{Ci} / \mathrm{cm}^{3}$ of ${ }^{137} \mathrm{Cs}$ based on the concentration of ${ }^{137} \mathrm{Cs}$ in the water during the previous basement pumpout. The concentration of activity in the water associated with the sludge was assumed to be $9.8 \mu \mathrm{Ci} / \mathrm{cm}^{3}$, twice that in the water. The teletector was assumed to measure a circular area on the floor of about $44 \mathrm{~cm}$ in diameter based on the angular response data, which indicated that the dose measured by the teletector decreased steadily at angles greater than 60 degrees off-center.

Between 180 and $195 \mu \mathrm{Ci} / \mathrm{cm}^{2}$ were estimated using an inhouse point kernal shielding code that models solid cylinders. This estimate resulted in 500 to 540 curies of activity in the concrete floor slab in the SE quadrant of the reactor building basement (the area within the D-rings was not included). The activity calculated for the SE quadrant of the basement floor slab should not be extrapolated to other areas of the basement. Variations in water and sludge levels and in dose rates from other quadrants indicate that the distribution of activity on the floor is nonuniform and thus the distribution of activity in the concrete slab is probably nonuniform. 
Table B.1 indicates how variations in the assumptions would change the result of the analysis. Varying the depth that ${ }^{137 C s}$ penetrates into the concrete $\mathrm{slab}$, within the range of 0.1 to $0.8 \mathrm{~cm}$, would cause little change in the amount of activity estimated to be present in the slab. The depth of the sludge above the floor also does not greatly impact the amount of activity calculated in the floor slab. Increasing the density of the sludge to that of

TABLE B.1. Effect of Various Assumptions on the Estimate of the Curie Content in the Concrete Floor Slab

Assumptions

Initial Assumptions

- $137 \mathrm{Cs}$ depth in concrete slab $-0.8 \mathrm{~cm}$

- Depth of sludge - 2 in.

- Depth of water (from floor) - 4 in.

- Activity in water $-4.9 \mu \mathrm{Ci} / \mathrm{cm}^{3}$

- Activity in sludge $-9.8 \mu \mathrm{Ci} / \mathrm{cm}^{3}$

- Density of sludge $-1.5 \mathrm{~g} / \mathrm{cm}^{3}$

Depth of $137 \mathrm{Cs}$ in Concrete Slab

$-0.8 \mathrm{~cm}$

- $0.4 \mathrm{~cm}$

$-0.1 \mathrm{~cm}$

Depth of Sludge

- 1 in.

- 2 in.

- 3 in.

Density of Sludge

$-2.3 \mathrm{~g} / \mathrm{cm}^{3}$

- $1.5 \mathrm{~g} / \mathrm{cm}^{3}$

$-1.0 \mathrm{~g} / \mathrm{cm}^{3}$

Depth of Water

-3 in.

- 4 in.

-5 in.

- 6 in. $\mu \mathrm{Ci} / \mathrm{cm}^{2}$

195

Activity in Water/Sludge

$-0.0 \mu \mathrm{Ci} / \mathrm{cm}^{3}$

- $4.9 \mu \mathrm{Ci} / \mathrm{cm}^{3}$

- $\quad 10 \mu \mathrm{Ci} / \mathrm{cm}^{3}$

Activity in Sludge

- $4.9 \mu \mathrm{Ci} / \mathrm{cm}^{3}$

- $9.8 \mu \mathrm{Ci} / \mathrm{cm}^{3}$

- $19.6 \mu \mathrm{Ci} / \mathrm{cm}^{3}$ 
concrete $\left(2.34 \mathrm{~g} / \mathrm{cm}^{3}\right)$ increases by less than $25 \%$ the estimated activity in the floor. Decreasing the density of the sludge to $1.0 \mathrm{~g} / \mathrm{cm}^{3}$ decreases the estimated floor activity only slightly.

The depth of water on the basement floor at the measurement locations may be critical to the analysis. Water standing to a depth of 5 inches or more above the floor will cause our estimate of 180 to $195 \mu \mathrm{Ci} / \mathrm{cm}^{2}$ to be conservatively high. If the upper level of the water is 6 inches above the floor (so that the detector is under 1 inch of water), the activity in the slab is calculated at $60 \mu \mathrm{Ci} / \mathrm{cm}^{2}$.

If the activity in the water is less than the estimated $4.9 \mu \mathrm{Ci} / \mathrm{cm}^{2}$, the activity in the concrete slab would be higher than our calculated estimate. If the concentration of activity in the water is higher than $4.9 \mu \mathrm{Ci} / \mathrm{m}^{3}$, we would expect less activity in the floor slab. The same relationship holds for the activity in the interstitial water of the sludge; the greater the concentration of activity in the sludge, the smaller the amount of activity in the concrete slab.

Thus, by varying the assumptions, the amount of activity in the floor slab may range between 60 and $280 \mu \mathrm{Ci} / \mathrm{cm}^{2}$ (160 to 780 curies) for the SE quadrant. The range of parameters used in this analysis includes the realistic extremes for each assumption. Therefore, the activity present in the floor slab of the SE quadrant will most likely fall within the range of 60 to $280 \mu \mathrm{Ci} / \mathrm{cm}^{2}$. 
APPENDIX C

MODEL OF THE ENCLOSED STAIRWELL/ELEVATOR SHAFT STRUCTURE 
APPENDIX C

\section{MODEL OF THE ENCLOSED STAIRWELL/ELEVATOR SHAFT STRUCTURE}

Data obtained by TLD strings and from detectors placed on the robot were used to estimate the amount of ${ }^{37} \mathrm{Cs}$ present in the enclosed stairwell/ elevator shaft (ES) structure. An inhouse point kernal shielding code was used to model the walls as solid slab sources composed of reinforced concrete block with a density of $1.2 \mathrm{~g} / \mathrm{cm}^{3}$.

The concrete block structure was modeled as five walls. Each wall was divided into three horizontal slabs. The door of the elevator shaft was not included in the model. The lowest slab ran from the floor to the 288.1-foot elevation. The top of the second slab was at the 289.4-foot elevation and the third slab extended to the 290.7-foot elevation. The activity in each slab was assumed to be uniform throughout the thickness of the concrete and in the horizontal direction. The source term was determined by fitting the dose rates measured by the robot at point $A A$ (located outside of the elevator shaft on the north end of the wall as shown in Figure 3.10, main text) to the dose rates obtained with the shielding code. The model indicated that the lower slab contained $1.3 \mu \mathrm{Ci} / \mathrm{cm}^{3}$, the middle slab contained $2.88 \mu \mathrm{Cj} / \mathrm{cm}^{3}$, and the upper slab $2.1 \mu \mathrm{Ci} / \mathrm{cm}^{3}$. This corresponds to an estimated 19,000 curies in the entire structure. Point AA was used for the initial fit of the data because the measurements were made with $\mathrm{R0}-7$ detectors, which have a more defined angular response than the TLD strings, and because the measurements were taken near the surface of an outside wall thus reducing the contributions from other sources, especially those located within the ES structure. Figure C.1 illustrates the closeness of the calculated dose rates and the measured dose rates.

The dose rates obtained by measurements with three TLD strings, B-15, $\mathrm{B}-23$, and $\mathrm{B}-3$, were compared with the measurements obtained at these locations using the model. TLD strings $B-15$ and $B-23$ were hung in the elevator shaft and $B-3$ was hung in the enclosed stairwell. The location of each of the TLD strings was estimated from Figure 3.4 (main text).

Figure C. 2 compares the dose rates measured with TLD string B-15 and those calculated at that location with the model. The two sets of calculated dose rates shown in the figure correspond to two different assumed locations for the TLD string. The model overestimates the dose rates by a factor of 1.2 to 2.3 (with the exception of the last data point) depending on the location of the TLD string. The second set of estimated dose rates corresponds to a location closer to the elevator door and nearer the midpoint between the north and south walls of the elevator shaft. This location results in a better fit with the measured dose rates. There are several possible explanations for the difference between the calculated and the measured doses. First, the exact location of the TLD string is not known. A second explanation is that the level of water located in the elevator pit may have been above the elevation of the floor (282.5-foot elevation) and thus was shielding some of the dose 


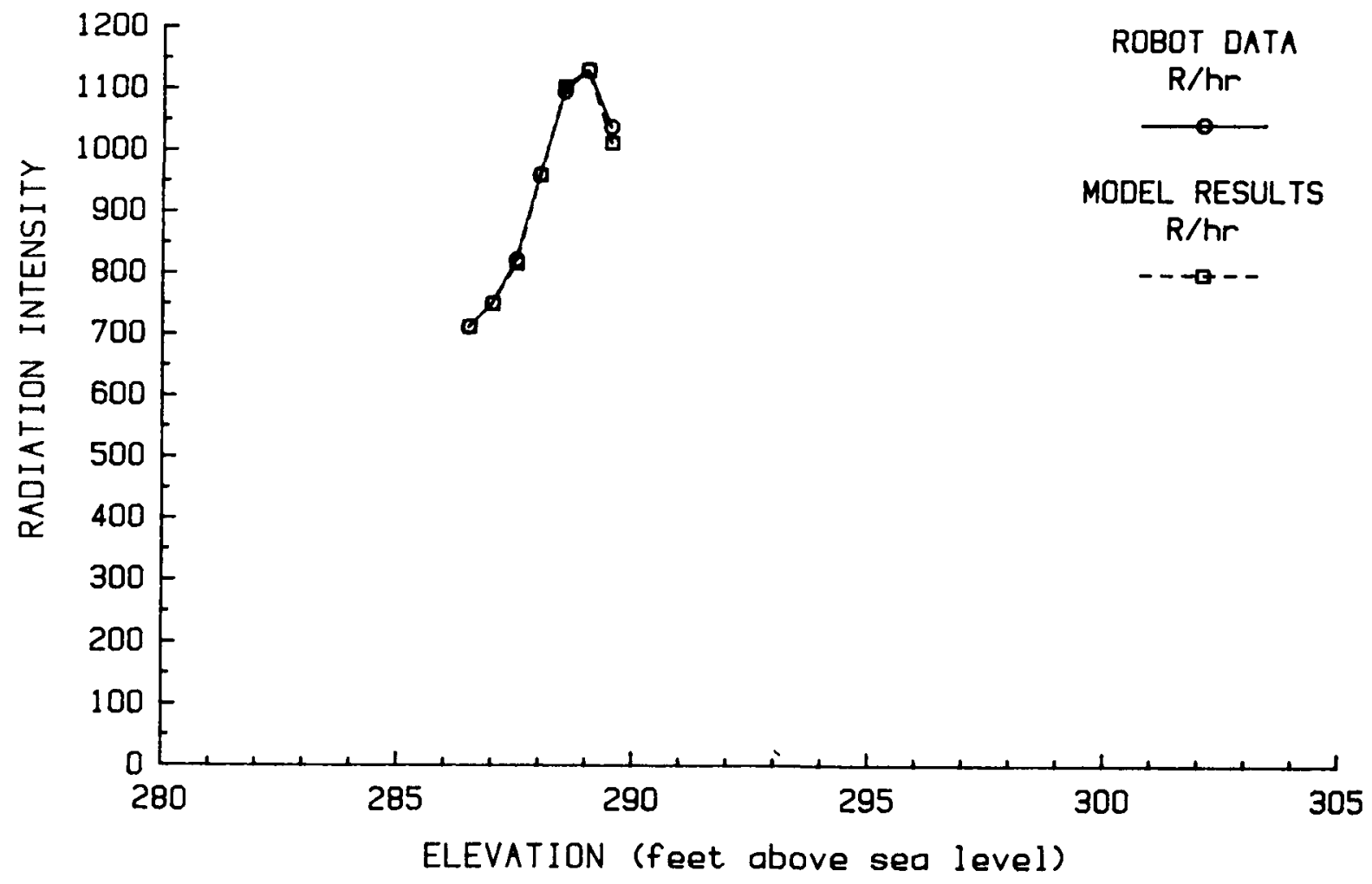

FIGURE C.1. Comparison of Robot Data and Model Results - Location AA

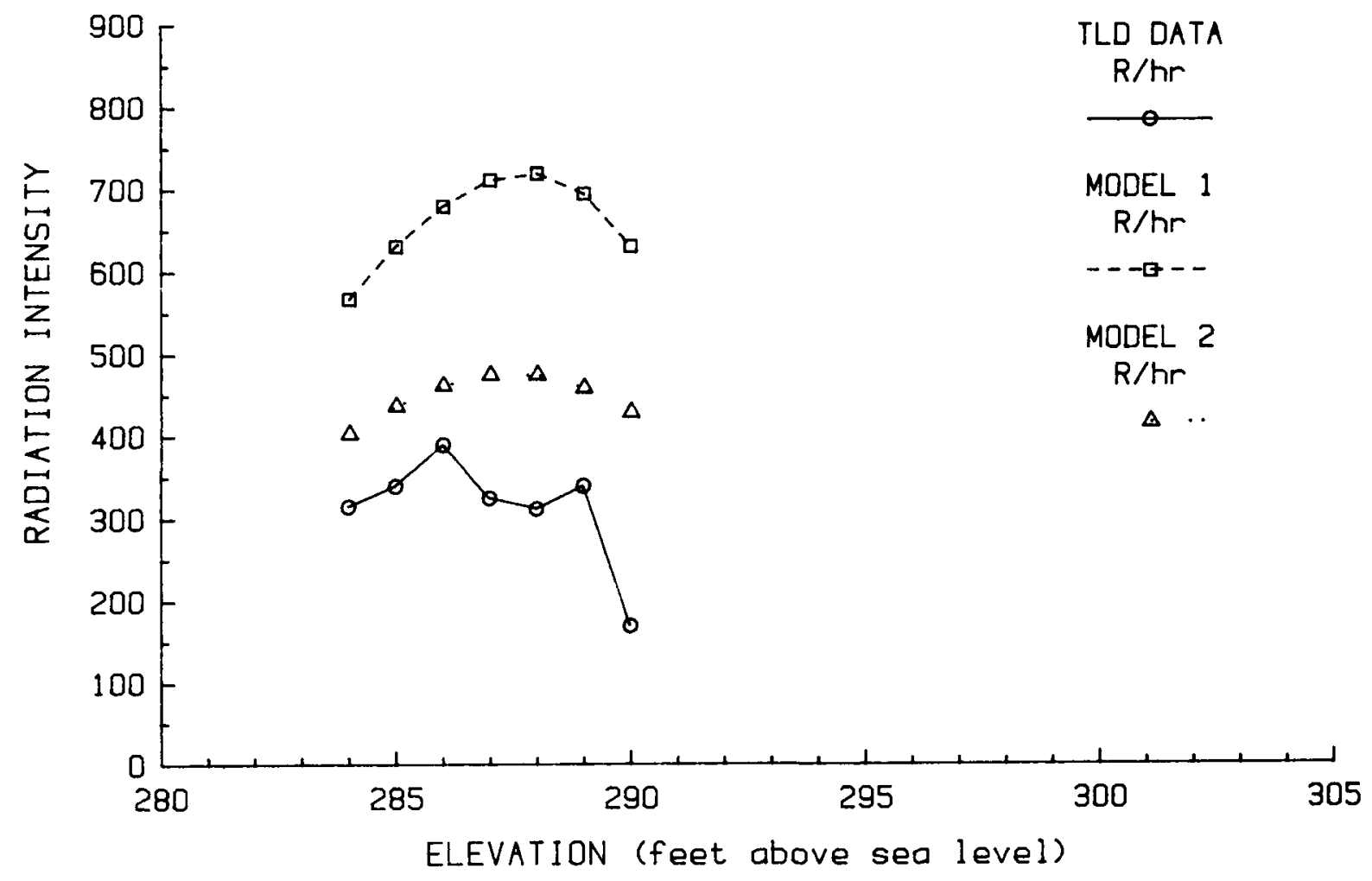

FIGURE C.2. Comparison of TLD String Measure with Model Results - B-15

$$
\text { C.2 }
$$


contributed from sources in the lower wall. A third explanation is that equipment in the elevator shaft was partially shielding the dosimeters from sources in the walls or the elevator pit.

TLD string B-23 (Figure C.3) showed much higher dose rates at the lower elevations than were found with string B-15, which was located closer to the concrete block walls. Above the 288-foot elevation, the dose rates obtained by the two strings were comparable. This indicates that TLD string B-23 was influenced by a source of activity at lower elevations that stpipg B-15 was not exposed to. The TMI Program Office's weekly status report 22-25 May 1983 stated that the major work activities for the following week would include, "pumping accident water from the elevator pit, flushing, and radiation profile of that area." The following week, measurements were made using TLD string B-23. The B-15 TLD string measurements were made during the previous month. Thus, it is possible that B-23 was exposed to a major source of activity in the elevator shaft that string B-15 was shielded from. This source would have the greatest effect on the lower four or five TLDs, thus negating the discrepancies between TLD strings $\mathrm{B}-23$ and $\mathrm{B}-15$ and between $\mathrm{B}-23$ and the model.

TLD string B-3 (Figure C.3) was hung in the enclosed stairwell. The dose readings calculated by the model are generally higher than the measured dose rates. The model did not include any shielding of the TLDs by the metal stairs or platforms. A closer match between the TLD string data and the model results would have been observed if the shielding provided by the stairs and platforms had been included in the model.

The conclusion of this analysis is that the enclosed stairwell/elevator shaft structure contains an estimated 19,099 curies (as compared to GPU's estimate of approximately 11,000 curies). (D) In addition, a sizeable source is present in the elevator shaft pit. A quantitative estimate of this source cannot be made with the available information. However, an estimate may not be required because remote dismantlement of the enclosed stairwell/elevator shaft will be necessary.

\footnotetext{
(a) Memo from L. H. Barrett to H. R. Denton and B. J. Snyder, "NRC TMI Program Office Weekly Status Report for May 22-28, 1983," U.S. Nuclear Regulatory Commission, dated 27 May 1983. NRC/TMI-83-033.

(b) Memo from S. R. Frey and H. K. Peterson to J. E. Hildebrand, "Updated TMI-2 Reactor Building Enclosed Stairwell Characterization," dated 26 January 1984. 9240-84-1943.
} 


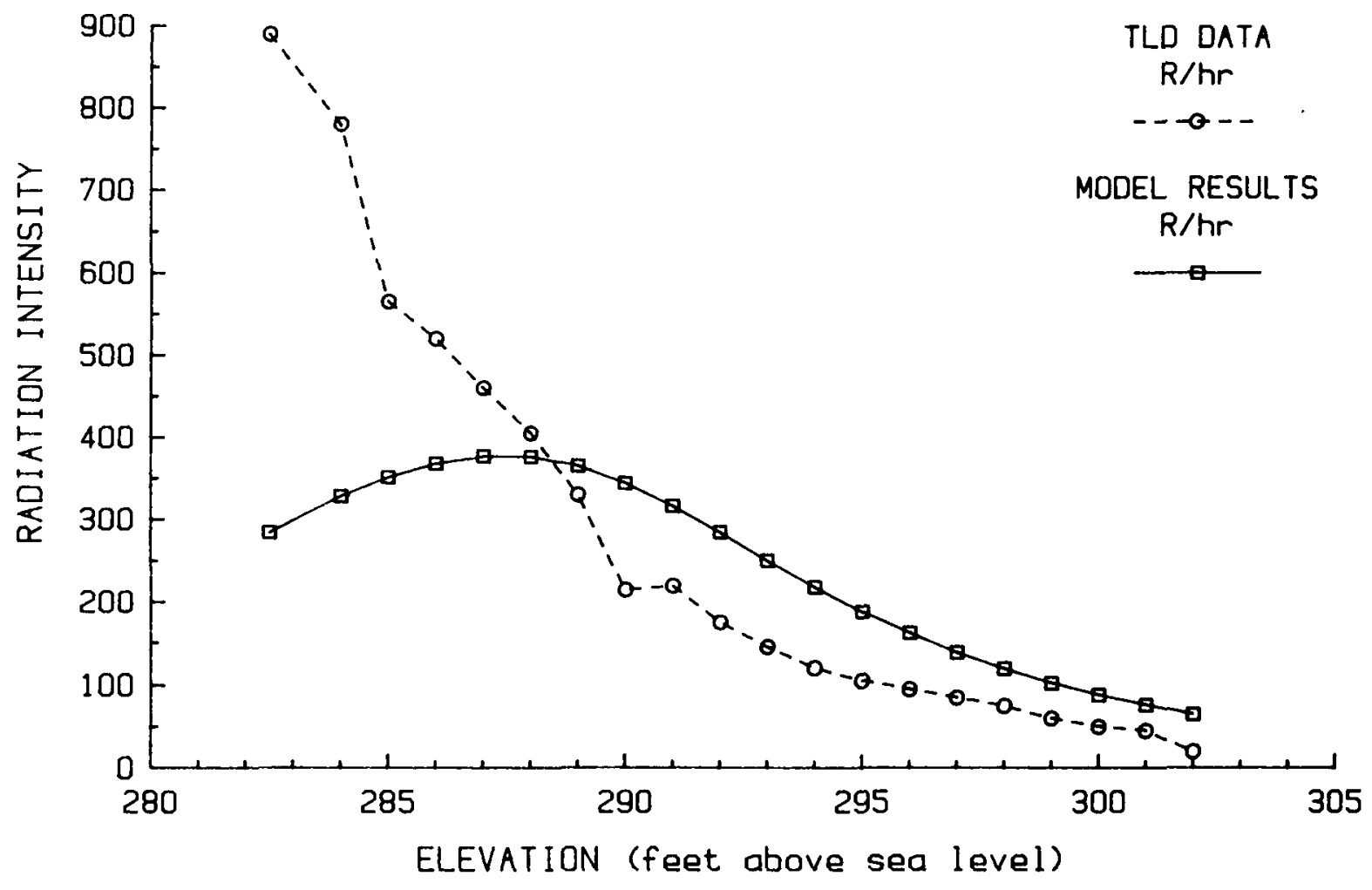

FIGURE C.3. Comparison of TLD String Measurements with Model Results - B-23

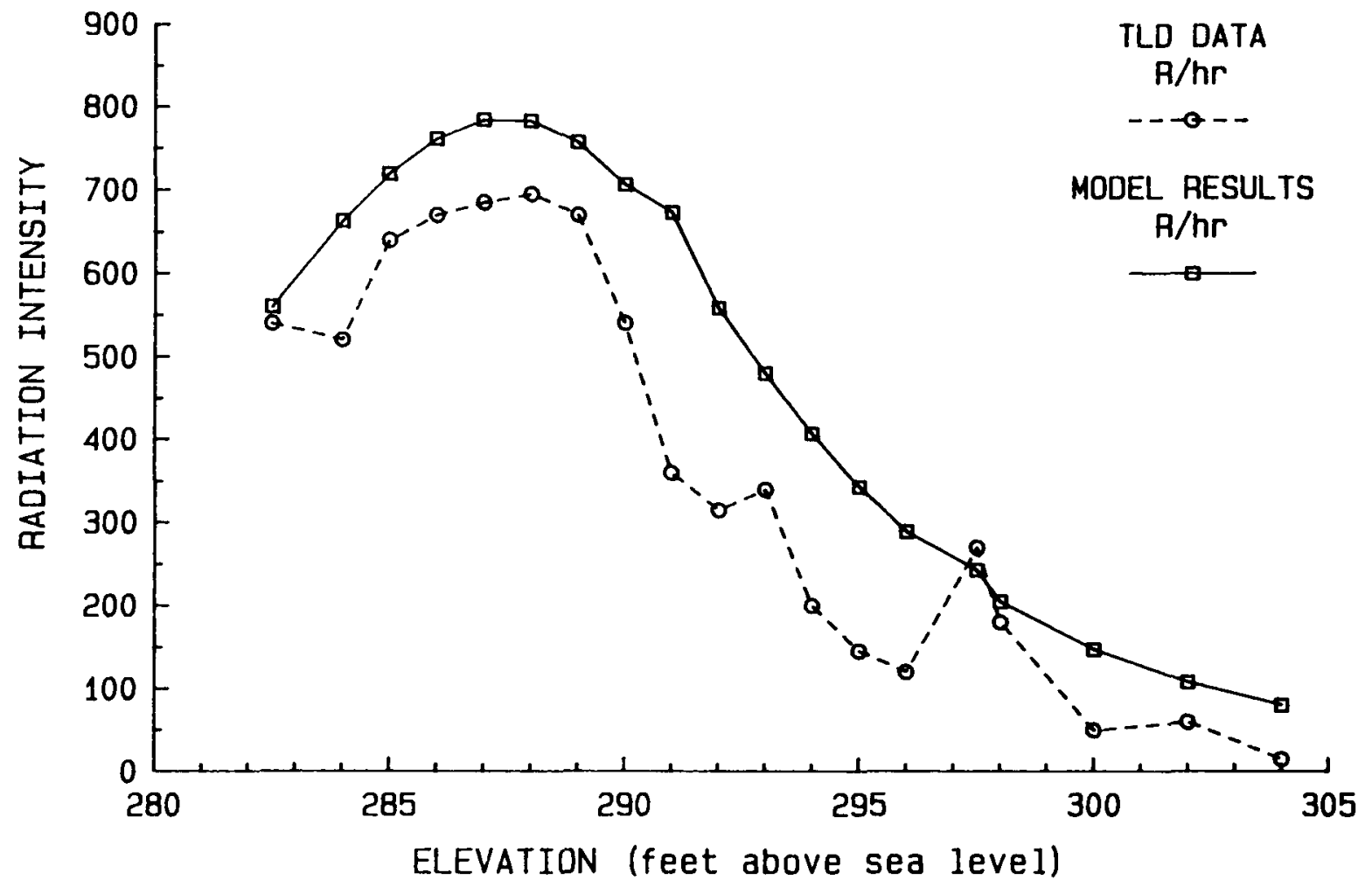

FIGURE C.4. Comparison of TLD String Measurements with Model Results - B-3 
APPENDIX D

DECONTAMINATION TECHNIQUES 
,

. 
DECONTAMINATION TECHNIQUES

A variety of decontamination techniques, including flushing, leaching, scabbling, and chemical cleaning have been used in the TMI cleanup and in other nuclear facilities. Background information on these and an assessment of the potential for automating them or performing them underwater is also included.

\section{D.1 FLUSHING}

Flushing with water is one of the oldest and most effective decontamination methods available. Low-velocity flushing is most useful for loosely adherent contamination and for removing sludge and other nonadherent bulk materials, but it may have only a minor impact on tightly adherent contamination. High-velocity flushing, or hydroblasting, will remove more tightly adherent contamination. The distance between the nozzle and the surface to be cleaned is important for all high-pressure water blasting. If pressures are high enough and if the nozzle distance is carefully chosen, hydroblasting can remove paint and other tightly adherent substances. For contamination associated with oil or grease, flushing might be more effective on some surfaces if the water were heated or if steam were used. The recent development of combining water with compressed air has been effective for spalling concrete surfaces. This technique has not been used extensively in the nuclear industry primarily because of recontamination. Recontamination of the cleaned surface is expected to have a minor effect on dose rates in the work environment but may increase the volume of radioactive waste generated. Concrete spalling with air and water might be reasonable for basement surfaces where the major radiation sources are in the top layer of concrete, but the subsurface concrete will also require disposal as radioactive waste.

High-pressure water-blasting techniques have the potential for generating airborne contamination; high-pressure blasting with borated water on the upper elevations of the containment building at TMI is thought to have contributed to the recontamination of cleaned surfaces.

Flushing and hydroblasting techniques are not expected to work well underwater; if the basement were reflooded for cleanup, an ultra-high-velocity concrete-blasting technique could be performed in an underwater air chamber.

Low- and high-velocity flushing were performed by a robot in the auxiliary building. The only constraint on a robot performing flushing would be the accessibility of the various areas of the basement to the robot.

All techniques using water are also likely to involve some leaching. The complex process of leaching is discussed in detail below. 


\section{D.2 LEACHING}

Leaching involves both physical and chemical processes. Leaching is discussed here in detail from both a theoretical and a practical standpoint as it applies to the decontamination of the TMI- 2 basement.

\section{D.2.1 Theoretical Considerations of Leaching}

Leaching is the complex chemical process of dissolving a soluble material from a solid matrix; this process is governed by the physical laws of kinetics and thermodynamics. Kinetics is important when considering the rate at which water may diffuse into concrete or other solid matrices and when considering the rate at which cesium may diffuse out. Diffusion kinetics also influences the rate of leaching in areas such as the interstitial spaces of the concrete blocks of the enclosed stairwell, where the concentrations of the leaching solution may differ from the concentration in the bulk of the basement solution.

Thermodynamics is important when considering the equilibrium conditions in the solid/liquid chemical system. The concrete, paint, fuel matrices, etc., may behave like weak ion exchangers. The ion exchange reaction is completely reversible and is described for cesium by the general reaction formula:

$$
C s_{s}^{+}+M_{r}^{+}=M_{s}^{+}+C s_{r}^{+}
$$

where: $\mathrm{Cs}_{s}^{+}$is the cesium ion in solution

$M_{r}^{+}$is the exchanging monovalent metal ion on the ion exchanger

$M_{S}^{+}$is the exchanging monovalent metal ion in solution

$\mathrm{Cs}_{r}^{+}$is the cesium ion on the ion exchanger.

The concentration of cesium in contact with a typical cesium ion exchanger is described by the expression:

$$
E=\frac{\left[\mathrm{M}_{s}^{+}\right]\left[\mathrm{Cs}_{r}^{+}\right]}{\left[\mathrm{Cs}_{s}^{+}\right]\left[\mathrm{M}_{r}^{+}\right]}
$$

where: $E$ is the equilibrium constant

$\left[\mathrm{M}_{\mathrm{S}}^{+}\right]$is the molar concentration of hydrogen or other competing
monovalent ions in the solution

$\left[\mathrm{Cs}_{r}^{+}\right]$is the molar concentration of cesium in the ion exchange media 
$\left[\mathrm{Cs}_{s}^{+}\right]$is the molar concentration of cesium in the solution

$\left[\mathrm{M}_{r}^{+}\right]$is the molar concentration of hydrogen and other competing monovalent ions in the ion exchange media.

The equilibrium constant will vary for different ion exchangers and different competing ions. The competing ions may include various species. For example, the zeolite resin used in the submerged demineralizer system selectively favors cesium. In that case, the competing ions are most likely to be sodium and hydrogen. For less selective ion exchanges, such as concrete, numerous ions may be exchanging. Certain divalent ions such as calcium may also exchange with cesium, in which case the equilibrium constant expression will be slightly different. However, when pure water is the leaching solution, cesium (and other exchanging ions) will move from the ion exchanger (concrete) into the solution until equilibrium is established. (In the case of a very selective ion exchanger, such as zeolite, the effect of the reverse reaction is practically negligible, and it is fully compensated for by the operation of the ion exchange media in a column where the last exchanger is in contact with a solution that contains essentialiy no cesium.)

It also follows that if the concentration of the nonradioactive competing ions were increased in the solution contacting the ion exchanger, the equilibrium would be shifted to favor cesium leaching. This may or may not be a practical consideration in the basement because it is also desirable to reduce waste volume and minimize the corrosive effects of the leaching solution.

\section{D.2.2 Practical Considerations of Leaching in the TMI-2 Basement}

In a complex system where there are multiple ion exchanges with various equilibrium constants (such as in the TMI-2 basement), cesium will leach into the solution until equilibrium is established for all of the ion exchange systems. The rate at which this occurs depends on the kinetics of diffusion and is very difficult to predict theoretically. If one of the ion exchangers leaches sufficient cesium into solution such that the equilibrium constant of another of the ion exchangers is exceeded, then cesium ions from the solution will be deposited in that matrix to satisfy that equilibrium constant, thus increasing the dose rate on the media.

In the absence of data on the ion exchange properties of the concrete block in the basement, it would be inappropriate to suggest that the basement be filled with water for leaching, as this could further concentrate cesium in the block. It is doubtful that there are cesium selective materials other than the concrete block that would become a problem if the basement, were leached.

The licensee is studying the ion exchange properties of the concrete block. The results will help determine the advisability of reflooding the basement and the methods that might reduce this source. 


\section{D.3 SCABBLING}

Scabbling is a technique for removing the surface of concrete. Usually the depth removed in a single pass varies from $1 / 4$ inch to 2 inches. On horizontal surfaces (floors), this is most often done with a device that resembles a miniature version of the equipment used to cut grooves in pavement for water drainage. On vertical surfaces, scabbling is usually a much slower process that requires drilling holes about six inches to one foot apart and inserting a hydraulically operated expansion head that cracks off some of the surface (Manion and LaGuardia 1980). Recontamination can be a minor problem in scabbling operations, so most scabblers used in nuclear applications are equipped with a filtered exhaust system. underwater.

Current scabbling equipment must be manually operated and cannot be used

\section{D.4 CHEMICAL CLEANING}

Chemical cleaning is sometimes very effective but is generally used quite sparingly because of the waste management difficulties. Chemicals are not expected to increase the solubility of cesium substantially, but they may be useful in removing oils, greases or paint. Detergents or solvents would be the most likely candidates for this application. Detergents will foul ion exchange resins and thus are incompatible with the present liquid waste management systems. The solvent with the greatest potential for use in the basement is Freon , since glosed systems exist for the application, removal and purification of Freon in the nuclear industry. Care must be used in selecting the particular product because some Freon compounds are quite toxic. Freon used in other nuclear operatjons has been manually applied with long-handled tools. Application of Freon compounds by robats or by long-handled tools from upper elevations would require a considerable development effort.

Scrubbing may enhance the effectiveness or rate of reaction of detergents, Freon or other chemicals, but dose rates in the basement are expected to preclude hand scrubbing for some time.

- Freon is a registered trademark of the E. I. DuPont de Nemours and Company, Inc. 


\section{REFERENCES}

Bechtold, D. B. 1981. KE Fuel Storage Basin Activity Mapping in Support of Exposure Reduction. UNI-1687, UNC Nuclear Industries, Richland, Washington.

Cox, T. E., J. T. Horan and G. Worku. 1983. Reactor Building - Basement Radionuclide and Source Distribution Studies. GEND-INF-011, Vol. II, EG\&G Idaho, Inc., Idaho Falls, Idaho.

GPU Nuclear, Inc.-Bechtel National, Inc. (GPU). November 1982. Data Report, Reactor Building Basement - History and Present Condition. TP0TTMI-027, Rev. O, Middletown, Pennsylvania.

GPU Nuclear, Inc.-Bechtel National, Inc. (GPU). January 1983. Technical Plan--Sludge Removal from Elevation 282'-6". TPO/TMI-034, Middletown, Pennsylvania.

GPU Nuclear, Inc.-Bechtel National, Inc. (GPU). August 1984. Reactor Building Radiological Characterization. TP0/TMI-125, Middletown, Pennsylvania.

Manion, W. J., and T. S. LaGuardia. 1980. Decommissioning Handbook. DOE/EV/10128-1, RL0/SFM-80-3, National Technical Information Service, Springfield, Virginia.

McIsaac, C. V. October 1983. Surface Activity and Radiation Field Measurements on the TMI-2 Reactor Building Cross Decon Exposure. GEND 037, EG\&G Idaho, Inc., Idaho Falls, Idaho.

McIsaac, C. V. October 1984. TMI-2 Reactor Building Source Term Measurements: Surfaces and Basement Water and Sediment. GEND 042, EG\&G Idaho, Inc., Idaho Falls, Idaho.

Meikrantz, D. H., C. P. Willis, J. D. Baker and C. V. McIsaac. JuTy 1981. First Results of TMI-2 Sump Samples Analyses--Entry 10. GEND-INF-011, EG\&G Idaho, Inc., Idaho Falls, Idaho.

Rogovin, M., and G. T. Frampton, Jr. 1979. Volume II, Part 2, Three Mile Island, A Report to the Commissioners and to the Public. NUREG/CR-1250, Vol. II, Part 2, Washington, D.C.

U.S. Nuclear Regulatory Commission (NRC). 1984. Programmatic Environmental Impact Statement Related to Decontamination and Disposal of Radioactive Wastes Resulting from the March 28, 1979, Accident, Three Mile Is land Nuclear Station, Unit 2. NUREG-0683, Suppl. No. 1, Final Report. Prepared by GPU Nuclear, Inc., for NRC's TMI Program Office, Washington, D.C. 


\section{BIBLIOGRAPHY}

Burns and Roe, Inc. November 1982. Dose Rates from Reactor Building Sludge. W.0. No. 3680-01, No. 3680-15-17. NRC Public Document Room, Middletown, Pennsylvania.

Cox, T. E., J. T. Horan and C. V. McIsaac. 1982. Reactor Building - Basement Radionuclide and Source Distribution Studies. GEND-INF-011, Vo1. II, EG\&G Idaho, Inc., Idaho Falls, Idaho.

Davis, C. 1984. Evaluation of Concrete Core Borings from TMI Unit 2 RB. Paper. given at Utilities Coating Work Committee Meeting in Scottsdale, Arizona. (Proceedings to be published.)

Dean, J. A. 1979. Langs Handbook of Chemistry. 12th Edition, McGraw-Hi11, New York.

GPU Nuclear, Inc.-Bechtel National, Inc. (GPU). February 1984. Determination of the Components Contributing to the Gamma Radiation Fields Within the Reactor Building. TP0/TMI-093, Middletown, Pennsylvania.

GPU Nuclear, Inc.-Bechtel National, Inc. (GPU). February 1984. Evaluation of Concrete Core Borings from Reactor Building. TP0/TMI-107, MiddTetown, Pennsylvania.

Hofstetter, K. J., and C. G. Hitz. 1983. "The Use of the Submerged Demineralizer System at Three Mile Island." Separation Science and Technology, 18(14815):1747-1764. 


\begin{tabular}{|c|c|}
\hline $\begin{array}{l}\text { NAC FOAM } 333 \\
\text { 12.84 } \\
\text { NRCM } 1102 . \\
3201,3202 \\
\text { SEE INSTRUCTIONS ON THE REVERSE }\end{array}$ & $\begin{array}{l}\text { AEPORT NUMBER (Asusnod bv TIOC, odd Vol No, if ony) } \\
\text { NUREG/CR }-4399 \\
\text { PNL }-5557\end{array}$ \\
\hline 2 TITLE AND SUBTITLE & 3 LEAVE BLANK \\
\hline \multirow[t]{2}{*}{$\begin{array}{l}\text { Possible Options for Reducing Occupational Dose } \\
\text { From the TMI-2 Basement }\end{array}$} & \\
\hline & $\begin{array}{l}4 \text { DATE REPORT COMPLETED } \\
\text { YONTH }\end{array}$ \\
\hline \multirow[t]{3}{*}{5 AUTHOAIS) } & September \\
\hline & 6 DATE REPORT ISSUED \\
\hline & \begin{tabular}{|c|c|} 
MONTH & YEAR \\
\end{tabular} \\
\hline L.F. Munson, R. Harty & November \\
\hline \multirow{2}{*}{$\begin{array}{l}7 \text { PEAFORMING ORGANIZATION NAME AND MAILING ADDRESS (Include Zip Codel } \\
\text { Pacific Northwest Laboratory } \\
\text { Richland, WA } 99352\end{array}$} & 8 PROJECT/TASKMOAK UNIT NUMBER \\
\hline & B2525 \\
\hline $\begin{array}{l}10 \text { SPONSOAING OAGANIZATION NAME AND MAILING ADDRESS IInclude ZiD Codel } \\
\text { TMI Program Office } \\
\text { Office of Nuclear Reactor Regulation } \\
\text { U.S. Nuclear Regulatory Commission } \\
\text { Washington, DC } 20555\end{array}$ & $\begin{array}{l}\text { 11. TYPE OF REPOAT } \\
\text { Technical } \\
\text { DEERIOD COVEAED (Inclusivo do doos) } \\
\text { March } 1979 \text { - December } 1984\end{array}$ \\
\hline \multicolumn{2}{|l|}{12 SUPPLEMENTARY NOTES } \\
\hline \multicolumn{2}{|c|}{$\begin{array}{l}\text { The March } 28,1979 \text { accident at Three Mile Island Unit } 2 \text { filled the basement to a } \\
\text { depth of several feet with highly contaminated water. The water has been drained } \\
\text { and various characterization efforts are underway. Dose rates range from approxi- } \\
\text { mately } 40 \text { to more than } 1100 \text { R/hr. Identified sources include a structure of hollow } \\
\text { concrete blocks that is estimated to contain between } 11,000 \text { and } 19,000 \text { curies of } \\
\text { cesium } 137 \text { and other quantified sources that contain between } 570 \text { and } 1800 \text { additional } \\
\text { curies. Decontamination methods and approaches available for cleanup are discussed. }\end{array}$} \\
\hline \multirow[t]{2}{*}{$\begin{array}{l}14 \text { DOCUMENT ANALYSIS - } 0 \text { KEYWORDS/DESCAIPTORS } \\
\text { TMI accident } \\
\text { cleanup } \\
\text { water } \\
\text { basement decontamination } \\
\text { Cesium } 137 \\
\text { D IDENTIFIEASIOPEN ENDED TERMS }\end{array}$} & 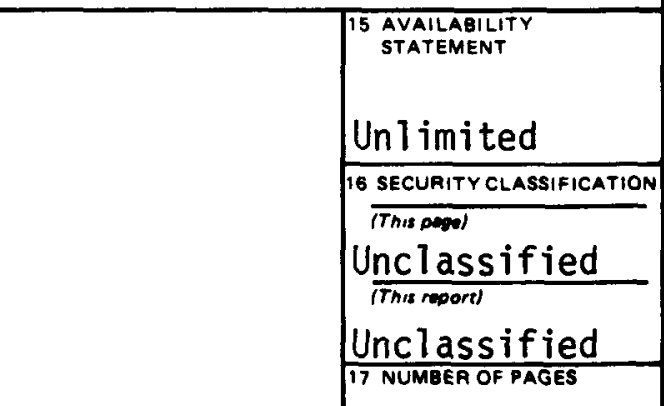 \\
\hline & 18 PAICE \\
\hline
\end{tabular}





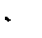


UNITED STATES

NUCLEAR REGULATORY COMMISSION

WASHINGTON, D.C. 20555

OFFICIAL BUSINESS

PENALTY FOR PRIVATE USE, $\$ 300$
FOURTH CLASS MAIL postage feEs paId Uswac

WASH DC

PEAMIT No $G$ O

$$
\begin{gathered}
\ddots \\
\varepsilon \cdot \ldots
\end{gathered}
$$

